Board of Governors of the Federal Reserve System

International Finance Discussion Papers

Number 647

October 1999

\title{
INVESTMENT AND THE CURRENT ACCOUNT \\ IN THE SHORT RUN AND THE LONG RUN
}

\author{
James M. Nason and John H. Rogers
}

NOTE: International Finance Discussion Papers are preliminary materials circulated to stimulate discussion and critical comment. References in publications to International Finance Discussion Papers (other than an acknowledgment that the writer has had access to unpublished material) should be cleared with the author or authors. Recent IFDPs are available on the Web at www.bog.frb.fed.us. 


\title{
Investment and the Current Account
}

\author{
in the Short Run and the Long Run
}

\author{
James M. Nason and John H. Rogers*
}

\begin{abstract}
Theoretical models of the relationship between investment and the current account impose restrictions on the joint dynamic behavior of these variables. These restrictions come in two forms. One imposes causal orderings on investment and the current account. The other restriction concerns the permanent responses of these variables to different shocks. We use these restrictions to identify empirically structural shocks from vector autoregressions of investment and the current account for Canada. Under certain identifications, our results support the implications of the intertemporal, small open economy model. However, these results are sensitive to perturbations of the identifications.
\end{abstract}

*The first author is an Associate Professor of Economics at the University of British Columbia. He can be reached at Department of Economics, University of British Columbia, 1873 East Mall, Vancouver, British Columbia, CANADA V6T 1Z1. The second author is a senior economist in the International Finance Division of the Federal Reserve Board. He can be reached at Mail Stop 22, Federal Reserve Board, Washington, D.C. 20551. email: nason@econ.ubc.ca and john.h.rogers@FRB.GOV. We thank Mick Devereux Enrique Mendoza, Jaume Ventura, seminar participants at the Research Triangle Econometrics Workshop, Duke University, and Virginia Tech, and especially Mark Watson. The views in this paper are solely the responsibility of the authors and should not be interpreted as reflecting the views of the Board of Governors of the Federal Reserve System or of any other person associated with the Federal Reserve System. 


\section{Introduction}

Since the oil price shocks of the 1970s, attempts to explain the seemingly aberrant behavior of investment and the current account in the Group of Seven $(\mathrm{G}-7)$ economies have driven economists to distraction. To explain this behavior, the literature emphasizes the responses of investment and the current account to a variety of shocks given different technology, utility, asset market, and informational structures. Often, the literature judges the success of these explanations within the framework of the intertemporal, small open economy model. ${ }^{1}$

Glick and Rogoff (1995) provide a leading example of the intertemporal, small open economy approach to studying the joint dynamic behavior of investment and the current account. The task Glick and Rogoff set for themselves is to provide some theoretical content to the conflicting claims of Feldstein and Horioka (1980) and Sachs (1981), among others, that concern the degree of international capital mobility during the post-war period. Feldstein and Horioka claim that the observed positive correlations between saving and investment across industrialized economies can only be explained by the isolation of national capital markets. Sachs reports a negative correlation between changes in the current account and changes in investment and arrives at the opposite conclusion.

The intertemporal, small open economy model yields an explicit prediction about the correlation of the current account and investment only given a specific collection of restrictions. For example, assuming perfect capital mobility, if the only source of uncertainty in the model is a country-specific technology shock and this shock has permanent effects, the model predicts that the correlation between the current account and investment equals negative one. As Glick and Rogoff and others note, without these restrictions, the intertemporal model predicts that this correlation can take on any value between zero and negative one. ${ }^{2}$

Glick and Rogoff report a correlation between the change in the current account and the change in investment of -0.39 for the $\mathrm{G}-7$ during the post-1975 period. At first glance, this correlation is puzzling in light of what appears to be open capital markets. To explain this puzzle, Glick and Rogoff argue that if variation in the world technology shock is large, theory predicts that the correlation of investment and the current account is larger than negative one (i.e., closer to zero) - even with perfect capital mobility. Glick and Rogoff's calculations suggest that variation in the world technology shock is indeed large. For the typical G-7 economy, their calculations show that the world technology shock accounts for nearly one-half of the variation in total productivity. ${ }^{3}$

\footnotetext{
${ }^{1}$ Obstfeld and Rogoff (1995) provide an excellent review of this research.

${ }^{2}$ Obstfeld (1986), Cardia (1991), and Mendoza (1991, 1993) discuss reasons for the confusion surrounding interpretations of the correlation of investment and saving (or the current account).

${ }^{3}$ The two-country real business cycle (RBC) model that Baxter and Crucini (1993) study typifies another path the literature has taken. According to Baxter and Crucini, the large positive correlation between saving and investment can be explained by positively correlated productivity shocks across economies. Glick and Rogoff's explanation is in this spirit. Tesar (1991) also examines this issue, adding a non-tradable good sector to the two-country RBC model. Since this sector introduces country-specific risk that cannot be diversified, it results in smaller correlations between aggregate quantities across economies.
} 
Glick and Rogoff go on to uncover a new puzzle. According to the intertemporal model, a permanent country-specific productivity shock has a larger effect on the current account than on investment. Since permanent income rises above current income following the shock, domestic saving falls, and the current account (equal to domestic saving less investment) falls by more than investment rises. However, Glick and Rogoff find that countryspecific technology shocks affect investment by two or three times more than they affect the current account. The authors offer a resolution to this puzzle by arguing that the countryspecific technology shock follows a near random walk rather than a random walk.

In this paper, we examine the joint dynamic behavior of investment and the current account, in order to empirically evaluate the intertemporal, small open economy model. One of the issues we confront is how to translate different aspects of the model into a just-identified SVAR. For example, Glick and Rogoff's results suggest an identification for an empirical version of the model with the following restrictions: $(i)$ the common, world technology shock is integrated; (ii) the country-specific technology shock is stationary; (iii) investment is causally prior to the current account, and (iv) innovations in the world technology shock do not matter for changes in the current account. Taken together, these restrictions yield an over-identified SVAR of investment and the current account.

Rather than work with this collection of over-identifying restrictions and the limitations it implies, we employ other SVAR methods that can potentially reveal more information about the joint dynamic behavior of investment and the current account. We use different aspects of the intertemporal model to construct several just-identified structural vector autoregressions (SVARs) of investment and the current account. Our strategy consists of two steps. First, we impose enough restrictions to just-identify the SVAR. In the second step, we ask if results from the estimated model are consistent with those predictions of the intertemporal model that were not imposed a priori. This process leads us to construct six just-identified SVARs of investment and the current account.

Generally, our identification restrictions come in two forms. The first concerns the permanent responses of investment and the current account to different shocks. Our particular interest centers on the response of one of the variables to a permanent one unit movement in the other variable. These long-run multiplier responses yield information about the behavior of either investment or the current account with respect to a permanent movement in the identified shock. For example, when we impose the restriction that the response of the current account to a one unit permanent increase in investment equals zero, the identification imposes a necessary condition of the intertemporal model - that the current account does not respond to common, world shocks. We label this identification $R 1$.

The second type of restriction concerns the contemporaneous interaction between changes in the current account and changes in investment. Since the intertemporal, small open economy model maintains that current account fluctuations are independent of common world shocks, the predicted impact response of a change in the current account to a change in investment equals zero. As in the case of $R 1$, this restriction is a necessary condition of the intertemporal model. We give this identification the label $R 3$. 
The methods we use to estimate the SVARs follow those of King and Watson (1997). They study the short-run and long-run interactions between nominal and real variables under a variety of assumptions about either impact responses or long-run multipliers. We begin with a dynamic, simultaneous equations system that consists of the change in investment and the change in the current account. Since this dynamic system is derived from a stochastic, intertemporal small open economy model, the system possesses a structural interpretation. We employ this model to study the short-run and long-run responses of investment and the current account to various identifications imposed on the dynamic system.

We focus on Canada, a proto-type small open economy, but note that most of our results hold for the rest of the $\mathrm{G}-7 .^{4}$ Although we find that some of the results generated by any particular identification support aspects of the intertemporal, small open economy model, the extent of this support varies across SVAR specifications.

We have four main results. First, most of our estimates indicate that investment booms are associated with current account deficits. Second, all identifications indicate that in the long run only permanent movements in world shocks matter for investment. Third, the size and sign of the impact response of the current account to investment (or world shocks) is sensitive to the identification. Finally, the current account exhibits a persistent response to movements in country-specific shocks that is statistically significant and economically important. As we discuss below, the first two results are consistent with the intertemporal, small open economy model. However, the final result, that the current account exhibits a persistent response to movements in country-specific shocks, contradicts a central tenet of the intertemporal model. Our empirical results thus serve as a reminder of the limitations of that model as an explanation of current account fluctuations.

The next section discusses the methods we use to construct and compute the SVARs, including discussion of the identifying restrictions. We describe the data and present our estimates in section 3. Conclusions are contained in section 4.

\section{A Structural VAR Approach}

Neoclassical theory makes several predictions regarding the responses of investment and the current account to different types of shocks in a small open economy. One prediction is that the current account does not respond to common, world shocks, only to countryspecific shocks. ${ }^{5}$ In a dynamic context, this places restrictions on the coefficients of the vector moving average (VMA) process of the change in investment, $\Delta I_{t}$, and the change in the current account, $\Delta C A_{t}$. Constructing tests of these restrictions is not a straightforward econometric exercise. If a structural model based on optimizing behavior is not available, it

\footnotetext{
${ }^{4}$ These results are available on request in an appendix to this paper.

${ }^{5}$ Obstfeld and Rogoff (1995) discuss that when a shock affects all economies in the same way, no gains to altering intertemporal allocations exist. All that occurs is the world real interest rate adjusts. On the other hand, a country-specific shock generates gains to changing intertemporal allocations because the domestic real interest rate, as defined by the marginal rate of substitution, differs from the world real interest rate.
} 
is difficult to impute structural content to results obtained from a bivariate autoregression of $\Delta I_{t}$ and $\Delta C A_{t}$.

To navigate our way around these problems, we adapt methods King and Watson (1997) develop. These authors explore the implications for various long-run neutrality propositions using bivariate SVARs. By imposing different identifying restrictions on a SVAR of output and money, they are able to ask which identifying restrictions are consistent with long-run monetary neutrality. In this way, they generate information about the neutrality proposition for a collection of different identifying assumptions. ${ }^{6}$ This permits an assessment of the validity of the neutrality proposition conditional on the restrictions required to produce it. By analogy, we use use different aspects of the intertemporal, small open economy model to construct six just-identified SVARs of $\Delta I_{t}$ and $\Delta C A_{t}$ and assess the predictions of the intertemporal model based on the estimated SVARs.

A key assumption of the King and Watson (1997) SVAR methods is that the observable variables of the VMA process are integrated. Our long-run neutrality test involves examining the permanent response, of say, the current account to a permanent and unanticipated change in investment. When we find this response to be either economically or statistically unimportant, we can state that the current account is independent of the sources of permanent fluctuations in investment. However, our analysis depends on the way in which we identify both the permanent component of investment and the connection between the current account and the permanent component of investment.

\subsection{Some Econometrics of the Intertemporal, Small Open Economy Model}

The intertemporal, small open economy model that Glick and Rogoff (1995) construct serves as an example to motivate these ideas. In a model in which households use the permanent income hypothesis consumption rule, firms maximize the present discounted value of net profits subject to adjustment costs in the capital stock, and world and country-specific technology shocks follow random walks, Glick and Rogoff generate the decision rule for the level of investment

$$
I_{t}=\phi_{1} I_{t-1}+\phi_{2} \Delta A_{C, t}+\phi_{3} \Delta A_{W, t},
$$

and show that the level of the current account follows

$$
C A_{t}=\varphi_{1} I_{t-1}+\varphi_{2} \Delta A_{C, t}+r C A_{t-1},
$$

where $A_{W, t}, A_{C, t}$, and $r$ denote the level of the world technology shock, the level of the country-specific technology shock, and the constant world real interest rate, respectively. ${ }^{7}$ The innovations to the technology shocks $A_{W, t}$ and $A_{C, t}$ are assumed to be uncorrelated at

\footnotetext{
${ }^{6}$ Jefferson (1997) presents results about the short-run and long-run neutrality of inside and outside money for the U.S. using similar methods.

${ }^{7}$ These are equations (15) and (17) in Glick and Rogoff. The coefficients, $\phi_{1}, \phi_{2}, \phi_{3}, \varphi_{1}$, and $\varphi_{2}$, are nonlinear functions of the technology and preference parameters of their small open economy model.
} 
all leads and lags. The change in the level of the world technology shock does not appear in equation (2) because of the small open economy assumption.

There are several ways to estimate the responses of investment and the current account to different types of shocks. Treating $A_{W, t}$ and $A_{C, t}$ as observable, Glick and Rogoff estimate variants of equations (1) and (2). Another way is to combine equations (1) and (2) and to construct the reduced form relationship

$$
C A_{t}=\left[\varphi_{1}+\left(1-\phi_{1}\right) \frac{\varphi_{2}}{\phi_{2}}\right] I_{t}-\left[\varphi_{1}-\varphi_{2} \frac{\phi_{1}}{\phi_{2}}\right] \Delta I_{t}-\varphi_{2} \frac{\phi_{3}}{\phi_{2}} \Delta A_{W, t}+r C A_{t-1} .
$$

From equation (3), we can evaluate the short-run and long-run responses of $C A_{t}$ to movements in $A_{W, t}$ when we treat $C A_{t-1}$ as a pre-determined variable. ${ }^{8}$ The direct impact on $C A_{t}$ of a transitory change in $A_{W, t}$ equals $-\varphi_{2} \phi_{3} / \phi_{2}$. However, $\Delta A_{W, t}$ has an indirect impact on $C A_{t}$ through $\Delta I_{t}$. This is measured by the term in brackets attached to $\Delta I_{t}$. The long-run impact of a permanent change in $A_{W, t}$ on $C A_{t}$ comes about because of the long run relationship between $A_{W, t}$ and $I_{t}$. Since equation (1) predicts that $I_{t}$ possesses a unit root when $A_{W, t}$ does, we can obtain the long-run response of $C A_{t}$ to a permanent change in $A_{W, t}$ through the relationship between $C A_{t}$ and $I_{t}$ in equation (3).

The consistency of estimates of equation (3) depends on whether the econometrician observes $A_{W, t}$. When we treat $A_{W, t}$ as unobservable, an OLS regression of $C A_{t}$ on $I_{t}$ and $\Delta I_{t}$ produces biased estimates of the short run and long-run responses of $C A_{t}$ to $A_{W, t}$. This occurs because $I_{t}$ and $\Delta I_{t}$ are correlated with the error term of the regression. Although this problem can be handled with an instrumental variables (IV) estimator, the reduced form equation (3) is limited because it possesses simple dynamics and only technology shocks. ${ }^{9}$

We take aim at a wider target in this paper. In particular, our goal is to construct just-identified SVARs of $I_{t}$ and $C A_{t}$ using the restrictions and shocks that arise from the intertemporal model. The estimates yield dynamic responses of $I_{t}$ and $C A_{t}$ to the shocks, conditional on the restrictions the just-identified structure requires. This approach extends our empirical analysis beyond the reduced form relationship of equation (3). Since many recent intertemporal, small open economy models posit that shocks besides $A_{W, t}$ and $A_{C, t}$ matter for current account fluctuations, we allow the error structure of our SVAR to contain a larger variety of shocks that includes, for example, taste, fiscal, and monetary shocks. Further, we introduce generic dynamics to capture aspects of monopolistic competition, menu costs, imperfect information, and generalized cost of adjustment functions. Our SVAR can handle these variations on the basic intertemporal model without any effect on the interpretation of the estimates of the impact and long-run responses of $I_{t}$ and the $C A_{t}$.

We consider a model that is linear in the observables, $\Delta I_{t}$ and $\Delta C A_{t}$, and the unobserved structural shock innovations. The infinite-order VMA of the observables can be

\footnotetext{
${ }^{8}$ For their estimation strategy, Glick and Rogoff handle $C A_{t-1}$ in this way.

${ }^{9}$ To identify demand shocks, Glick and Rogoff add world and country-specific government spending shocks to their model. Also, they analyze their model when the level of the country-specific technology shock is a stationary first-order autoregressive process. This introduces one lag of $\Delta A_{C, t}$ into equation (2).
} 
written

$$
\Delta I_{t}=\mu_{I}+\alpha_{I, C}(\mathbf{L}) \eta_{C, t}+\alpha_{I, W}(\mathbf{L}) \eta_{W, t}
$$

and

$$
\Delta C A_{t}=\mu_{C A}+\alpha_{C A, C}(\mathbf{L}) \eta_{C, t}+\alpha_{C A, W}(\mathbf{L}) \eta_{W, t}
$$

where $\mu_{I}$ and $\mu_{C A}$ are constant terms, the lag polynomial operators are of infinite order, $\eta_{C, t}$ is a vector of innovations of country-specific shocks that includes the innovation of $A_{C, t}$, and $\eta_{W, t}$ is a vector of innovations of world shocks that includes the innovation of $A_{W, t}$. Since $\eta_{C, t}$ and $\eta_{W, t}$ contain more than the innovations of technology shocks, we allow for $\Delta I_{t}$ and $\Delta C A_{t}$ to respond to a diverse collection of shocks that includes, for example, taste, fiscal, and, monetary shocks. We assume that the innovations are uncorrelated at all leads and lags. The dynamics of this bivariate system reside in the lag polynomial operators $\alpha_{I, C}(\mathbf{L}), \alpha_{I, W}(\mathbf{L}), \alpha_{C A, C}(\mathbf{L})$, and $\alpha_{C A, W}(\mathbf{L})$. Using this system, we impose, one-by-one, several theoretical restrictions on the dynamics of equations (4) and (5), by analogy to King and Watson (1995).

To implement the King-Watson method, the observables, $I_{t}$ and $C A_{t}$, need to be integrated. We first calculate the Elliot, Rothenberg, and Stock (1996) generalized least squares modification of the Dickey-Fuller (GLS-DF) $t$-ratio and the Dickey-Fuller (DF) $t$-ratio from the augmented $\mathrm{DF}$ (ADF) regression. We fail to reject the unit root null at 5 percent for both $I_{t}$ and $C A_{t}$. The OLS estimate of the autoregressive (AR) root from the ADF regression is 0.85 for investment and 0.87 for $C A_{t}$; the Stock (1991) lower and upper 95 percent asymptotic confidence limits of these AR roots are $(0.73,1.04)$ and $(0.85,1.05)$, respectively. Given the well known power problems inherent in tests for unit roots and the length of our sample, it is not possible to make definitive statements about the size of the largest AR root in our series. Nonetheless, it is apparent that these series are extremely persistent. We take this evidence to imply that the unit root assumption is not an unreasonable approximation.

\subsection{SVAR Identifications}

Under the assumption that $I_{t}$ and $C A_{t}$ are integrated, we construct identifications of the SVAR implied by (4) and (5). We use the permanent responses of $I_{t}$ and the $C A_{t}$ to different shocks to construct one type of identification restriction. We identify technology shocks as the only source of long-run movements in $I_{t}$ and $C A_{t} \cdot{ }^{10}$ That is, we assume that the only permanent world disturbance is the world technology shock, $A_{W, t}$. Likewise, the only permanent country-specific disturbance is the country-specific technology shock, $A_{C, t}$. In this case, innovations in $A_{W, t}$ and $A_{C, t}$, are identified as exogenous shocks with (potentially) permanent affects on $I_{t}$ and $C A_{t}$. We measure the long-run responses of $I_{t}$ and $C A_{t}$ to permanent movements in $A_{W, t}$ and $A_{C, t}$ using sums of the lag polynomial operators of the

\footnotetext{
${ }^{10}$ Although this assumption identifies the source of long-run movements in $I_{t}$ and $C A_{t}$, other shocks may exist, for example fiscal shocks, that generate observationally equivalent fluctuations in these variables.
} 
VMA of (4) and (5). For example, the sum of the elements of $\alpha_{I, W}(\mathbf{L})$, denoted $\alpha_{I, W}(\mathbf{1})$, captures the long-run response of $I_{t}$ to a one unit, permanent move in $A_{W, t}$. To distinguish the permanent impact of $A_{W, t}$ on $I_{t}$ and $C A_{t}$ from that of $A_{C, t}$, we adopt restrictions that represent different aspects of the intertemporal, small open economy model.

To motivate the first of our alternative identifying restrictions, we begin by noting that under the assumptions that countries share the same technology, possess identical preferences, and have similar (initial) wealth positions, the small open economy model predicts that common, world shocks do not matter for the current account at any forecast horizon. Since all small open economies react in the same way to world shocks, the reaction of each economy's permanent income is the same. As a result, current accounts remain unchanged. This implies that the elements of the lag polynomial operator $\alpha_{C A, W}(\mathbf{L})$ in equation (5) are jointly restricted by

$$
\alpha_{C A, W, 0}=\alpha_{C A, W, 1}=\ldots=\alpha_{C A, W, j}=\ldots=0 .
$$

Glick and Rogoff (1995) test and cannot reject the hypothesis that $\alpha_{C A, W, 0}=0$ for a variant of the VMA of (4) and (5) that sets $\mathbf{L}=0$ and given their (observable) proxies for $\Delta A_{C, t}$ and $\Delta A_{W, t}$.

When we identify long-run fluctuations in $I_{t}$ with a permanent change in the level of $A_{W, t}$, equation (4) implies it is measured by $\alpha_{I, W}(\mathbf{1}) \eta_{W, t}$. Likewise, the long run response of $C A_{t}$ to a permanent change in the level of $A_{W, t}$ is measured by $\alpha_{C A, W}(\mathbf{1}) \eta_{W, t}$. The long-run change in $C A_{t}$ with respect to a permanent change in $I_{t}$, is then given by

$$
\mathcal{L R}_{C A, I}=\frac{\alpha_{C A, W}(\mathbf{1})}{\alpha_{I, W}(\mathbf{1})}
$$

The long-run multiplier of (7) allows us to study an implication of the joint restriction of (6). In this case, exogenous, permanent changes in the level of the world technology shock, $A_{W, t}$, do not matter for $C A_{t}$ in the long run. This is

$$
R 1: \quad \mathcal{L R}_{C A, I}=0 .
$$

An interpretation of $R 1$ is that $C A_{t}$ is neutral with respect to permanent movements in the level of $A_{W, t}$. This makes $R 1$ part of the maintained hypothesis of the intertemporal, small open economy model. Since the restrictions of (6) imply the long-run multiplier of (7) equals zero, $R 1$ is a necessary condition fot the intertemporal, small open economy model.

The other long-run derivative we construct captures the response of $I_{t}$ to a permanent one unit change in $C A_{t}$

$$
\mathcal{L R}_{I, C A}=\frac{\alpha_{I, C}(\mathbf{1})}{\alpha_{C A, C}(\mathbf{1})}
$$

When $I_{t}$ is independent of long-run changes in the country-specific technology shock, the only source of long-run fluctuations in $I_{t}$ is permanent changes in the level of $A_{W, t}$. In this case, the long-run movement in $I_{t}$ with respect to a permanent changes in $C A_{t}$ is 


$$
R 2: \quad \mathcal{L R}_{I, C A}=0 .
$$

When we find that the data supports $R 2$ the inference we draw is that only the world technology shock, $A_{W, t}$, drives $I_{t}$ in the long run. ${ }^{11}$ Implicitly, Glick and Rogoff invoke $R 2$ to explain their empirical observation that $\Delta I_{t}$ responds by more to $A_{C, t}$ than does $\Delta C A_{t} \cdot{ }^{12}$

The other type of theoretical restriction we study imposes a causal ordering on $I_{t}$ and $C A_{t}$. This kind of identification requires us to move to the SVAR implied by the VMA of equations (4) and (5):

$$
\Delta I_{t}=\lambda_{I, C A, 0} \Delta C A_{t}+\lambda_{I, I}(\mathbf{L}) \Delta I_{t-1}+\lambda_{I, C A}(\mathbf{L}) \Delta C A_{t-1}+\eta_{W, t},
$$

and

$$
\Delta C A_{t}=\lambda_{C A, I, 0} \Delta I_{t}+\lambda_{C A, I}(\mathbf{L}) \Delta I_{t-1}+\lambda_{C A, C A}(\mathbf{L}) \Delta C A_{t-1}+\eta_{C, t},
$$

where the polynomial lag operators are of order $p$ and it is assumed that

$$
\mathbf{E}\left\{\eta_{W, t}\right\}=0, \quad \mathbf{E}\left\{\eta_{C, t}\right\}=0, \quad \mathbf{E}\left\{\eta_{W, t+j} \eta_{C, t+s}\right\}=0, \quad \forall j, s .
$$

The last equality implies the covariance matrix of $\eta_{W, t}$ and $\eta_{C, t}$ is diagonal.

One way to just-identify the SVAR of equations (9) and (10) is to restrict the impact response of $\Delta I_{t}$ to $\Delta C A_{t}$, denoted $\lambda_{I, C A, 0}$. For example, imposing the restriction

$$
R 3: \lambda_{I, C A, 0}=0
$$

is equivalent to the equilibrium structure of the Glick-Rogoff version of the intertemporal model in which $I_{t}$ is determined prior to $C A_{t}$ in equilibrium. ${ }^{13}$ That is, this version of the intertemporal model yields an impact response of $\Delta I_{t}$ to $\Delta C A_{t}$ equal to zero.

Our fourth restriction explores an implication of (6) on the short-run dynamics of the SVAR of (9) and (10). Note that the restrictions of (6) imply that

$$
\lambda_{C A, I, 0}=\lambda_{C A, I, 1}=\ldots=\lambda_{C A, I, p}=0 .
$$

\footnotetext{
${ }^{11}$ It should be noted that for $\mathcal{L} \mathcal{R}_{C A, I}$ to exist, $I_{t}$ must be integrated. However, this long-run multiplier places no restrictions on the order of integration of $C A_{t}$. For example, when $C A_{t}$ is stationary, it cannot respond to permanent shocks of any kind. In this case, $\mathcal{L} \mathcal{R}_{C A, I}$ equals zero by definition. On the other hand, when we study the long-run response of $I_{t}$ to permanent changes in the country-specific technology shock, we need to assume that $C A_{t}$ is integrated.

${ }^{12}$ To explain their empirical results, Glick and Rogoff argue that $A_{W, t}$ follows a random walk and that a stationary but persistent AR process generates $A_{C, t}$. Within the context of an intertemporal, small open economy model that possesses a balanced growth path, these restrictions on $A_{W, t}$ and $A_{C, t}$ imply that the only source of permanent movements in $I_{t}$ is $A_{W, t}$.

${ }^{13} C A_{t}$ is computed as a residual from the aggregate resource constraint - subsequent to the determination of investment, consumption, and output - in Glick and Rogoff's model. This restriction is not a feature of all versions of the intertemporal model. For example, in Mendoza $(1991,1993), I_{t}$ and $C A_{t}$ are determined simultaneously.
} 
That is, the small open economy hypothesis that $C A_{t}$ does not respond to world shocks implies that $\Delta I_{t}$ and its lags have no predictive power for $\Delta C A_{t}$. Instead of directly using the restrictions of (12), we only pre-set the impact response of $\Delta C A_{t}$ to $\Delta I_{t}$

$$
R 4: \quad \lambda_{C A, I, 0}=0
$$

on the SVAR. However, we do present some direct evidence about the joint hypothesis that (12) embodies. Given a restriction on either $\lambda_{I, C A, 0}, \lambda_{C A, I, 0}, \mathcal{L} \mathcal{R}_{I, C A}$ or $\mathcal{L R}_{C A, I}$, we compute a Wald statistic to test the hypothesis that the $\lambda_{C A, I, j}$ terms are all zero. The Wald statistic is distributed asymptotically $\chi^{2}$ with either $p+1$ or $p$ degrees of freedom depending on whether $\lambda_{C A, I, 0}$ is estimated or pre-set.

Finally, we apply restrictions that are at odds with the joint restriction of (12). One is the impact restriction

$$
\text { R5: } \lambda_{C A, I, 0}=-1,
$$

while the other is its long-run analogue,

$$
R 6: \quad \mathcal{L R}_{C A, I}=-1
$$

$R 5$ and $R 6$ represent hypotheses that are the objects of interest for Feldstein and Horioka (1980), Sachs (1981), Obstfeld (1986), Baxter and Crucini (1993), and Tesar (1991). By comparing the SVAR estimates under these restrictions to the predictions of the intertemporal, small open economy model that are not imposed, we obtain information about the support for the Feldstein-Horioka hypothesis. However, it is possible to make inferences about the degree of international capital mobility under $R 5$ and $R 6$ only with a specific collection of restrictions placed on the type of shocks within the model. Thus $R 5$ and $R 6$ represent reduced form identifications of the SVAR of (9) and (10) rather than having a generic structural interpretation within the intertemporal model.

Table 1 compactly summarizes the restrictions imposed in each of our six cases, $R 1$ through $R 6$. (It will be useful to refer back to this table throughout the paper.) We can bring the discussion of the various restrictions together by describing how we impose $R 1-R 6$ on the SVAR of equations (9) and (10). To be able to estimate the SVAR, we have to pre-set one of the four parameters $\lambda_{I, C A, 0}, \lambda_{C A, I, 0}, \mathcal{L R}_{I, C A}$, and $\mathcal{L R}_{C A, I}$. Subsequently, estimation of the remaining three parameters is handled in a recursive fashion. ${ }^{14}$

\footnotetext{
${ }^{14}$ The technical appendix of King and Watson (1997) provides a fuller description of the estimation strategy as does our appendix.
} 


\section{Structural VAR Estimates}

This section reports the results of estimating the SVAR of equations (9) and (10) under one of the six alternative identifying conditions. We work with data on Canadian investment and the current account, in real Canadian dollars. Observations are quarterly, span the period 1973.1 - 1995.4, and are seasonally adjusted at annual rates. Our estimates are based on the 1975.1 - 1995.4 sample, with data prior to 1975.1 used as lags. We focus on Canada because it fits the description of the textbook small open economy, but we also conduct the analysis on the rest of the $\mathrm{G}-7$. These results, and additional details about the data, are available on request in an appendix.

Our data set produces reduced form estimates of the contemporaneous correlation of $\Delta C A_{t}$ and $\Delta I_{t}$ that resemble estimates reported elsewhere. Glick and Rogoff (1995) estimate the equation

$$
\Delta C A_{t}=b_{0}+b_{1} \Delta I_{t}+v_{t}
$$

These authors note that much of the literature that studies the degree of international capital mobility examines the slope coefficient of this regression. Glick and Rogoff report that the slope coefficient is less than zero, which casts doubt on the Feldstein and Horioka (1980) story of isolated capital markets, but less (in absolute terms) than the value of negative one that some argue represents perfect capital mobility internationally. Our estimate of $b_{1}$ for Canada is -0.38 , with a standard error of 0.08 . Glick and Rogoff report an analogous estimate of -0.30 with a standard error of 0.10 . Of course, without an identification scheme, no structural interpretation can be given to these estimates.

\subsection{Zero Long Run Multiplier Restrictions: $\quad$ R1 and R2}

In the first two rows of table 2 , we present estimates conditional on the restrictions $R 1$ and $R 2$, respectively. The first four columns display the estimates of $\lambda_{I, C A, 0}, \lambda_{C A, I, 0}$, $\mathcal{L R}_{I, C A}$, and $\mathcal{L} \mathcal{R}_{C A, I}$, respectively. Recall from table 1 that under $R 1, C A_{t}$ is by construction independent of permanent changes in $A_{W, t}$. As seen from the first cell of table 2, the estimated impact response of $\Delta I_{t}$ to $\Delta C A_{t}, \lambda_{I, C A, 0}$, is -0.56 , with a $t$-ratio greater than two (in absolute value). The estimate of $\mathcal{L R}_{I, C A}$ is negative as well but with a $t$-ratio of only -1.36. The estimate of $\lambda_{C A, I, 0}$ is insignificantly different from zero, suggesting a lack of predictive power of $\Delta I_{t}$ for $\Delta C A_{t}$.

The Wald statistics in the final column are computed for the joint hypothesis $\lambda_{C A, I, j}=$ $0, j=0, \ldots, 4$, given $R 1$. The test statistic of 9.09 indicates that the null hypothesis can be rejected, but only at the 11 percent level of significance. At either the 5 percent or 10 percent levels, $\Delta I_{t}$ and its lags are unimportant for $\Delta C A_{t}$, under $R 1$, which supports the model's prediction that world shocks do not matter for movements in $C A_{t}$.

The second row displays estimates under the restriction $R 2: \mathcal{L R}_{I, C A}=0$. This identifies fluctuations in $I_{t}$ exclusively with permanent changes in $A_{W, t}$. The first of these 
estimates, $\lambda_{I, C A, 0}$, is insignificantly different from zero, suggesting that investment is determined prior to the current account in the short run. The estimate of $\lambda_{C A, I, 0}$ is negative, at -0.30 with a standard error of 0.17 . The estimate of $\mathcal{L R}_{C A, I}$ is also negative, but insignificant. The Wald statistic in the final column indicates a rejection of the joint hypothesis that $\lambda_{C A, I, j}=0, j=0, \ldots, 4$, at better than the five percent level. This implies that world shocks do affect the current account.

\subsection{Zero Impact Restrictions : $R 3$ and $R 4$}

The third row of table 2 contains the results of estimating equations (9) and (10) given $R 3, \lambda_{I, C A, 0}=0$. This identifying restriction implies that $I_{t}$ is determined prior to $C A_{t}$. In addition, $R 3$ is one of several assumptions necessary to interpret $\lambda_{C A, I, 0}$ as a measure of (short-run) international capital mobility within the intertemporal model.

The estimate of $\lambda_{C A, I, 0},-0.36$, is quite close to the estimate of $b_{1}$ from the reducedform regression reported above. The estimate possesses a $t$-ratio of -4.5 . This result echoes those of other researchers, as we note in the Introduction. Estimates of $\mathcal{L R}_{I, C A}$ provide information about the long-run effect of a permanent change in $A_{C, t}$ on $I_{t}$, conditional on $R 3$. Since the estimate is insignificantly different from zero, it suggests that permanent fluctuations in investment do not depend on the level of $A_{C, t}$. The estimate of $\mathcal{L R}_{C A, I}$ under $R 3$ is -0.26 with a standard error of 0.12 . The Wald statistic indicates that the hypothesis

$\lambda_{C A, I, j}=0, \forall j=0, \ldots, 4$, is strongly rejected. This rejection reflects the large $t$-ratio on $\lambda_{C A, I, 0}$ under $R 3$.

The next row reports the results under $R 4, \lambda_{C A, I, 0}=0$. The results are very similar to those under $R 1$ discussed above: $\mathcal{L R}_{C A, I}$ is insignificantly different from zero, while $\lambda_{I, C A, 0}$ and $\mathcal{L R}_{I, C A}$ are negative with $t$-ratios near or greater than two in absolute terms. The estimates of $\lambda_{I, C A, 0}$ and $\mathcal{L R}_{I, C A}$ are -0.54 and -0.64 , respectively. Since fluctuations in $\Delta C A_{t}$ drive $\Delta I_{t}$, it suggests that the current account is causally prior to investment. These results also imply that larger current account deficits have the effect of increasing investment in the long run. Finally, the Wald statistic used to test the hypothesis $\lambda_{C A, I, j}=0, j=$ $1, \ldots, 4$ indicates a borderline rejection, just as under $R 1$ (the p-value is 0.15 ). However, we cannot reject at five percent the hypothesis that $C A_{t}$ does not depend on permanent changes in the world shock. Thus, across the identifications $R 1-R 4$, rejection of the null hypothesis of (12) are fairly common; indeed, all reject at the fifteen percent level.

\subsection{Reduced Form Restrictions : $R 5$ and $R 6$}

Perhaps the most studied aspect of the intertemporal, small open economy model is its assumption of perfect capital mobility. Although $R 5, \lambda_{C A, I, 0}=-1$, and $R 6, \mathcal{L R}_{C A, I, 0}=$ -1 , represent only reduced form identifications, they provide us with useful information to evaluate the claims of Feldstein and Horioka (1980), Sachs (1981), and others.

The results under $R 5$ appear in the fifth row of table 2 . The most notable differences from imposing this restriction appear in the estimates of $\lambda_{I, C A, 0}$ and $\mathcal{L} \mathcal{R}_{C A, I}$. Under $R 5$, 
$\lambda_{I, C A, 0}$ is positive with a $t$-ratio greater than two. This estimate implies that $\Delta I_{t}$ rises by over two units given a one unit increase in $\Delta C A_{t}$. The estimate of $\mathcal{L R}_{I, C A}$ is also positive, although with a $t$-ratio only slightly larger than 1.0. The fact that this estimate is insignificantly different from zero suggests that permanent, country-specific shocks have no effect on investment, so that $I_{t}$ depends only on permanent changes in the level of $A_{W, t}$. The estimate of $\mathcal{L R}_{C A, I}$ is negative and has a two standard deviation confidence interval that does not include zero, but does include negative one. The Wald statistic used to test the hypothesis $\lambda_{C A, I, j}=0, j=1, \ldots, 4$ is 0.90 , implying that we cannot reject the null hypothesis at any reasonable significance level. This is a marked reversal from the Wald tests under $R 1-R 4$, where there were either strong rejections or borderline rejections of the null.

In the final row of table 2 , we display estimates of $\lambda_{I, C A, 0}, \lambda_{C A, I, 0}$ and $\mathcal{L R}_{I, C A}$ conditional on the reduced form-long run identification $R 6$. The point estimates are similar to those under $R 5$ : $\lambda_{I, C A, 0}$ and $\mathcal{L} \mathcal{R}_{I, C A}$ are positive but insignificant in this instance, while $\lambda_{C A, I, 0}$ is negative, significantly different from zero, and insignificantly different from -1 . Together, these estimates of $\lambda_{I, C A, 0}, \lambda_{C A, I, 0}$, and $\mathcal{L} \mathcal{R}_{I, C A}$ suggest that investment is determined prior to the current account, that the response of $C A_{t}$ to $I_{t}$ is about negative one in the short run (which is imposed under $R 5$ ), and that $\Delta I_{t}$ depends only on permanent movements in $A_{W, t}$. As discussed above, these results are all consistent with predictions of the intertemporal, small open economy model. In addition, the Wald test indicates a failure to reject the joint hypothesis $\lambda_{C A, I, j}=0, j=0, \ldots, 4$. Thus, under the restriction $R 6$, the Canadian data appear to satisfy many predictions of the intertemporal model.

\subsection{Some Graphical Evidence}

The results in table 2 provide some support for the restrictions that make only permanent movements in $A_{W, t}$ matter for $I_{t}$ and that place the determination of $I_{t}$ prior to $C A_{t}$. That is, our results support $R 2$ and $R 3$. On the other hand, our results provide evidence to reject the identifications of $R 4$ and $R 5$.

At the same time, the evidence on $R 1\left(\mathcal{L R}_{C A, I}=0\right)$ and $R 6\left(\mathcal{L} \mathcal{R}_{C A, I}=-1\right)$ is mixed. Although we obtain estimates of $\mathcal{L} \mathcal{R}_{C A, I}$ insignificantly different from negative one under $R 5$, the hypothesis $\mathcal{L} \mathcal{R}_{C A, I}=0$ (as implied by $R 1$ ) cannot be rejected under $R 2$ and $R 4$. The latter result lends support to the prediction that permanent movements in $A_{W, t}$ do not matter for $C A_{t}$. However, those estimates provide greater support for the model under $R 6$ (which we have argued possesses no structural interpretation) than under $R 1$. This mixed evidence questions the robustness of the estimated SVAR when $\mathcal{L R}_{C A, I}$ serves as the source of identification.

In order to obtain additional information on the plausibility of $R 1$ versus $R 6$, we ask whether there exist other identifications built on either $\lambda_{I, C A, 0}, \lambda_{C A, I, 0}$ or $\mathcal{L R}_{I, C A}$ that yield estimates of $\mathcal{L R}_{C A, I}$ significantly different from either zero or negative one. This approach produces information that allows us to evaluate the competing hypotheses of $R 1$ and $R 6$. We build these alternative identifications on the closed interval $[-1,1]$ for either $\lambda_{I, C A, 0}$ or 
$\mathcal{L} \mathcal{R}_{I, C A}$ and the closed interval $[-1,0]$ for $\lambda_{C A, I, 0}$ running in increments of 0.05 .

The graphical evidence appears in figure 1. The top row and lower left panel of the figure contain the 95 percent confidence interval of $\mathcal{L R}_{C A, I}$ with respect to $\lambda_{I, C A, 0}, \lambda_{C A, I, 0}$, and $\mathcal{L R}_{I, C A}$. The lower right panel displays the 95 percent confidence ellipse of $\lambda_{I, C A, 0}$ and $\lambda_{C A, I, 0}$ under $R 6$ (i.e., given $\mathcal{L R}_{C A, I}=-1$ ).

First, consider the 95 percent confidence interval of $\mathcal{L} \mathcal{R}_{C A, I}$ given $\lambda_{I, C A, 0}$, which appears in the top left panel of figure 1 . The confidence interval always includes zero as $\lambda_{I, C A, 0}$ moves from negative one toward zero. However, as $\lambda_{I, C A, 0}$ begins to approach zero and then turns positive, $\mathcal{L} \mathcal{R}_{C A, I}$ becomes significantly less than zero, thereby rejecting $R 1$ under those values of $\lambda_{I, C A, 0}$. However, even as we push $\lambda_{I, C A, 0}$ toward one, the 95 percent confidence interval never includes negative one, as would be implied by $R 6$. Hence, this plot provides evidence that can both support and reject $R 1$, but no evidence to support $R 6$.

Evidence is similarly mixed in the confidence intervals displayed in the upper right and lower left panels of figure 1 . In the upper right panel, the 95 percent confidence interval of $\mathcal{L R}_{C A, I}$ given $\lambda_{C A, I, 0}$ includes both zero, when $\lambda_{C A, I, 0}$ is near zero, and negative one, when we pre-set $\lambda_{C A, I, 0}$ to be negative (beginning at around -0.87 ). Thus, depending on the pre-set range of values of $\lambda_{C A, I, 0}$ there exists identifications that generate evidence to support either $R 1$ or $R 6$. We examine the link between pre-set values of $\lambda_{C A, I, 0}$ and the resulting estimate of $\mathcal{L R}_{C A, I}$ analytically in the next sub-section.

Examining the lower left hand panel, support for $R 1$ appears for any value of $\mathcal{L} \mathcal{R}_{I, C A}$ we pre-select. At the same time, there are no values of $\mathcal{L} \mathcal{R}_{I, C A}$ in the range we consider that provide support for $R 6$ and at the same time reject $R 1$.

In summary, the 95 percent confidence intervals of $\mathcal{L} \mathcal{R}_{C A, I}$ make clear that the identification matters for inference about hypotheses tests of $R 1$ and $R 6$. We can choose identifications using either $\lambda_{I, C A, 0}$ or $\mathcal{L} \mathcal{R}_{I, C A}$ to generate confidence intervals for $\mathcal{L R}_{C A, I}$ that include zero. Although there exist other identifications using these parameters in which the hypothesis $\mathcal{L} \mathcal{R}_{C A, I}=0$ is rejected, these identifications require implausible values for either $\lambda_{I, C A, 0}$ or $\mathcal{L} \mathcal{R}_{I, C A}$; for example positive values for these parameters are often required in order to reject the hypothesis of $R 1$. On the other hand, we rarely find evidence to sustain $R 6$. The only way to identify this SVAR and not reject $R 6$ sets $\lambda_{C A, I, 0}$ close to, if not equal to, negative one. On the other hand, when the identification selects a value of $\lambda_{C A, I, 0}$ close to zero, the 95 percent confidence interval of $\mathcal{L} \mathcal{R}_{C A, I}$ contains support for $R 1$.

Finally, the 95 percent confidence ellipse in the lower right hand panel of figure 1 displays the joint distribution of $\lambda_{I, C A, 0}$ and $\lambda_{C A, I, 0}$ given $\mathcal{L R}_{C A, I}=-1$. We use this to test the joint hypothesis $\lambda_{I, C A, 0}=0$ and $\lambda_{C A, I, 0}=-1$. The joint hypothesis makes $I_{t}$ causally prior to $C A_{t}$ and contains the reduced form-short run restriction $R 5$, given the reduced form-long run identification $R 6$ (as implied by the intertemporal model).

The ellipse appears large. This reflects the size and standard errors of the estimates as well as the large negative correlation between $\lambda_{I, C A, 0}$ and $\lambda_{C A, I, 0}$ under $R 6$. Although the ellipse shows that it is not possible to reject the joint hypothesis $\lambda_{I, C A, 0}=0$ and 
$\lambda_{C A, I, 0}=-1$, it also indicates that there are many other combinations of $\lambda_{I, C A, 0}$ and $\lambda_{C A, I, 0}$ that are equally valid. The 95 percent confidence ellipse thus displays the extent of the uncertainty that exists under the identification $R 6$ and makes it next to impossible to select between different combinations of $\lambda_{I, C A, 0}$ and $\lambda_{C A, I, 0}$.

Figure 2 extends the analysis of the previous plot, by depicting 95 percent confidence ellipses of $\lambda_{I, C A, 0}$ and $\lambda_{C A, I, 0}$ under four different pre-set values of $\mathcal{L R}_{C A, I}: 0.00,-0.25,-0.5$, and -0.75 . Once again, we are interested in seeing if these ellipses contain the combination $\lambda_{I, C A, 0}=0$ and $\lambda_{C A, I, 0}=-1$. Two results are clear. First, as the pre-set value of $\mathcal{L R}_{C A, I}$ goes toward zero, the size of the ellipse decreases. Second, the combination of $\lambda_{I, C A, 0}=0$ and $\lambda_{C A, I, 0}=-1$ no longer appears within the 95 percent confidence ellipse as $\mathcal{L} \mathcal{R}_{C A, I}$ becomes less negative than -0.75 . The results show quite vividly one of the main points of the paper: that support for the intertemporal model is sensitive to seemingly small perturbations in the identification.

\subsection{How Do $\lambda_{I, C A, 0}, \lambda_{C A, I, 0}$, and $\mathcal{L R}_{I, C A}$ Affect Estimates of $\mathcal{L R}_{C A, I}$ ?}

From the discussion above, it appears difficult to decide on the merits of an identification that sets $\mathcal{L R}_{C A, I}$ equal to, say, either -0.85 , negative one (as would be suggested by $R 6$ ), or zero (as would be suggested by $R 1$ ). Nonetheless, we can provide analysis that helps to explain why this difficulty exists.

Following King and Watson (1994), we derive the analytical response of $I_{t}$ to a permanent movement in $C A_{t}$ and of $C A_{t}$ to a permanent movement in $I_{t}$. To begin, note that the reduced-form $\operatorname{VAR}(4)$

$$
\left[\begin{array}{c}
I_{t} \\
C A_{t}
\end{array}\right]=\left[\begin{array}{cc}
A_{\Delta I, \Delta I}(\mathbf{L}) & A_{\Delta I, \Delta C A}(\mathbf{L}) \\
A_{\triangle C A, \Delta I}(\mathbf{L}) & A_{\Delta C A, \Delta C A}(\mathbf{L})
\end{array}\right]\left[\begin{array}{c}
I_{t-1} \\
C A_{t-1}
\end{array}\right]+\left[\begin{array}{c}
\varepsilon_{\Delta I, t} \\
\varepsilon_{\Delta C A, t}
\end{array}\right],
$$

implies that

$$
\left[\begin{array}{c}
\varepsilon_{\Delta I, t} \\
\varepsilon_{\Delta C A, t}
\end{array}\right]=\left[\begin{array}{cc}
1 & -\lambda_{I, C A, 0} \\
-\lambda_{C A, I, 0} & 1
\end{array}\right]^{-1}\left[\begin{array}{c}
\eta_{W, t} \\
\eta_{C, t}
\end{array}\right],
$$

or equation-by-equation $\varepsilon_{\Delta I, t}=\left[1-\lambda_{I, C A, 0} \lambda_{C A, I, 0}\right]^{-1}\left[\eta_{W, t}+\lambda_{I, C A, 0} \eta_{C, t}\right]$ and $\varepsilon_{\Delta C A, t}=$ $\left[1-\lambda_{I, C A, 0} \lambda_{C A, I, 0}\right]^{-1}\left[\lambda_{C A, I, 0} \eta_{W, t}+\eta_{C, t}\right]$. The former expression reveals that movements in $\eta_{C, t}$ become less important for fluctuations in $\Delta I_{t}$ as $\lambda_{I, C A, 0}$ goes toward zero. In symmetric fashion, the expression for $\varepsilon_{\Delta C A, t}$ shows that fluctuations in $\eta_{W, t}$ matter more for $\Delta C A_{t}$ as $\lambda_{C A, I, 0}$ moves from zero toward negative one. Next, construct the long-run trends of $I_{t}$ and $C A_{t}$

$$
\mathcal{L R}_{I, t}=\left[1-A_{\Delta I, \Delta I}(\mathbf{1})\right]^{-1}\left[A_{\Delta I, \Delta C A}(\mathbf{1}) \mathcal{L R}_{C A, t}+\varepsilon_{\Delta I, t}\right],
$$


and

$$
\mathcal{L R}_{C A, t}=\left[1-A_{\Delta C A, \Delta C A}(\mathbf{1})\right]^{-1}\left[A_{\Delta C A, \Delta I}(\mathbf{1}) \mathcal{L} \mathcal{R}_{I, t}+\varepsilon_{\Delta C A, t}\right] .
$$

Substituting $\varepsilon_{\Delta I, t}$ and $\varepsilon_{\Delta C A, t}$ from above into these expressions, and doing a bit of algebra, it is straightforward to show

$$
\frac{\partial \mathcal{L} \mathcal{R}_{I, t+j} / \partial \eta_{C, t}}{\partial \mathcal{L} \mathcal{R}_{C A, t+j} / \partial \eta_{C, t}}=\frac{\lambda_{I, C A, 0}\left[1-A_{\Delta C A, \Delta C A}(\mathbf{1})\right]+A_{\Delta I, \Delta C A}(\mathbf{1})}{\lambda_{I, C A, 0} A_{\Delta C A, \Delta I}(\mathbf{1})+\left[1-A_{\Delta I, \Delta I}(\mathbf{1})\right]},
$$

and

$$
\frac{\partial \mathcal{L} \mathcal{R}_{C A, t+j} / \partial \eta_{W, t}}{\partial \mathcal{L} \mathcal{R}_{I, t+j} / \partial \eta_{W, t}}=\frac{\lambda_{C A, I, 0}\left[1-A_{\Delta I, \Delta I}(\mathbf{1})\right]+A_{\Delta C A, \Delta I}(\mathbf{1})}{\lambda_{C A, I, 0} A_{\Delta I, \Delta C A}(\mathbf{1})+\left[1-A_{\Delta C A, \Delta C A}(\mathbf{1})\right]}
$$

The long-run derivatives (13) and (14) are equivalent to $\mathcal{L} \mathcal{R}_{I, C A}$ and $\mathcal{L} \mathcal{R}_{C A, I}$, respectively. Since $\lim _{j \rightarrow \infty} \partial X_{t+j} / \partial \eta_{W, t}=\partial \mathcal{L} \mathcal{R}_{X, t} / \partial \eta_{W, t}$ and $\lim _{j \rightarrow \infty} \partial X_{t+j} / \partial \eta_{C, t}=\partial \mathcal{L} \mathcal{R}_{X, t} / \partial \eta_{C, t}$, where $X_{t}=I_{t}, C A_{t}$, we can equate the left hand sides of (13) and (14) with the response of $I_{t}$ to a permanent movement in $C A_{t}$ and to the response of $C A_{t}$ to a permanent movement in $I_{t}$, respectively.

We use the derivatives (13) and (14) to study the effect of the different identification schemes on estimates of $\mathcal{L R}_{C A, I}$. First, consider imposing $R 3$ on (13) which yields $\mathcal{L R}_{I, C A}(R 3)=\left[1-A_{\Delta I, \Delta I}(\mathbf{1})\right]^{-1} A_{\Delta I, \Delta C A}(\mathbf{1})$. Second, evaluate (14) at $R 4$ to produce $\mathcal{L R}_{C A, I}(R 4)=\left[1-A_{\triangle C A, \Delta C A}(\mathbf{1})\right]^{-1} A_{\triangle C A, \Delta I}(\mathbf{1})$. These long-run multipliers, $\mathcal{L} \mathcal{R}_{I, C A, I}(R 3)$ and $\mathcal{L} \mathcal{R}_{C A, I}(R 4)$, together with a bit of algebra, allows us to write the derivative of (14) as

$$
\mathcal{L R}_{C A, I}=\frac{\lambda_{C A, I, 0}+\mathcal{L R}_{C A, I}(R 4)\left[1-A_{\Delta I, \Delta I}(\mathbf{1})\right]^{-1}\left[1-A_{\Delta C A, \Delta C A}(\mathbf{1})\right]}{\lambda_{C A, I, 0} \mathcal{L} \mathcal{R}_{I, C A}(R 3)+\left[1-A_{\Delta I, \Delta I}(\mathbf{1})\right]^{-1}\left[1-A_{\Delta C A, \Delta C A}(\mathbf{1})\right]},
$$

where we use $\mathcal{L} \mathcal{R}_{C A, I} \equiv\left[\partial \mathcal{L} \mathcal{R}_{C A, t+j} / \partial \eta_{W, t}\right] /\left[\partial \mathcal{L} \mathcal{R}_{I, t+j} / \partial \eta_{W, t}\right]$.

Equation (15) shows how our assumptions about $\lambda_{C A, I, 0}$ drive point estimates of $\mathcal{L} \mathcal{R}_{C A, I}$. The second term in the numerator, $\mathcal{L R}_{C A, I}(R 4)\left[1-A_{\triangle I, \Delta I}(\mathbf{1})\right]^{-1}\left[1-A_{\triangle C A, \Delta C A}(\mathbf{1})\right]$, is equal to 0.01 . Thus, when $\lambda_{C A, I, 0}$ (the only other term in the numerator) is close to zero, the numerator itself is close to zero. As $\lambda_{C A, I, 0}$ becomes smaller than, say -0.35 , the numerator of (15) takes on the sign (negative), and approximately the value, of $\lambda_{C A, I, 0}$. In the denominator, the term $\left[1-A_{\Delta I, \Delta I}(\mathbf{1})\right]^{-1}\left[1-A_{\triangle C A, \Delta C A}(\mathbf{1})\right]$ dominates. Since $\left[1-A_{\Delta I, \Delta I}(\mathbf{1})\right]^{-1}\left[1-A_{\triangle C A, \Delta C A}(\mathbf{1})\right]$ takes on the value of 0.66 for Canada, this term is greater than $\lambda_{C A, I, 0} \mathcal{L R}_{I, C A}(R 3)$ for any value we choose to impose on $\lambda_{C A, I, 0}$ in order to identify the SVAR.

As a result, estimates of $\mathcal{L} \mathcal{R}_{C A, I}$ depend crucially on the value of $\lambda_{C A, I, 0}$. If we assume that $\Delta C A_{t}$ does not respond to $\Delta I_{t}$ at impact, we find the current account to be independent 
of permanent movements in investment. However, when we impose $\lambda_{C A, I, 0}=-1$ under $R 5$, the current account responds in an equal and opposite direction to a one unit change in $A_{W, t}$. The top right panel of figure 1 verifies this.

\subsection{Forecast Error Variance Decompositions}

In order to measure the importance of world shocks, $\eta_{W, t}$, and country-specific shocks, $\eta_{C, t}$, for fluctuations in $I_{t}$ and $C A_{t}$ under the identifications $R 1, R 2$, and $R 6$, we compute forecast error variance decompositions (FEVDs). Our choice of identifications $R 1, R 2$, and $R 6$ follows from table 2 and figure 1, where we find that these identifications produce the most economically sensible results. We estimate the contribution of, say, $\eta_{W, t}$ for fluctuations in $I_{t}$ at various forecasting horizons. This provides additional evidence on the plausibility of the intertemporal, small open economy model.

Table 3 contains the results. The top panel reports the response of $I_{t}$ to $\eta_{W, t}$ and the bottom panel reports the response of $C A_{t}$ to $\eta_{C, t}$. The FEVDs are reported at horizons of zero, two, four, 12, and 24 quarters. We supply small sample standard errors as well. ${ }^{15}$ According to the FEVDs reported in the top row, under $R 1\left(\mathcal{L R}_{C A, I}=0\right), \eta_{W, t}$ accounts for more than 79 percent of the variance of $I_{t}$ at impact, a share that changes only slightly over the forecast horizon. This lends support to the hypothesis that $I_{t}$ depends mostly on $\eta_{W, t}$. The top row of the bottom panel reports the FEVD of the current account response to $\eta_{C, t}$ under $R 1$. These FEVDs show that more than 85 percent of the fluctuations in $C A_{t}$ are explained by $\eta_{C, t}$ at all horizons. Since $R 1$ imposes that $\eta_{C, t}$ explains 100 percent of the fluctuations in $C A_{t}$ only in the long run, this provides support for the intertemporal model's hypothesis that $\eta_{W, t}$ does not matter for movements in the current account.

The second row of the top and bottom panel of table 3 contain the FEVDs under $R 2$, $\mathcal{L R}_{I, C A}=0$. In this case, all fluctuations in $I_{t}$ are by assumption explained by $\eta_{W, t}$ in the long run. We find that $\eta_{W, t}$ also accounts for nearly 100 percent of the fluctuations in $I_{t}$ at all the forecast horizons. The contribution of country-specific shocks to the FEVDs of $C A_{t}$ under $R 2$ is in row two of the bottom panel. We find that $\eta_{C, t}$ accounts for about 90 percent of the fluctuations in $C A_{t}$ at all forecast horizons, implying that movements in $\eta_{W, t}$ do not matter for $C A_{t}$. This is consistent with the FEVDs under $R 1$, and is evidence in favor of the prediction of the intertemporal model that only country-specific shocks should matter.

In the third row of table 3, we present the FEVDs of $I_{t}$ with respect to $\eta_{W, t}$ under $R 6, \mathcal{L R}_{C A, I}=-1$. These begin to resemble the FEVDs under $R 1$ and $R 2$ only beginning at forecast horizons approaching six years. The FEVDs of $C A_{t}$ with respect to $\eta_{C, t}$ under $R 6$ appear in the final row of table 3. Although $\eta_{W, t}$ contributes 100 percent to long-run

\footnotetext{
${ }^{15}$ As Shapiro and Watson (1988) do, we compute the standard errors of the FEVDs by generating 1000 bootstrap replications using the covariance matrix of the residuals of the reduced form VARs. This gives the standard errors a small sample interpretation as the uncertainty surrounding the FEVD point estimate at a particular horizon. To study the robustness of the bootstrap standard errors, we also examined the Monte Carlo integration method of Sims and Zha (1995). For the most part, this method generates standard errors that are slightly smaller than the bootstrap standard errors. Since the latter objects yield a small sample interpretation, we choose to report these standard errors.
} 
fluctuations in $C A_{t}$ by construction, at impact and shorter forecast horizons, $\eta_{W, t}$ explains at least 90 percent of $C A_{t}$ movements. This shows that the reduced-form claim of perfect capital markets in the long-run implied by $R 6$ produces FEVDs not in agreement with the intertemporal model.

The FEVDs that appear in table 3 are generally consistent with the intertemporal, small open economy model. The top panel indicates that $\eta_{W, t}$ contribute more to fluctuations in $I_{t}$ than do country-specific shocks. This evidence is particularly striking for $I_{t}$ at the lowerorder forecast horizons under $R 1$ and $R 2$ and for the higher-order forecast horizons under $R 6$. In the bottom panel of table 3 , we find generally that $\eta_{C, t}$ contributes most to fluctuations in $C A_{t}$. One caveat is that the reduced-form identification $R 6$ produces FEVDs, especially for $C A_{t}$, that reflect the a priori restriction of this identification.

\section{Conclusion}

We study the joint dynamic behavior of investment and the current account during the post-1975 period, focusing on Canada, a proto-type small open economy. The restrictions we place on the dynamics arise from different aspects of the intertemporal, small open economy model. Using these restrictions, we construct six just-identified SVARs and compare estimates to the predictions of the intertemporal model that are not imposed a priori. We find that identifications with differences that appear innocuous produce different levels of empirical support for the model. It appears that tests of the predictions of the intertemporal, small open economy model can be made arbitrarily to deliver almost any particular result.

Perhaps the best way to interpret our results is to consider the effect of the different identifications on the joint dynamic behavior of investment and the current account. Since different identifications change the cross-equation restrictions placed on this dynamic system, perturbations to the identification scheme alter these restrictions and as a result alter the observed empirical relationship between investment and the current account. Although there exist some elements of this relationship that are robust across identifications, our results make plain that the observed relationship between investment and the current account often depends fundamentally on the identification. Indeed, our results suggest that understanding the effects of the identification used to construct and interpret empirical models of investment and the current account is as important as analysis of the sampling distribution of the estimates. Minus an appreciation of the effect of the identification, claims can be made about the relationship between investment and the current account that turn out not to be robust.

Although many of our results are sensitive to seemingly minor perturbations of the identification scheme, there exists some consistency across identifications. We find four main results, each of which has implications for the intertemporal approach. First, most estimates indicate that investment booms are associated with current account deficits. Second, investment is independent of country-specific shocks, particularly in the long run. Third, the size and sign of the impact response of the current account to investment (or world shocks) is 
sensitive to the identification. Finally, the current account exhibits a persistent response to movements in country-specific shocks that is statistically significant and economically important. The first result is a fundamental implication of the intertemporal model, and stands in contrast with the predictions of the standard Mundell-Fleming model. Since the second result implies a balanced growth path, it can be made consistent with the intertemporal, small open economy model with little effort. Our third result suggests that estimates of the impact response of the current account to investment contain little useful information for tests of the intertemporal, small open economy model. This echoes findings elsewhere in the literature. The final result, that the current account exhibits a persistent response to movements in country-specific shocks, contradicts a central tenet of the intertemporal model. At present, there is no consensus intertemporal model that generates persistence in the level of the current account. Our empirical results thus serve as a reminder of the limitations of the intertemporal model to explain current account fluctuations.

\section{References}

Baxter, M., and M.J. Crucini, 1993, "Explaining Saving-Investment Correlations", American Economic Review, 83, 416 - 436.

Cardia, E., 1991, "The Dynamics of Savings and Investment in Response to Monetary, Fiscal, and Productivity Shocks", Journal of Monetary Economics, 28, 411 - 434.

Elliot, G., T.J. Rothenberg, and J.H. Stock, 1996, "Efficient Tests for an Autoregressive Root", Econometrica, 64, $813-836$.

Feldstein, M.S., and C.Y. Horioka, 1980, "Domestic Savings and International Capital Flows", Economic Journal, 90, 314 - 329.

Ghosh, A.R., 1995, "International Capital Mobility Amongst the Major Industrialized Countries: Too Little or Too Much?", Economic Journal, 105, 107 - 128.

Glick, R., and K. Rogoff, 1995, "Global Versus Country-Specific Productivity Shocks and the Current Account", Journal of Monetary Economics, 35, 159 - 192.

Jefferson, P.N., 1998, "On the Neutrality of Inside and Outside Money", Economica, 64, $567-586$.

King, R.G., and M.W. Watson, 1997, "Testing Long-Run Neutrality", Economic Quarterly, Federal Reserve Bank of Richmond, 83(Summer), 69 - 101.

King, R.G., and M.W. Watson, 1994, "The Post-War Phillips Curve: A Revisionist Econometric History", Carnegie-Rochester Conference Series on Public Policy, 41, 157 - 219. 
Mendoza, E.G., 1991, "Real Business Cycles in a Small Open Economy", American Economic Review, 81, $797-818$.

Mendoza, E.G., 1993, "The Robustness of Macroeconomic Indicators of Capital Mobility", in Capital Mobility: The Impact on Consumption, Investment and Growth, Razin, A., and L. Leiderman, eds., Cambridge University Press, Cambridge, U.K..

Obstfeld, M., 1986, "Capital Mobility in the World Economy: Theory and Evidence", Carnegie-Rochester Conference Series on Public Policy, 24, 55 - 104.

Obstfeld, M., and K. Rogoff, 1995, "The Intertemporal Approach to the Current Account", in Handbook of International Economics, Grossman, G.M, and K. Rogoff, eds., NorthHolland Publishing Co., New York.

Otto, G., 1992, "Testing a Present Value Model of the Current Account: Evidence from the U.S. and Canadian Time Series", Journal of International Money and Finance, 11, $414-430$.

Sachs, J., 1981, "The Current Account and Macroeconomic Adjustment in the 1970s", Brookings Papers on Economic Activity, 12, $201-268$.

Shapiro, M.D., and M.W. Watson, 1988, "Sources of Business Cycle Fluctuations", in NBER Macroeconomic Annual, Fischer, S., eds., MIT Press, Cambridge, MA.

Sheffrin, S.M., and W.T. Woo, 1990, "Present Value Tests of an Intertemporal Model of the Current Account", Journal of International Economics, 29, 237 - 253.

Sims, C.A., and T. Zha, 1995, "Error Bands for Impulse Responses", Working Paper 95 - 6, Federal Reserve Bank of Atlanta.

Stock, J.H., 1991, "Confidence Intervals for the Largest Autoregressive Root in U.S. Macroeconomic Time Series", Journal of Monetary Economics, 28, 435 - 459.

Tesar, L.L., 1991, "Savings, Investment and International Capital Flows", Journal of International Economics, 31, $55-78$.

Trehan, B., and C.E. Walsh, 1991, "Testing Intertemporal Budget Constraints: Theory and Applications to U.S. Federal Budget and Current Account Deficits", Journal of Money Credit, and Banking, 23, $206-223$. 
Table 1. Six Identification Restrictions

Definition Restriction Implication

$R 1 \quad \mathcal{L R}_{C A, I}=0 \quad C A_{t}$ Neutral to $\eta_{W, t}$
in the Long Run

$R 2 \quad \mathcal{L R}_{I, C A}=0 \quad I_{t}$ Neutral to $\eta_{C, t}$ in the Long Run

R3 $\quad \lambda_{I, C A, 0}=0 \quad$ At Impact $\eta_{C, t}$ Does Not Matter for $\Delta I_{t}$

$R 4 \quad \lambda_{C A, I, 0}=0 \quad$ Necessary for $\eta_{W, t}$ to Not Matter for $\triangle C A_{t}$

R5 $\lambda_{C A, I, 0}=-1 \quad$ Reduced-Form Claim of Perfect Capital Markets in the Short Run

$\begin{array}{rr}R 6 \quad \mathcal{R}_{C A, I}=-1 & \text { Reduced-Form Claim of } \\ & \begin{array}{c}\text { Perfect Capital Markets } \\ \text { in the Long Run }\end{array}\end{array}$

The impact response (long-run multiplier) of $X_{t}$ to $Z_{t}$ is denoted as $\lambda_{X, Z, 0}\left(\mathcal{L R}_{X, Z}\right)$, where $X, Z=I, C A$. The vector of innovations to world (country-specific) shocks is $\eta_{W, t}\left(\eta_{C, t}\right)$. 


\section{Table 2. $\quad$ SVAR Parameter Estimates}

$\begin{array}{ccccc}\lambda_{I, C A, 0} & \lambda_{C A, I, 0} & \mathcal{L R}_{I, C A} & \mathcal{L R}_{C A, I} & \text { Wald Statistic }\end{array}$

\begin{tabular}{|c|c|c|c|c|c|}
\hline$R 1$ & $\begin{array}{l}-0.56 \\
(0.27)\end{array}$ & $\begin{array}{c}0.02 \\
(0.20)\end{array}$ & $\begin{array}{l}-0.68 \\
(0.50)\end{array}$ & $\begin{array}{l}0 \\
-\end{array}$ & $\begin{array}{c}9.09 \\
{[0.11]}\end{array}$ \\
\hline$R 2$ & $\begin{array}{l}-0.11 \\
(0.25)\end{array}$ & $\begin{array}{l}-0.30 \\
(0.17)\end{array}$ & $\begin{array}{l}0 \\
-\end{array}$ & $\begin{array}{l}-0.21 \\
(0.19)\end{array}$ & $\begin{array}{l}11.37 \\
{[0.04]}\end{array}$ \\
\hline$R 3$ & $\begin{array}{l}0 \\
-\end{array}$ & $\begin{array}{l}-0.36 \\
(0.08)\end{array}$ & $\begin{array}{c}0.17 \\
(0.42)\end{array}$ & $\begin{array}{l}-0.26 \\
(0.12)\end{array}$ & $\begin{array}{l}28.40 \\
{[0.00]}\end{array}$ \\
\hline$R 4$ & $\begin{array}{l}-0.54 \\
(0.12)\end{array}$ & $\begin{array}{l}0 \\
-\end{array}$ & $\begin{array}{l}-0.64 \\
(0.35)\end{array}$ & $\begin{array}{l}-0.01 \\
(0.13)\end{array}$ & $\begin{array}{c}6.75 \\
{[0.15]}\end{array}$ \\
\hline$R 5$ & $\begin{array}{c}2.06 \\
(0.79)\end{array}$ & $\begin{array}{l}-1 \\
-\end{array}$ & $\begin{array}{c}3.45 \\
(2.98)\end{array}$ & $\begin{array}{l}-0.75 \\
(0.19)\end{array}$ & $\begin{array}{c}0.90 \\
{[0.92]}\end{array}$ \\
\hline$R 6$ & $\begin{array}{c}4.50 \\
(5.05)\end{array}$ & $\begin{array}{l}-1.29 \\
(0.34)\end{array}$ & $\begin{array}{c}7.69 \\
(13.44)\end{array}$ & $\begin{array}{l}-1 \\
-\end{array}$ & $\begin{array}{c}1.43 \\
{[0.92]}\end{array}$ \\
\hline
\end{tabular}

The table contains estimates of the parameter listed in the top row, under each of the six alternative identifications listed in the first column. Standard errors appear in parenthesis and the brackets contain p-values. For $R 1, R 2, R 3$, and $R 6$, the Wald statistic and p-values are based on the hypothesis $\lambda_{C A, I, j}=0, j=0, \ldots, 4$, and five degrees of freedom. For $R 4$ and $R 5$, the hypothesis is that $\lambda_{C A, I, j}=0, j=0, \ldots, 4$, and the Wald statistic has four degrees of freedom. 


\section{Table 3. Variance Decompositions}

$I_{t}$ Response to the World Shock

\begin{tabular}{cccccc} 
& 0 & 2 & 4 & 12 & 24 \\
\hline \multirow{4}{*}{$R 1$} & 79.14 & 77.54 & 78.29 & 79.01 & 79.22 \\
& $(18.64)$ & $(19.81)$ & $(19.70)$ & $(19.89)$ & $(19.95)$ \\
& & & & & \\
$R 2$ & 99.27 & 98.91 & 99.02 & 99.20 & 99.25 \\
& $(5.70)$ & $(6.13)$ & $(6.00)$ & $(5.857)$ & $(5.80)$ \\
& & & & & \\
$R 6$ & 38.46 & 52.76 & 64.58 & 65.11 & 90.13 \\
& $(17.64)$ & $(20.03)$ & $(22.84)$ & $(21.59)$ & $(19.49)$ \\
\hline
\end{tabular}

$C A_{t}$ Response to the Country-Specific Shock

\begin{tabular}{cccccc} 
& 0 & 2 & 4 & 12 & 24 \\
\hline \multirow{4}{*}{$R 1$} & 87.01 & 86.13 & 86.87 & 86.74 & 86.70 \\
& $(6.88)$ & $(7.08)$ & $(7.43)$ & $(7.49)$ & $(7.58)$ \\
& & & & & \\
$R 2$ & 91.94 & 89.62 & 91.44 & 91.64 & 91.71 \\
& $(14.39)$ & $(15.97)$ & $(16.79)$ & $(17.72)$ & $(17.97)$ \\
& & & & & \\
$R 6$ & 4.54 & 6.21 & 8.46 & 2.21 & 1.00 \\
& $(9.61)$ & $(11.82)$ & $(14.55)$ & $(17.25)$ & $(18.21)$ \\
\hline
\end{tabular}

The top (bottom) panel reports the contribution of world (country-specific) shocks to explaining the forecast error variance of investment (the current account) at the particular forecast horizon. Small sample empirical standard errors appear in parenthesis. We generate 1000 replications of the SVAR to compute the empirical standard errors. 

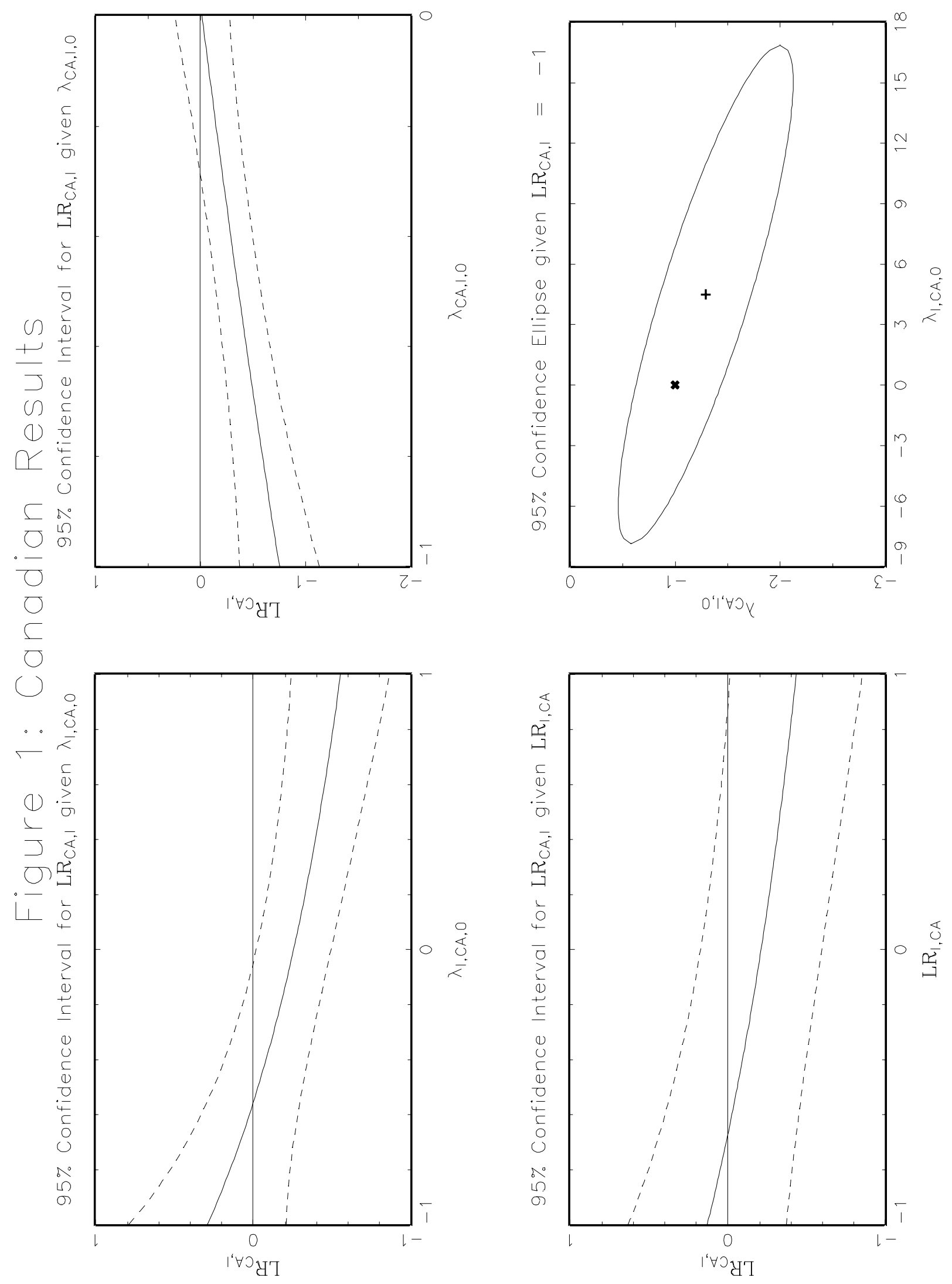

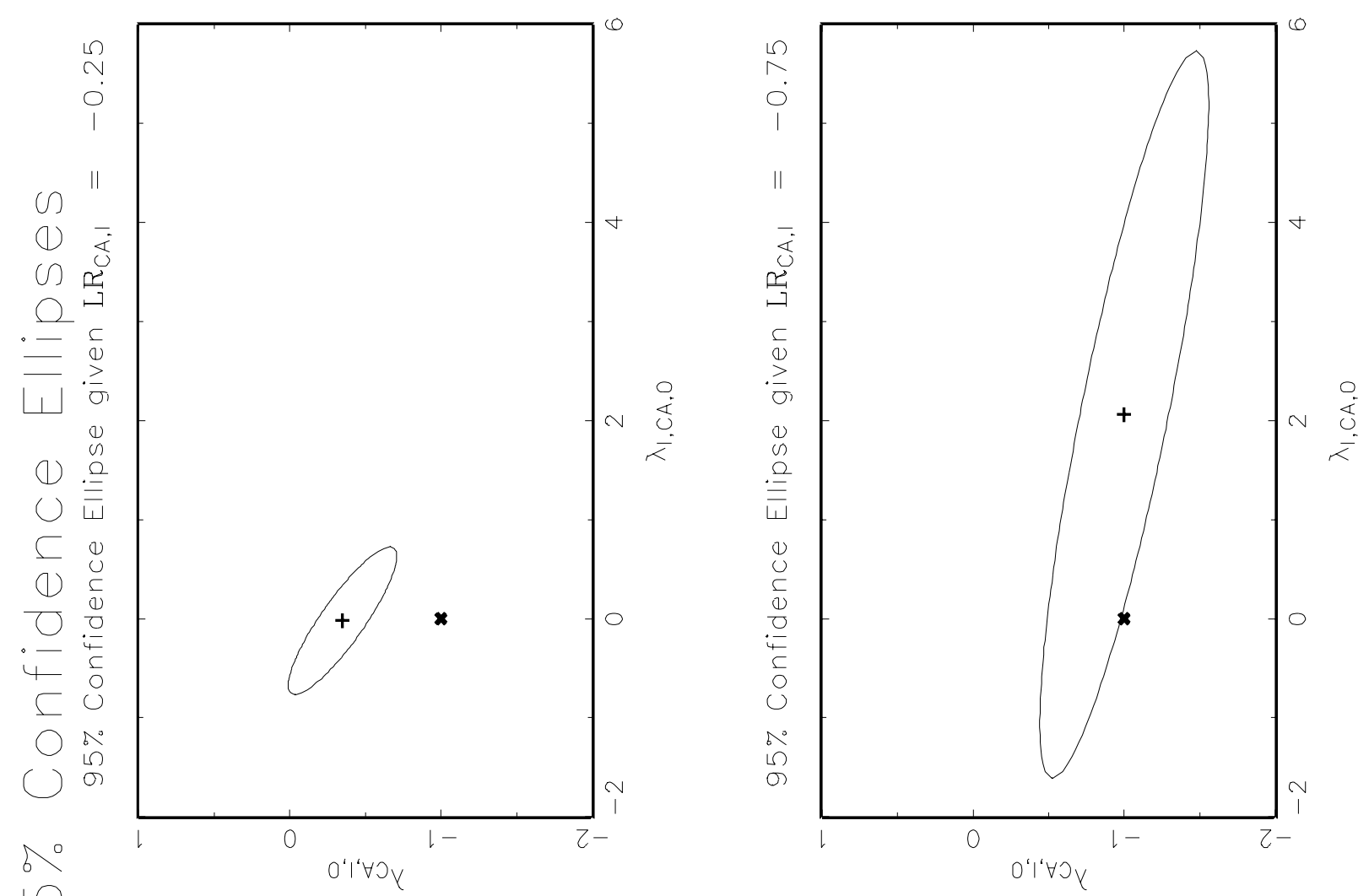

L
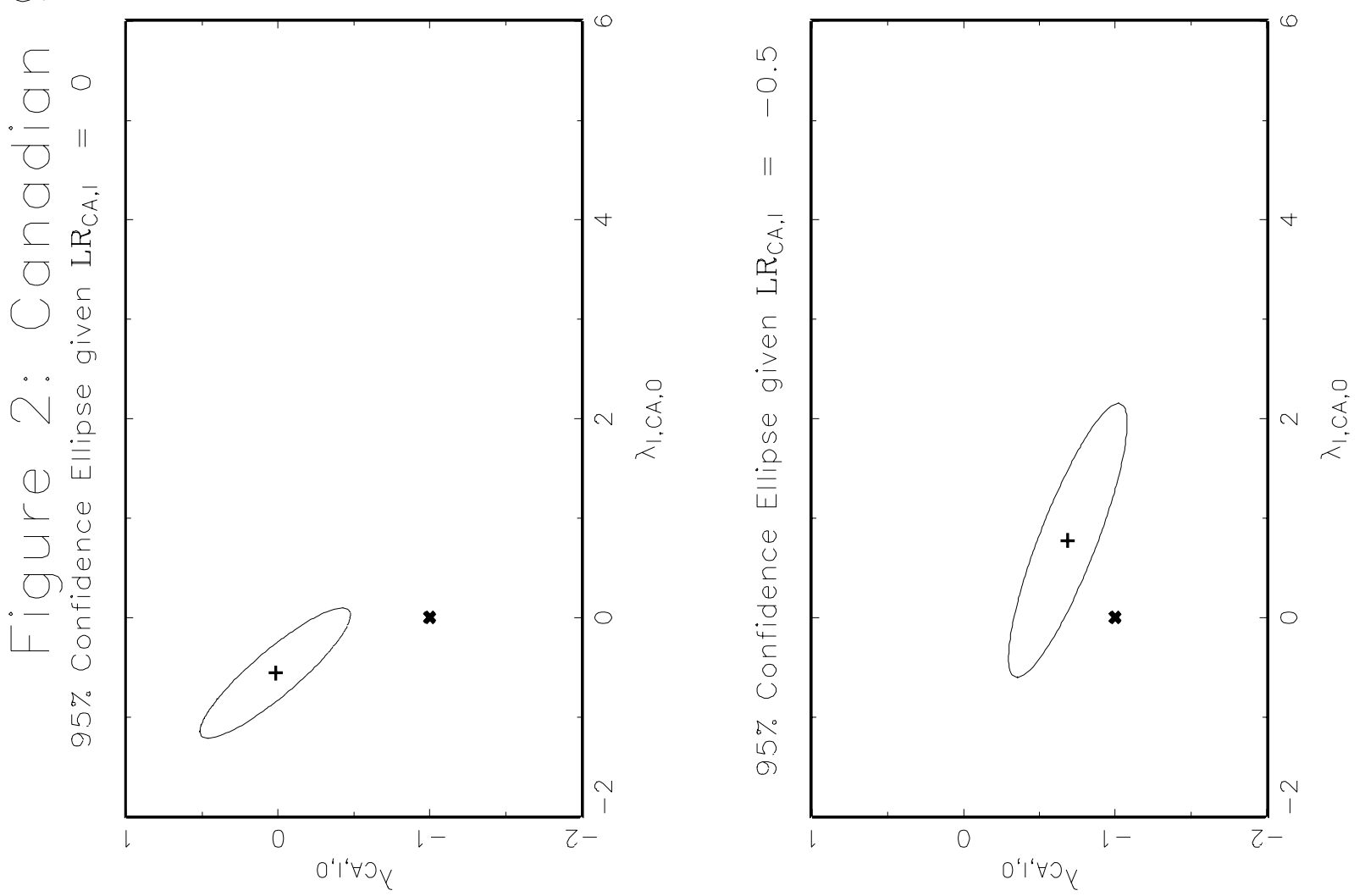


\section{Appendix}

This appendix contains more information about our data set and describes our estimation methods. Details about our data set appear in section A.1. Estimates of the contemporaneous correlation of the first differences of the current account, $\Delta C A_{t}$, and investment $\Delta I_{t}$ for the rest of the G-7 economies (i.e., France, Germany, Italy, Japan, the U.K., and the U.S.) are found in section A.2. Section A.3 discusses reduced-form VAR (RFVAR) estimation procedures and results for the entire $\mathrm{G}-7$. Unit root tests and the results of these tests are furnished in section A.4. Section A.5 outlines the way in which we estimate the structural VARs (SVARs) of section 4 of the paper. Further, section A.5 provides estimates of the relevant SVAR coefficients, forecast error variance decompositions (FEVDs), and graphical evidence for the remainder of the $\mathrm{G}-7$ in support of the conclusions of the paper.

\section{A.1 Data}

The paper uses quarterly data that spans the period 1973.1-1995.4. All of our estimates are based on the 1975.1 - 1995.4 sample. We require data earlier than 1975.1 for lags when computing ADF regressions and estimating VARs. Our definition of investment equals the sum of gross capital formation and the change in stocks (i.e. inventories) with one exception. The U.S. investment series includes gross capital formation of the government. This definition of investment is the same one Glick and Rogoff (1995) use. The source of the quarterly gross capital formation series is Datastream. In Datastream, this data appears in billions of constant local currency units and is seasonally adjusted at annual rates. Quarterly data for the change in stocks for the $\mathrm{G}-7$ and the U.S. gross capital formation of the government series are found in the IFS data bank. The IFS provides this data in current local currency units, seasonally adjusted, at annual rates. We convert this nominal data to real data using the GDP price deflators of the G-7. We obtain the GDP price deflators from Datastream. Subsequent to making an adjustment to annual rates where appropriate, this completes the task of creating the investment series.

Datastream reports quarterly current account data in millions of current U.S. dollars for the $\mathrm{G}-7$ with the exception of the current account series for Canada, Japan, and the U.K. In Datastream, the current account series for Japan appears at the monthly frequency in millions of U.S. dollars. We temporally aggregate the monthly data to form a quarterly series. The current account series for Canada and the U.K. are provided in millions of current local currency units. All of the current account data in Datastream are seasonally adjusted with the exception of the series for France and Italy. We apply the X-11 filter to seasonally adjust these series. To convert the current account series for France, Germany, Italy, and Japan to millions of constant local currency units, we apply the appropriate U.S. dollar/local currency exchange rate. The quarterly exchange rate data we employ is from the IFS and has been generously provided by Mick Devereux. Next, we use GDP deflators

to create quarterly current account series in millions of constant local currency units. The final step produces current account series for the $G-7$ in billions of constant local currency units at annual rates. 
Figures A1 and A2 contain time plots of the level of investment, $I_{t}$, and the level of the current account, $C A_{t}$, for the $\mathrm{G}-7$ economies in alphabetical order. The most striking aspect of this data is the observed inverse relationship between $I_{t}$ and the $C A_{t}$. However, no structural interpretation can be given to this observation.

\section{A.2 Reduced Form Univariate Regressions}

At the beginning of section 3 of the paper, we present evidence that the contemporaneous correlation of $\Delta C A_{t}$ and $\Delta I_{t}$ for Canada matches estimates reported elsewhere. In this section, we present evidence that our entire $\mathrm{G}-7$ data set produces similar estimates of the slope coefficient of the regression

$$
\Delta C A_{t}=b_{0}+b_{1} \Delta I_{t}+v_{t}
$$

Among others, Glick and Rogoff (1995) note that much of the literature that studies the degree of international capital mobility examines the slope coefficient of this regression. Since Glick and Rogoff report estimates of $b_{1}$ that are less than zero, the estimates make dubious the Feldstein and Horioka (1980) story of autarkic national capital markets. However, at face value the Glick and Rogoff estimates cannot be taken as evidence of perfect capital mobility internationally because these estimates of $b_{1}$ are less negative than negative one.

The upper half of table $A 1$ reproduces Glick and Rogoff's ordinary least squares (OLS) estimates. Our results appear in the bottom half of the table. The sample period for our regression begins with 1975.1 and ends at 1995.4, while the Glick-Rogoff estimates are based on annual data from 1975 to 1990. ${ }^{\text {A.1 }}$ For our estimates of $b_{1}$, we provide both OLS and Newey-West (1994) standard errors. Our estimates of $b_{1}$ are all negative with an average estimate of -0.33 . The average Glick-Rogoff estimate is about -0.39 . With the exception of Germany, all of our estimates of $b_{1}$ are smaller (in absolute value) than those Glick and Rogoff report. All of our estimates of $b_{1}$ possess $t$-ratios greater than two in absolute value. ${ }^{\text {A.2 }}$

Thus, our estimates of the reduced form regressions indicate that the correlation between $\Delta C A_{t}$ and $\Delta I_{t}$ in our data set is similar to that found by other researchers. To reiterate our discussion just before section 3.1 of the paper, no structural interpretation can be given to these estimates without an identification scheme.

\section{A.3 Reduced-Form VAR Estimation}

The results of estimating the reduced form VAR of $\Delta C A_{t}$ and $\Delta I_{t}$ appear in tables $A 2.1$ - 2. For each G-7 member, we compute OLS estimates of the fourth-order VAR

\footnotetext{
${ }^{\text {A.1 }}$ Estimates for the 1975.1-1990.4 sample are qualitatively similar to those for the 1975.1-1995.4 sample.

A.2 The major difference between our estimates and those of Glick and Rogoff is the $R^{2}$ and Durbin-Watson (D-W) statistics. For six of the seven regressions, the value of $R^{2}$ we report is smaller than those in the top panel of table $A 1$. On the other hand, the Glick-Rogoff $\mathrm{D}-\mathrm{W}$ statistics are smaller than ours. Most likely, the source of these differences is temporal aggregation.
} 


$$
\Delta I_{t}=A_{\Delta I, \Delta I}(\mathbf{L}) \Delta I_{t-1}+A_{\Delta I, \Delta C A}(\mathbf{L}) \Delta C A_{t-1}+\varepsilon_{\Delta I, t},
$$

and

$$
\Delta C A_{t}=A_{\triangle C A, \Delta I}(\mathbf{L}) \Delta I_{t-1}+A_{\triangle C A, \Delta C A}(\mathbf{L}) \Delta C A_{t-1}+\varepsilon_{\Delta C A, t} .
$$

We estimate the reduced form VAR of (A3.1) and (A3.2) by ordinary least squares (OLS). These results appear in table A2.1. The Granger-causality tests we present in table $A 2.1$ follow the advice of Hamilton (1994) and construct a test statistic that asymptotically possesses the $\chi^{2}$ distribution with four degrees of freedom. To compute the forecast errors and shocks to the stochastic trends that appear in table $A 2.2$, we estimate a slightly altered reduced form VAR. In this instance, we write equations (A3.1) and (A3.2) as

$$
\begin{aligned}
\Delta I_{t} & =A_{\Delta I, \Delta I}(\mathbf{1}) \Delta I_{t-1}+A_{\Delta I, \Delta I}(\mathbf{L}) \Delta^{2} I_{t-1} \\
& +A_{\Delta I, \Delta C A}(\mathbf{1}) \Delta C A_{t-1}+A_{\Delta I, \Delta C A}(\mathbf{L}) \Delta^{2} C A_{t-1}+\varepsilon_{\Delta I, t},
\end{aligned}
$$

and

$$
\begin{aligned}
\Delta C A_{t} & =A_{\Delta C A, \Delta I}(\mathbf{1}) \Delta I_{t-1}+A_{\Delta C A, \Delta I}(\mathbf{L}) \Delta^{2} I_{t-1} \\
& +A_{\Delta C A, \Delta C A}(\mathbf{1}) \Delta C A_{t-1}+A_{\triangle C A, \Delta C A}(\mathbf{L}) \Delta^{2} C A_{t-1}+\varepsilon_{\Delta C A, t},
\end{aligned}
$$

where the lag operators are of order $p-1$. Standard deviations of the forecast errors and their correlations are calculated from the OLS residuals of the regressions (A3.3) and (A3.4) for all of the $\mathrm{G}-7$ economies. To generate the standard deviations of the stochastic trends and their correlation for the $\mathrm{G}-7$, we combine the OLS estimates of the coefficients $A_{\triangle I, \triangle C A}(\mathbf{1}), A_{\triangle I, \triangle I}(\mathbf{1}), A_{\triangle C A, \triangle I}(\mathbf{1})$, and $A_{\triangle C A, \triangle C A}(\mathbf{1})$ with the covariance matrix of the reduced form OLS residuals of the regressions (A3.3) and (A3.4). We follow King and Watson (1997) and compute the standard errors of the stochastic trends and their correlation by the delta method.

In table $A 2.1$, we report sums of the estimated coefficients of equations (A3.1) and (A3.2), their standard errors, LM tests, and Granger-causality tests. Although there are some noticeable patterns across the $\mathrm{G}-7$ in the signs of these sums of coefficients, only those for Japan and the U.K. have a $t$-ratio greater than two. For Japan, the coefficient sums with a $t$-ratio greater than two are the autoregressive parameters of equations (A3.1) and (A3.2). For the U.K., the coefficient sums with $t$-ratios greater than two (in absolute terms) are in equation (A3.2), the $\Delta C A_{t}$ regression.

Results of the LM and Granger-causality tests produce a similar picture. The LM test computes the statistic $T \times R^{2}$ to provide information about the hypothesis that all of the slope coefficients of either equation (A3.1) or equation (A3.2) are jointly equal to zero. In this 
case, the test statistic is asymptotically distributed $\chi^{2}$ with eight degrees of freedom. Of the 14 regressions, only four regressions, the $\Delta I_{t}$ regression for Japan and the $\Delta C A_{t}$ regressions for France, the U.K. and the U.S., reject the hypothesis at the five percent significance level. Likewise, the tests for Granger-causality suggest that $\triangle C A$ possesses no forecasting power for $\Delta I$ across the $\mathrm{G}-7$. On the other hand, using equation (A3.2) to test the hypothesis that $A_{\triangle C A, \Delta I}(j)=0, j=1, \ldots, 4$, yields evidence that is a bit more mixed. In this case, $\Delta I$ possesses forecasting power for $\Delta C A$ for France, the U.K., and the U.S. at the five percent significance level or better. These Granger-causality tests lend some support for the notion that lags of $\Delta I_{t}$ do not matter for $\Delta C A_{t}$, as implied by the intertemporal, small open economy model. There exists stronger evidence that lags of $\Delta C A_{t}$ do not predict movements in $\Delta I_{t} .{ }^{\text {A.3 }}$ Taken together with the estimates of the coefficient sums, the results of the LM tests and the Granger-causality tests appear to support the inference that, except for Japan, $\Delta I_{t}$ is to a first approximation white noise, but that $\Delta C A_{t}$ is white noise for Canada, Germany, and Italy, at least, in the context of the RFVAR of (A3.1) and (A3.2).

The top panel of table 2.2 contains summary statistics of the one-step ahead forecast errors. Except for the U.K., the standard deviation of the innovation of the $\Delta I_{t}$ regression is greater than that for the $\Delta C A_{t}$ regression for all $\mathrm{G}-7$ economies. In addition, all of the estimated standard deviations possess $t$-ratios greater than two. As expected, the contemporaneous correlation between the innovations of $\Delta I_{t}$ and $\Delta C A_{t}$ regressions is negative. Aside from the U.K., the absolute value of the $t$-ratios of these correlations is less than two. At short horizons, news about unrestricted forecasts of $\Delta I_{t}$ and $\Delta C A_{t}$ are orthogonal.

Estimates of the stochastic trends appear in the bottom panel of table 2.2. For the entire $\mathrm{G}-7$, the standard deviation of the permanent component of the innovation of the $\Delta I_{t}$ regression is greater than the same statistic for the $\Delta C A_{t}$ regression. Among this set of standard deviations, the standard deviation of the permanent component of the innovation of the $\Delta I_{t}$ regression for the U.K. possesses the smallest $t$-ratio of 1.94 . For each of the $\mathrm{G}-7$, the contemporaneous correlation between the permanent innovations in the $\Delta I_{t}$ and $\Delta C A_{t}$ regressions is negative. However, only the $t$-ratios for Italy, the U.K., and the U.S. are greater than two (in absolute terms). This suggests that unrestricted long-run movements in $I_{t}$ and $C A_{t}$ have a common source.

\section{A.4 Unit Root Tests}

Elliot, Rothenberg, and Stock (1996) present a method to test for a unit root in the presence of a deterministic mean or trend that is asymptotically more powerful than the usual DF $t$-ratio. This method begins by estimating the regression $y_{t}=\beta_{0}+\beta_{1} t+\omega_{t}$. The next step constructs the predicted values of $\hat{\omega}_{t}=y_{t}-\hat{\beta}_{0}-\hat{\beta}_{1} t$ to use in the augmented DF regression

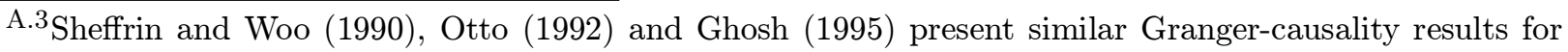
these countries. However, the regressions these authors estimate use the $C A_{t}$ instead of $\Delta C A_{t}$.
} 


$$
\hat{\omega}_{t}=\rho \hat{\omega}_{t-1}+\sum_{j=1}^{k} \vartheta_{j} \Delta \hat{\omega}_{t-j}+u_{t, k}
$$

where the lag length, $k$, is chosen using the BIC criterion to render $u_{t}$ white noise. ${ }^{\text {A. }}$ The GLS-DF $t$-ratio is constructed using the OLS estimates of $\rho$ and its standard error. Elliot, Rothenberg, and Stock provide asymptotic ten percent, five percent, and one percent critical values for the GLS-DF $t$-ratio equal to $-2.57,-2.89$, and -3.48 , respectively.

We present OLS estimates of the standard ADF $t$-ratio using the regression

$$
y_{t}=\psi_{0}+\psi_{1} t+\gamma y_{t-1}+\sum_{j=1}^{k} \xi_{j} \Delta y_{t-j}+e_{t}
$$

where the lag length, $k$, is chosen to render $e_{t}$ white noise. The lag length, $k$, is chosen using the Campbell and Perron (1991) rule. This rule selects a maximum $k$ a priori and then discards lags until the $t$-ratio of $\Delta y_{t-k}$ becomes less than 1.6 (in absolute value). MacKinnon (1991) provides asymptotic ten percent, five percent, and one percent critical values for the DF $t$-ratio equal to $-3.13,-3.41$, and -3.96 , respectively.

Unit root tests are often criticized because of power problems these tests have, for example, with trend stationary alternatives. ${ }^{\text {A.5 }}$ Another problem that face unit root tests is an inability to provide information about the sampling variability of the estimate of $\gamma$. Stock (1991) presents the results of Monte Carlo simulations that are the building blocks for the construction of asymptotic confidence intervals. We present 95 percent asymptotic confidence intervals using the ADF regression with an intercept and a linear trend. As Stock suggests, we use linear interpolation to construct the asymptotic confidence intervals of $\gamma$.

\section{A.5 SVAR Estimation Methods}

Our estimation strategy follows closely that of King and Watson (1997). Since the appendix King and Watson (1997) supply contains a large amount of detail about their estimation methods, this section of our appendix provides only a brief sketch of the way in which we adapt these estimation methods. In particular, this section includes a description of the methods we use to estimate the SVAR when either $\mathcal{L R}_{I, C A}$ or $\mathcal{L R}_{C A, I}$ serves as the identifying restriction.

To estimate a SVAR when a long run multiplier acts as the identifying restriction, King and Watson (1997) use the technique of rewriting a regression to include second difference terms. When $\mathcal{L R}_{I, C A}$ identifies the SVAR, we develop the bivariate system to estimate by writing equation (9) as

\footnotetext{
A.4 To choose the lag length, the BIC criterion, $\ln \left[\hat{\sigma}_{u, k}^{2}\right]+(k / T) \ln [T]$, is minimized over $k$.

A. 5 These problems are at the center of the debate of the source of the trend in real U.S. GNP. Diebold and Senhadji (1996) and Nelson and Murray (1997) present contrasting views of this issue.
} 


$$
\begin{aligned}
\Delta I_{t}=\lambda_{I, C A}(\mathbf{1}) \Delta C A_{t}+\lambda_{I, I}(\mathbf{1}) \Delta I_{t-1} \\
\quad+\quad \Lambda_{I, I}(\mathbf{L}) \Delta^{2} I_{t-1}+\Lambda_{I, C A}(\mathbf{L}) \Delta^{2} C A_{t-1}+\eta_{W, t},
\end{aligned}
$$

where, for example,

$$
\Lambda_{I, I}(\mathbf{L}) \Delta^{2} I_{t-1}=-\sum_{j=1}^{p-1}\left(\sum_{s=j+1}^{p} \lambda_{I, I, s}\right) \Delta^{2} I_{t-j} .
$$

From (9), it follows that $\mathcal{L R}_{I, C A}=\lambda_{I, C A}(\mathbf{1}) /\left[1-\lambda_{I, I}(\mathbf{1})\right]$. With a bit of algebra, this yields the regression

$$
\begin{aligned}
\Delta I_{t}-\mathcal{L R}_{I, C A} \Delta C A_{t} & =\lambda_{I, I}(\mathbf{1})\left[\Delta I_{t-1}-\mathcal{L R}_{I, C A} \Delta C A_{t}\right] \\
& +\Lambda_{I, I}(\mathbf{L}) \Delta^{2} I_{t-1}+\Lambda_{I, C A}(\mathbf{L}) \Delta^{2} C A_{t-1}+\eta_{W, t}
\end{aligned}
$$

Since $\Delta C A_{t}$ can be correlated with $\eta_{W, t}$, we compute the coefficients of this equation with an IV estimator using the instruments $\left\{\Delta I_{t-j}, \Delta C A_{t-j}\right\}_{j=1}^{p}$ for the $\mathrm{G}-7$ economies. With the coefficient estimates of the regression of (A5.2) in hand, we estimate equation (10) by IV with the instruments $\left\{\Delta I_{t-j}, \Delta C A_{t-j}\right\}_{j=1}^{p}$ and $\hat{\eta}_{W, t}$. The instrument $\hat{\eta}_{W, t}$ denotes the residuals of regression (A5.2). We use a symmetric procedure when $\mathcal{L R}_{C A, I}$ serves to identify the SVAR. Across the $\mathrm{G}-7$, the standard errors of the estimates of $\mathcal{L R}_{I, C A}$ and $\mathcal{L R}_{C A, I}$ are computed using the delta method.

Another issue we face is that the procedure just described uses a generated regressor, $\hat{\eta}_{W, t}$, as an instrument to estimate equation (10). The generated regressor problem arises because the variables on the right hand side of equation (10) and $\hat{\eta}_{W, t}$ may be correlated. As a result, an adjustment is needed to the estimator of the covariance matrix of the coefficients of equation (10). King and Watson (1997) present the details of the adjustment to this covariance matrix. We do not duplicate their efforts here.

To compute the empirical standard errors of the FEVDs we report in tables 3 and A5.1-3, the Monte Carlo procedure begins with estimates of the intercepts, slope coefficients, and the covariance matrix of the residuals of the RFVAR of equations (A3.1) and (A3.2) for each member of the $\mathrm{G}-7$. Using these reduced-form estimates, we generate 1000 pairs of normally distributed, mean zero random variates. The covariance matrix of these random variates equals the covariance matrix of the reduced-form residuals. From these synthetic residuals and the estimated intercepts and slope coefficients we build up artificial $I_{t}$ and the $C A_{t}$ series. Next, we estimate the SVARs under the identifications of $R 1, R 2$, and $R 6$ using these 1000 replications. The estimates of the SVAR using the artificial data allows us to construct the small sample standard errors of the FEVDs. Since this procedure builds the Monte Carlo up from the distribution of the RFVAR residuals, the standard errors of 
the FEVDs possesses only an interpretation as draws from the small sample or empirical distribution of the joint dynamic process that generates $I_{t}$ and the $C A_{t}$.

\section{A.6 SVAR Results for the G-7 sans Canada}

Tables $A 4.1-3$ contain point estimates of $\lambda_{I, C A, 0}, \lambda_{C A, I, 0}, \mathcal{L R}_{I, C A}$, and $\mathcal{L R}_{C A, I}$ as well as Wald statistics that test a key prediction of the intertemporal model under restrictions $R 1-R 6$ for the $\mathrm{G}-7$ minus Canada. The point estimates we present in these tables reinforce the results for Canada of table 2. These results are that

(a) estimates of $\mathcal{L} \mathcal{R}_{I, C A}$ back the inference that only the common world shock, $\eta_{W, t}$, drive permanent fluctuations in $I_{t}$,

(b) estimates of the impact coefficients $\lambda_{I, C A, 0}$ and $\lambda_{C A, I, 0}$ are sensitive to the identification scheme,

(c) estimates of $\mathcal{L R}_{C A, I}$ are closely tied to the value of $\lambda_{C A, I, 0}$, and

(d) rejections of the hypothesis of the intertemporal, small open economy prediction that movements in the $C A_{t}$ are independent of $\eta_{W, t}$ and its lags depend on the choice of the identification scheme.

Support for item $(a)$ arise in tables $A 4.1-3$ because of the $t$-ratios the estimates of $\mathcal{L R}_{I, C A}$ imply. Of the 30 estimates of $\mathcal{L R}_{I, C A}$ that appear in these tables, only six yield a $t$-ratio greater than two in absolute value (see the top panel of table $A 4.1$ and the bottom panel of table A4.2). Italy and the U.K. produce two-thirds of these estimates.

Item $(b)$ stands out clearly from an inspection of tables $A 4.1-3$. For example, under $R 1$ (the top panel of table $A 4.1$ ) all the estimates of $\lambda_{I, C A, 0}$ are negative and four of the six estimates possess $t$-ratios greater than two in absolute value. However, under $R 2$ (the bottom panel of table $A 4.1$ ) four of the six estimates of $\lambda_{I, C A, 0}$ are positive and none of these estimates are statistically different from zero at any reasonable significance level.

We show in section 3.5 of the paper that estimates of $\mathcal{L R}_{C A, I}$ are tied either to the identification of $\lambda_{C A, I, 0}$ or its point estimate. The estimates of $\mathcal{L R}_{C A, I}$ we report in tables $A 4.1-3$ bolster this analysis. This observation marks the basis for item $(c)$. Except for the identification scheme $R 2$ (see the bottom panel of table $A 4.1$ ), country-by-country estimates of $\mathcal{L} \mathcal{R}_{C A, I}$ are quite close to the value of $\lambda_{C A, I, 0}$ given an identification.

Casual inspection of the Wald statistics of tables $A 4.1-3$ is enough to clinch support for item $(d)$. The Wald statistics that identifications $R 1$ and $R 3$ generate make this plain. Under $R 1$ the null hypothesis of (12) is only rejected by the French data (see the top panel of table A4.1). However, this hypothesis receives strong rejections by data from France, Germany, Italy, the U.K., and the U.S. under $R 3$ (see the top panel of table A4.2). The Wald statistics continue to back our thesis that tests of many of the predictions of the intertemporal model yield inferences sensitive to the identification.

The forecast error variance decompositions (FEVD) lend support to item $(a)$. When $\mathcal{L R}_{I, C A}=0$ is not imposed as the identifying restriction (i.e., $R 2$ ), we find that the common world shock $\eta_{W, t}$ explains more than 65 percent of the variation in $I_{t}$ at a 24 quarter forecast 
horizon in eight of the remaining 12 FEVDs. In the case of $R 2$, the FEVDs of $I_{t}$ reveals that anywhere from 95 to 100 percent can be attributed to $\eta_{W, t}$ at impact (see the top panel of table A5.2). The FEVDs of $I_{t}$ for France, Germany, Italy, Japan, the U.K., and the U.S. that we report in the top panels of tables $A 5.1-3$ provide economically meaningful evidence that a shock common to the $\mathrm{G}-7$ contributes most to fluctuation in $I_{t}$. This evidence is particularly strong at longer forecast horizons.

Tables $A 5.1-3$ also contain results that help to sustain our claim that the persistence in the $C A_{t}$ of the $\mathrm{G}-7$ is an important and neglected aspect of the intertemporal approach to the current account. Under $R 1$ (see the bottom panel of table A5.1), country-specific shocks in the form of $\eta_{C, t}$ generate about three-fourths or more of movements in the $C A_{t}$ from impact to a forecast horizon of one year for the G-7 minus Canada. Since $R 1$ restricts longrun fluctuations in the $C A_{t}$ to respond only to $\eta_{C, t}$, it is expected that the analogous FEVDs at the longer forecast horizons should approach 100 percent. In this regard, the FEVDs in the bottom half of table $A 5.2$ are particularly striking. These FEVDs are calculated under a long-run identifying restriction imposed on $I_{t}, R 2$. Given no restriction on the behavior of the $C A_{t}$, we find that about 60 percent or more of the variation in this variable is explained by $\eta_{C, t}$ at all forecast horizons for all six economies. The reduced-form long-run identification of $R 6$ reverses this result. The bottom half of table $A 5.3$ contains only one FEVD that possesses a $t$-ratio greater than two (see the impact FEVD for the U.K.) and none of these FEVDs is greater than 32 percent.

Our analysis of section 3.5 of the paper resolves the disparate results of the FEVDs of the $C A_{t}$ we report in the bottom panels of tables $A 5.1-3$. This analysis outlines the close connection between identifications that impose a restriction on the behavior of $C A_{t}$ within the SVAR of (9) and (10) and the estimated unrestricted behavior of the $C A_{t}$. As a result, we should expect to observe FEVDs in which only $\eta_{C, t}$ should matter for the $C A_{t}$ under $R 1$. The FEVDs of the bottom panel of table $A 5.1$ back this expectation. Likewise, under $R 6$, we should anticipate that only common world shocks are responsible for fluctuations in the $C A_{t}$ as we observe in the bottom panel of table $A 5.3$. Hence, the FEVDs of the $C A_{t}$ under $R 2$ (see the bottom panel of table $A 5.2$ ) are a strong signal for the importance of $\eta_{C, t}$ and the impact of these shocks on the persistence of the $C A_{t}$.

Figures $A 3-8$ and $A 9-14$ replicate figures 1 and 2 of the paper, respectively. By and large, the information that figures $A 3-8$ and $A 9-14$ contain reinforce the discussion we present in the paper for figures 1 and 2 . That is, the 95 percent confidence intervals of figures $A 3-8$ show that the identification matters for inference about $R 1$ and $R 6$. These figures are in line with figure 1 because support for the restriction of $R 6$ exists only when $\lambda_{C A, I, 0}$ is close to negative one. The 95 percent confidence ellipses of figures $A 9-14$ provide more evidence to back our conclusion that minor changes to the identification leads to different views of the efficacy of the intertemporal, small open economy model. 


\section{References}

Campbell, J.Y., and P. Perron, 1991, "Pitfalls and Opportunities: What Macroeconomics Should Know about Unit Roots", in NBER Macroeconomic Annual, Blanchard, O.J, and S. Fischer, eds., MIT Press, Cambridge, MA.

Diebold, F.X., and A.S. Senhadji, 1996, "The Uncertain Unit Root in Real GNP", American Economic Review, 86, 1291 - 1298.

Elliot, G., T.J. Rothenberg, and J.H. Stock, 1996, "Efficient Tests for an Autoregressive Root", Econometrica, 64, $813-836$.

Feldstein, M.S., and C.Y. Horioka, 1980, "Domestic Savings and International Capital Flows", Economic Journal, 90, $314-329$.

Ghosh, A.R., 1995, "International Capital Mobility Amongst the Major Industrialized Countries: Too Little or Too Much?", Economic Journal, 105, 107 - 128.

Glick, R., and K. Rogoff, 1995, "Global Versus Country-Specific Productivity Shocks and the Current Account", Journal of Monetary Economics, 35, 159 - 192.

Hamilton, J.D., 1994, Time Series $\underline{\text { Analysis, }}$, Princeton University Press, Princeton, NJ.

King, R.G., and M.W. Watson, 1994, "The Post-War Phillips Curve: A Revisionist Econometric History", Carnegie-Rochester Conference Series on Public Policy, 41, 157 - 219.

King, R.G., and M.W. Watson, 1997, "Testing Long-Run Neutrality", Economic Quarterly, Federal Reserve Bank of Richmond, 83(Summer), 69 - 101.

MacKinnon, J.G., 1991, "Critical Values for Cointegration Tests", in Long-Run Economic

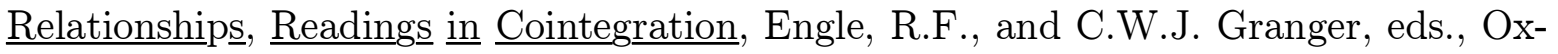
ford University Press, Oxford, U.K..

Nelson, C.R., and C.J. Murray, 1997, "The Uncertain Trend in U.S. GNP", mimeo, Department of Economics, University of Washington.

Newey, W.K., and K.D. West, 1994, "Automatic Lag Selection in Covariance Matrix Estimation", Review of Economic Studies, 61, 631 - 654.

Otto, G., 1992, "Testing a Present Value Model of the Current Account: Evidence from the U.S. and Canadian Time Series", Journal of International Money and Finance, 11, $414-430$.

Sheffrin, S.M., and W.T. Woo, 1990, "Present Value Tests of an Intertemporal Model of the Current Account", Journal of International Economics, 29, 237 - 253.

Stock, J.H., 1991, "Confidence Intervals for the Largest Autoregressive Root in U.S. Macroeconomic Time Series", Journal of Monetary Economics, 28, 435 - 459. 


\section{Table A1. Reduced Form Univariate Regressions}

\begin{tabular}{|c|c|c|c|c|c|c|c|}
\hline \multirow{3}{*}{ 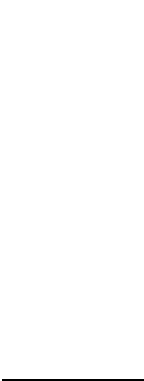 } & \multicolumn{7}{|c|}{ Glick and Rogoff Results } \\
\hline & \multicolumn{3}{|c|}{ Sample Period: } & \multicolumn{2}{|c|}{$1975-1990$} & \multirow[b]{2}{*}{ U.K. } & \multirow[b]{2}{*}{ U.S. } \\
\hline & Canada & France & Germany & Italy & Japan & & \\
\hline$\hat{b}_{1}$ & $\begin{array}{l}-0.30 \\
(0.10)\end{array}$ & $\begin{array}{l}-0.42 \\
(0.12)\end{array}$ & $\begin{array}{l}-0.23 \\
(0.19)\end{array}$ & $\begin{array}{l}-0.59 \\
(0.10)\end{array}$ & $\begin{array}{l}-0.37 \\
(0.10)\end{array}$ & $\begin{array}{l}-0.60 \\
(0.10)\end{array}$ & $\begin{array}{c}-0.20 \\
(0.09)\end{array}$ \\
\hline$R^{2}$ & 0.38 & 0.47 & 0.10 & 0.71 & 0.49 & 0.72 & 0.27 \\
\hline $\mathrm{D}-\mathrm{W}$ & 1.88 & 1.42 & 1.60 & 1.19 & 1.54 & 1.81 & 1.18 \\
\hline
\end{tabular}

Results Using Quarterly Data Sample Period: $\quad 1975.1-1995.4$

\begin{tabular}{cccccccc} 
& Canada & France & Germany & Italy & Japan & U.K. & U.S. \\
\hline \multirow{2}{*}{$\hat{b}_{1}$} & -0.37 & -0.37 & -0.33 & -0.43 & -0.20 & -0.54 & -0.11 \\
& $(0.08)$ & $(0.09)$ & $(0.09)$ & $(0.09)$ & $(0.08)$ & $(0.11)$ & $(0.04)$ \\
& {$[0.07]$} & {$[0.09]$} & {$[0.15]$} & {$[0.11]$} & {$[0.06]$} & {$[0.09]$} & {$[0.04]$} \\
$R^{2}$ & 0.20 & 0.17 & 0.13 & 0.22 & 0.07 & 0.22 & 0.09 \\
& & & & & & & \\
$\mathrm{D}-\mathrm{W}$ & 2.34 & 2.46 & 2.50 & 2.36 & 1.64 & 2.72 & 2.20 \\
& & & & & & & \\
\hline
\end{tabular}

The Glick and Rogoff (1995) estimates, taken from the bottom panel of their table 1, are based on annual data. We use OLS to compute estimates of the slope coefficient $b_{1}$ as do Glick and Rogoff. OLS standard errors appear in parenthesis. The values in brackets are Newey-West corrected standard errors. The Newey-West standard errors are constructed using an automatic lag length adjustment. 


\section{Table A2.1 Reduced Form VARs \\ Sample Period: $\quad 1975.1-1995.4$}

\section{Coefficient Sums and Tests of Predictive Content}

\begin{tabular}{|c|c|c|c|c|c|c|c|}
\hline & Canada & France & Germany & Italy & Japan & U.K. & U.S. \\
\hline$A_{\Delta I, \Delta I}(\mathbf{1})$ & $\begin{array}{c}0.07 \\
(0.23)\end{array}$ & $\begin{array}{c}0.31 \\
(0.20)\end{array}$ & $\begin{array}{c}-0.16 \\
(0.28)\end{array}$ & $\begin{array}{c}0.00 \\
(0.22)\end{array}$ & $\begin{array}{c}0.46 \\
(0.14)\end{array}$ & $\begin{array}{c}0.18 \\
(0.30)\end{array}$ & $\begin{array}{l}-0.09 \\
(0.24)\end{array}$ \\
\hline$A_{\Delta I, \Delta C A}(\mathbf{1})$ & $\begin{array}{c}0.16 \\
(0.37)\end{array}$ & $\begin{array}{c}0.30 \\
(0.34)\end{array}$ & $\begin{array}{c}-0.28 \\
(0.33)\end{array}$ & $\begin{array}{c}0.05 \\
(0.30)\end{array}$ & $\begin{array}{c}-0.03 \\
(0.22)\end{array}$ & $\begin{array}{c}-0.02 \\
(0.36)\end{array}$ & $\begin{array}{l}-0.26 \\
(0.72)\end{array}$ \\
\hline$A_{\triangle C A, \Delta I}(\mathbf{1})$ & $\begin{array}{c}-0.02 \\
(0.19)\end{array}$ & $\begin{array}{c}-0.10 \\
(0.17)\end{array}$ & $\begin{array}{c}0.14 \\
(0.26)\end{array}$ & $\begin{array}{c}-0.26 \\
(0.22)\end{array}$ & $\begin{array}{c}-0.02 \\
(0.12)\end{array}$ & $\begin{array}{c}-0.93 \\
(0.32)\end{array}$ & $\begin{array}{l}-0.13 \\
(0.09)\end{array}$ \\
\hline$A_{\triangle C A, \triangle C A}(\mathbf{1})$ & $\begin{array}{c}-0.42 \\
(0.30)\end{array}$ & $\begin{array}{c}-0.51 \\
(0.29)\end{array}$ & $\begin{array}{c}0.04 \\
(0.31)\end{array}$ & $\begin{array}{c}-0.26 \\
(0.29)\end{array}$ & $\begin{array}{c}0.37 \\
(0.18)\end{array}$ & $\begin{array}{c}-1.12 \\
(0.38)\end{array}$ & $\begin{array}{c}-0.04 \\
(0.26)\end{array}$ \\
\hline$\Delta I$ Regression : $R^{2}$ & $\begin{array}{c}0.09 \\
{[0.44]}\end{array}$ & $\begin{array}{c}0.11 \\
{[0.34]}\end{array}$ & $\begin{array}{c}0.15 \\
{[0.12]}\end{array}$ & $\begin{array}{c}0.15 \\
{[0.14]}\end{array}$ & $\begin{array}{c}0.36 \\
{[0.00]}\end{array}$ & $\begin{array}{c}0.03 \\
{[0.95]}\end{array}$ & $\begin{array}{c}0.09 \\
{[0.44]}\end{array}$ \\
\hline$\Delta C A$ Regression : $R^{2}$ & $\begin{array}{c}0.11 \\
{[0.31]}\end{array}$ & $\begin{array}{c}0.19 \\
{[0.04]}\end{array}$ & $\begin{array}{c}0.07 \\
{[0.66]}\end{array}$ & $\begin{array}{c}0.06 \\
{[0.76]}\end{array}$ & $\begin{array}{c}0.10 \\
{[0.42]}\end{array}$ & $\begin{array}{c}0.20 \\
{[0.03]}\end{array}$ & $\begin{array}{c}0.21 \\
{[0.02]}\end{array}$ \\
\hline Wald Test: $\triangle C A \rightarrow \Delta I:$ & $\begin{array}{c}2.77 \\
{[0.60]}\end{array}$ & $\begin{array}{c}3.46 \\
{[0.48]}\end{array}$ & $\begin{array}{c}7.40 \\
{[0.12]}\end{array}$ & $\begin{array}{c}6.73 \\
{[0.15]}\end{array}$ & $\begin{array}{c}5.81 \\
{[0.21]}\end{array}$ & $\begin{array}{c}0.49 \\
{[0.97]}\end{array}$ & $\begin{array}{c}0.36 \\
{[0.99]}\end{array}$ \\
\hline Wald Test: $\Delta I \rightarrow \Delta C A$ : & $\begin{array}{c}6.75 \\
{[0.15]}\end{array}$ & $\begin{array}{l}11.05 \\
{[0.03]}\end{array}$ & $\begin{array}{c}1.29 \\
{[0.86]}\end{array}$ & $\begin{array}{c}3.72 \\
{[0.45]}\end{array}$ & $\begin{array}{c}1.37 \\
{[0.85]}\end{array}$ & $\begin{array}{l}10.46 \\
{[0.03]}\end{array}$ & $\begin{array}{c}9.51 \\
{[0.05]}\end{array}$ \\
\hline
\end{tabular}

Standard errors appear in parenthesis. The values in brackets are p-values. The p-values that appear below the $R^{2}$ s represent significance levels for the LM test statistic $T \times R^{2}$. These statistics are asymptotically distributed $\chi^{2}$ with eight degrees of freedom. The Wald statistics that tests the predictive power of either $\Delta I$ for $\Delta C A$ or $\Delta C A$ for $\Delta I$ possess a $\chi^{2}$ distribution with four degrees of freedom asymptotically. 


\section{Table A2.2 Reduced Form VARs}

Sample Period: $1975.1-1995.4$

\begin{tabular}{cccccccc}
\multicolumn{8}{c}{ Forecast Errors } \\
& Canada & France & Germany & Italy & Japan & U.K. & U.S. \\
\hline \multirow{2}{*}{$\sigma\left(\varepsilon_{\Delta I}\right)$} & 4.40 & 21.64 & 22.25 & 10716.18 & 1639.38 & 4.22 & 58.04 \\
& $(1.03)$ & $(5.06)$ & $(5.20)$ & $(2502.97)$ & $(382.91)$ & $(0.98)$ & $(13.56)$ \\
$\sigma\left(\varepsilon_{\Delta C A}\right)$ & 3.60 & 18.40 & 20.75 & 10332.76 & 1312.30 & 4.45 & 21.05 \\
& $(0.84)$ & $(4.30)$ & $(4.85)$ & $(2413.41)$ & $(306.51)$ & $(1.04)$ & $(4.92)$ \\
$\operatorname{Corr}\left(\varepsilon_{\Delta I}, \varepsilon_{\Delta C A}\right)$ & -0.44 & -0.40 & -0.46 & -0.49 & -0.23 & -0.51 & -0.35 \\
& $(0.27)$ & $(0.28)$ & $(0.26)$ & $(0.25)$ & $(0.31)$ & $(0.24)$ & $(0.29)$ \\
& & & & & & & \\
\hline
\end{tabular}

Shocks to Stochastic Trends

\begin{tabular}{cccccccc} 
& Canada & France & Germany & Italy & Japan & U.K. & U.S. \\
\hline \multirow{2}{*}{$\sigma\left(\varepsilon_{I}\right)$} & 4.54 & 28.79 & 21.32 & 10409.73 & 3096.24 & 5.26 & 56.84 \\
& $(1.49)$ & $(10.80)$ & $(5.28)$ & $(3741.63)$ & $(1279.11)$ & $(2.71)$ & $(17.22)$ \\
$\sigma\left(\varepsilon_{C A}\right)$ & 2.54 & 12.86 & 19.79 & 9369.82 & 2104.67 & 3.85 & 24.11 \\
& $(0.67)$ & $(3.01)$ & $(8.67)$ & $(2269.92)$ & $(889.18)$ & $(0.51)$ & $(10.81)$ \\
$\operatorname{Corr}\left(\varepsilon_{I}, \varepsilon_{C A}\right)$ & -0.37 & -0.39 & -0.54 & -0.63 & -0.30 & -0.88 & -0.65 \\
& $(0.38)$ & $(0.45)$ & $(0.35)$ & $(0.26)$ & $(0.45)$ & $(0.28)$ & $(0.26)$
\end{tabular}

Standard errors appear in parenthesis. 
Table A3. Unit Root Tests

Sample Period: $\quad 1975.1-1995.4$

\begin{tabular}{cccccccc}
\multicolumn{9}{c}{ Investment } \\
& Canada & France & Germany & Italy & Japan & U.K. & U.S. \\
\hline $\begin{array}{c}\text { DF-GLS } t \text {-ratio } \\
\text { Lag Length }\end{array}$ & -2.64 & -1.80 & -1.48 & -3.88 & -2.56 & -1.82 & -3.37 \\
& 1 & 1 & 1 & 2 & 3 & 1 & 1 \\
ADF $t$-ratio & -2.78 & -2.40 & -1.67 & -4.07 & -1.99 & -2.11 & -3.90 \\
Lag Length & 1 & 2 & 0 & 2 & 3 & 0 & 3 \\
& & & & & & & \\
ADF AR Root & 0.85 & 0.90 & 0.93 & 0.74 & 0.96 & 0.90 & 0.73 \\
95\% CI: LL & 0.73 & 0.79 & 0.89 & -- & 0.85 & 0.83 & -- \\
95\% CI: UL & 1.04 & 1.05 & 1.06 & 0.90 & 1.05 & 1.05 & 0.93 \\
& & & & & & & \\
\hline
\end{tabular}

Current Account

Canada France Germany Italy Japan U.K. U.S.

$\begin{array}{cccccccc}\text { DF-GLS } t \text {-ratio } & -1.72 & -2.81 & -1.41 & -1.80 & -2.41 & -2.15 & -1.88 \\ \text { Lag Length } & 1 & 1 & 1 & 1 & 2 & 1 & 1 \\ & & & & & & & \\ \text { ADF } t \text {-ratio } & -2.00 & -3.41 & -1.86 & -2.30 & -2.39 & -2.57 & -1.84 \\ \text { Lag Length } & 0 & 0 & 4 & 0 & 2 & 1 & 3 \\ & & & & & & & \\ \text { ADF AR Root } & 0.87 & 0.75 & 0.91 & 0.86 & 0.91 & 0.85 & 0.92 \\ \text { 95\% CI: LL } & 0.85 & 0.61 & 0.86 & 0.80 & 0.79 & 0.76 & 0.87 \\ \text { 95\% CI: UL } & 1.05 & 1.02 & 1.05 & 1.05 & 1.05 & 1.04 & 1.05\end{array}$

The asymptotic ten percent, five percent, and one percent critical values for the GLS-DF $(\mathrm{ADF}) t$-ratio equal $-2.57(-3.13),-2.89(-3.41)$, and $-3.48(-3.96)$, respectively. 


\section{Table A4.1 Structural VARs}

Sample Period: $\quad 1975.1-1995.4$

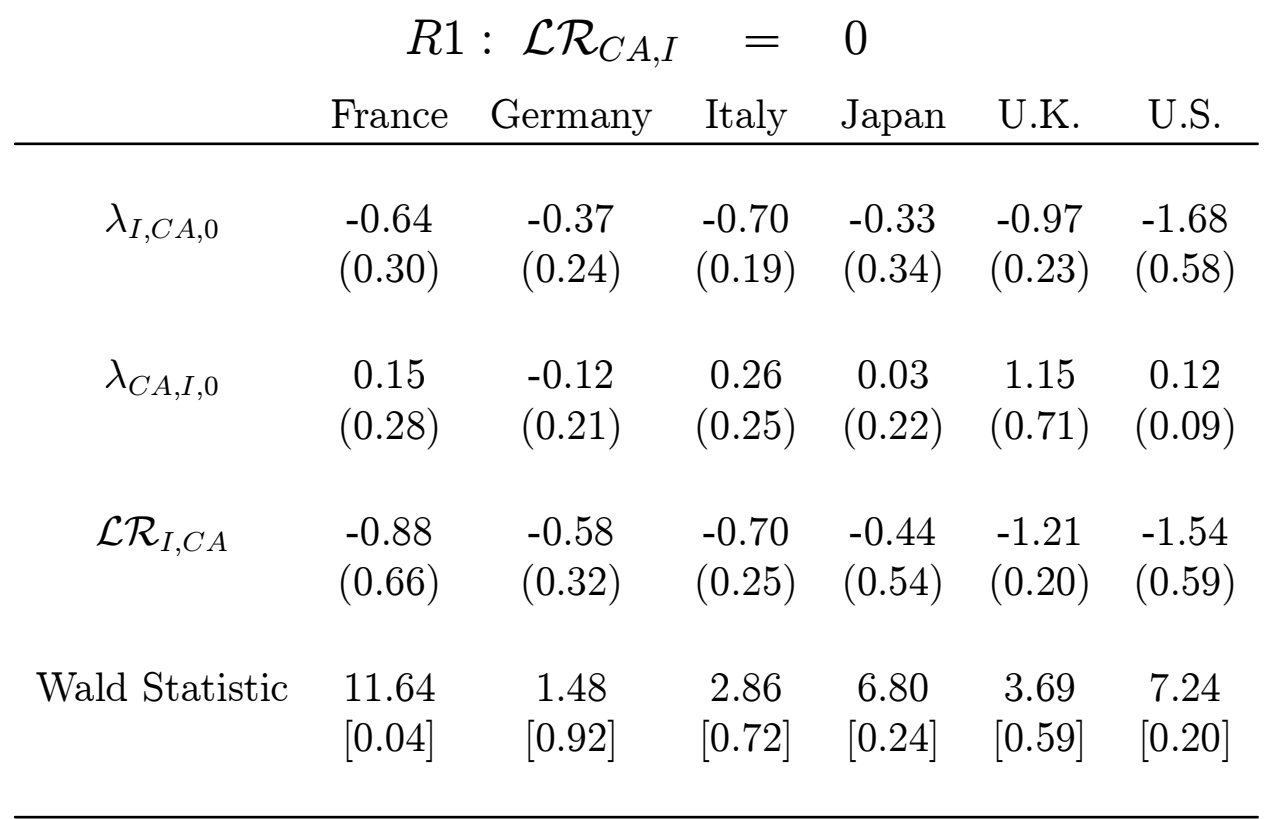

\begin{tabular}{|c|c|c|c|c|c|c|}
\hline & $\begin{array}{r}R 2 \\
\text { France }\end{array}$ & $\begin{array}{l}: \mathcal{L R}_{I, C f} \\
\text { Germany }\end{array}$ & $\begin{array}{r}\quad= \\
\text { Italy }\end{array}$ & $\begin{array}{l}0 \\
\text { Japan }\end{array}$ & U.K. & U.S. \\
\hline$\lambda_{I, C A, 0}$ & $\begin{array}{l}-0.20 \\
(0.21)\end{array}$ & $\begin{array}{c}0.30 \\
(0.40)\end{array}$ & $\begin{array}{c}-0.04 \\
(0.24)\end{array}$ & $\begin{array}{c}0.05 \\
(0.36)\end{array}$ & $\begin{array}{c}0.01 \\
(0.17)\end{array}$ & $\begin{array}{c}0.25 \\
(0.72)\end{array}$ \\
\hline$\lambda_{C A, I, 0}$ & $\begin{array}{l}-0.21 \\
(0.17)\end{array}$ & $\begin{array}{l}-0.61 \\
(0.24)\end{array}$ & $\begin{array}{c}-0.44 \\
(0.20)\end{array}$ & $\begin{array}{l}-0.21 \\
(0.23)\end{array}$ & $\begin{array}{l}-0.54 \\
(0.17)\end{array}$ & $\begin{array}{c}-0.15 \\
(0.09)\end{array}$ \\
\hline $\mathcal{L} \mathcal{R}_{C A, I}$ & $\begin{array}{l}-0.18 \\
(0.18)\end{array}$ & $\begin{array}{l}-0.50 \\
(0.21)\end{array}$ & $\begin{array}{c}-0.57 \\
(0.19)\end{array}$ & $\begin{array}{l}-0.20 \\
(0.26)\end{array}$ & $\begin{array}{l}-0.65 \\
(0.12)\end{array}$ & $\begin{array}{c}-0.28 \\
(0.22)\end{array}$ \\
\hline Wald Statistic & $\begin{array}{l}14.40 \\
{[0.01]}\end{array}$ & $\begin{array}{c}8.13 \\
{[0.15]}\end{array}$ & $\begin{array}{c}9.96 \\
{[0.08]}\end{array}$ & $\begin{array}{c}2.31 \\
{[0.80]}\end{array}$ & $\begin{array}{l}24.24 \\
{[0.00]}\end{array}$ & $\begin{array}{l}13.94 \\
{[0.02]}\end{array}$ \\
\hline
\end{tabular}

In the top and bottom panels, standard errors appear in parenthesis and the brackets contain p-values. The Wald statistic and p-values in the top and bottom panel are based on the hypothesis $\lambda_{C A, I, j}=0, j=0, \ldots, 4$, and five degrees of freedom. 
Table A4.2 Structural VARs

Sample Period: $\quad 1975.1-1995.4$

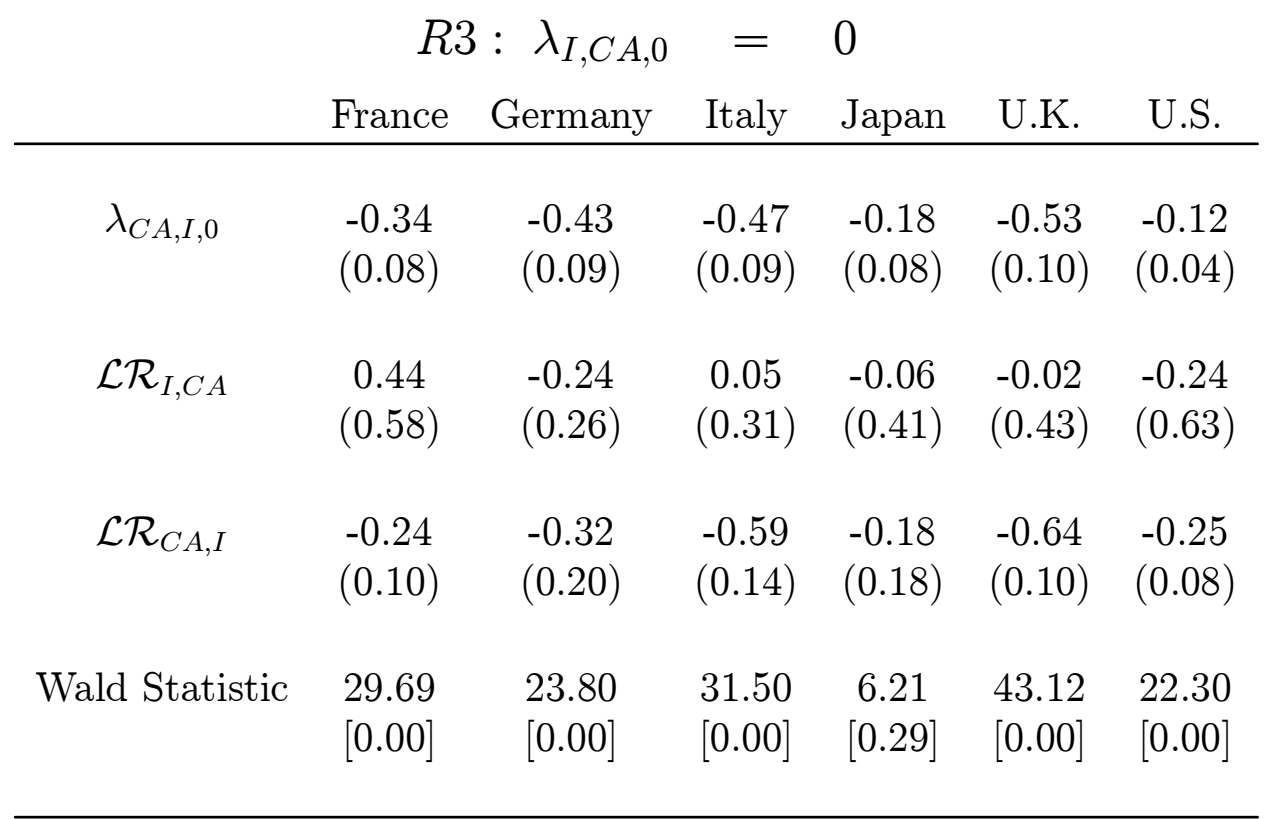

\begin{tabular}{|c|c|c|c|c|c|c|}
\hline & France & Germany & Italy & Japan & U.K. & U.S. \\
\hline$\lambda_{I, C A, 0}$ & $\begin{array}{l}-0.48 \\
(0.12)\end{array}$ & $\begin{array}{l}-0.49 \\
(0.10)\end{array}$ & $\begin{array}{c}-0.50 \\
(0.10)\end{array}$ & $\begin{array}{c}-0.29 \\
(0.13)\end{array}$ & $\begin{array}{l}-0.48 \\
(0.09)\end{array}$ & $\begin{array}{c}-0.96 \\
(0.28)\end{array}$ \\
\hline $\mathcal{L R}_{I, C A}$ & $\begin{array}{l}-0.56 \\
(0.43)\end{array}$ & $\begin{array}{l}-0.69 \\
(0.23)\end{array}$ & $\begin{array}{c}-0.52 \\
(0.21)\end{array}$ & $\begin{array}{c}-0.39 \\
(0.40)\end{array}$ & $\begin{array}{l}-0.82 \\
(0.19)\end{array}$ & $\begin{array}{l}-1.04 \\
(0.53)\end{array}$ \\
\hline $\mathcal{L R}_{C A, I}$ & $\begin{array}{l}-0.07 \\
(0.11)\end{array}$ & $\begin{array}{c}0.15 \\
(0.30)\end{array}$ & $\begin{array}{c}-0.21 \\
(0.14)\end{array}$ & $\begin{array}{c}-0.02 \\
(0.18)\end{array}$ & $\begin{array}{c}-0.44 \\
(0.11)\end{array}$ & $\begin{array}{c}-0.13 \\
(0.07)\end{array}$ \\
\hline Wald Statistic & $\begin{array}{l}11.05 \\
{[0.03]}\end{array}$ & $\begin{array}{c}1.29 \\
{[0.86]}\end{array}$ & $\begin{array}{c}3.72 \\
{[0.44]}\end{array}$ & $\begin{array}{c}1.37 \\
{[0.85]}\end{array}$ & $\begin{array}{l}10.46 \\
{[0.03]}\end{array}$ & $\begin{array}{c}9.52 \\
{[0.05]}\end{array}$ \\
\hline
\end{tabular}

In the top and bottom panels, standard errors appear in parenthesis and the brackets contain p-values. The Wald statistic and p-values in the top (bottom) panel are based on the hypothesis $\lambda_{C A, I, j}=0, j=0, \ldots, 4(j=1, \ldots, 4)$, and five (four) degrees of freedom. 


\section{Table A4.3 Structural VARs}

Sample Period: $\quad 1975.1-1995.4$

\begin{tabular}{|c|c|c|c|c|c|c|}
\hline & France & Germany & Italy & Japan & U.K. & U.S. \\
\hline$\lambda_{I, C A, 0}$ & $\begin{array}{c}1.73 \\
(0.61)\end{array}$ & $\begin{array}{c}1.29 \\
(0.47)\end{array}$ & $\begin{array}{c}1.15 \\
(0.43)\end{array}$ & $\begin{array}{c}1.79 \\
(0.52)\end{array}$ & $\begin{array}{c}0.80 \\
(0.31)\end{array}$ & $\begin{array}{c}151.88 \\
(985.90)\end{array}$ \\
\hline $\mathcal{L R}_{I, C A}$ & $\begin{array}{c}5.75 \\
(6.35)\end{array}$ & $\begin{array}{c}0.71 \\
(0.74)\end{array}$ & $\begin{array}{c}2.16 \\
(2.20)\end{array}$ & $\begin{array}{c}2.16 \\
(1.85)\end{array}$ & $\begin{array}{c}26.96 \\
(254.35)\end{array}$ & $\begin{array}{l}-8.37 \\
(5.93)\end{array}$ \\
\hline $\mathcal{L R}_{C A, I}$ & $\begin{array}{l}-0.66 \\
(0.17)\end{array}$ & $\begin{array}{c}-0.82 \\
(0.20)\end{array}$ & $\begin{array}{c}-1.04 \\
(0.20)\end{array}$ & $\begin{array}{c}-0.83 \\
(0.31)\end{array}$ & $\begin{array}{c}-0.82 \\
(0.10)\end{array}$ & $\begin{array}{c}-0.93 \\
(0.42)\end{array}$ \\
\hline Wald Statistic & $\begin{array}{c}2.91 \\
{[0.57]}\end{array}$ & $\begin{array}{l}12.77 \\
{[0.01]}\end{array}$ & $\begin{array}{c}7.96 \\
{[0.09]}\end{array}$ & $\begin{array}{l}10.37 \\
0.03\end{array}$ & $\begin{array}{l}10.68 \\
{[0.03]}\end{array}$ & $\begin{array}{l}11.22 \\
{[0.02}\end{array}$ \\
\hline
\end{tabular}

\begin{tabular}{|c|c|c|c|c|c|c|}
\hline & France & Germany & Italy & Japan & U.K. & U.S. \\
\hline$\lambda_{I, C A, 0}$ & $\begin{array}{c}4.55 \\
(4.87)\end{array}$ & $\begin{array}{c}2.49 \\
(2.55)\end{array}$ & $\begin{array}{c}1.00 \\
(0.76)\end{array}$ & $\begin{array}{l}2.49 \\
(2.06)\end{array}$ & $\begin{array}{c}3.02 \\
(3.80)\end{array}$ & $\begin{array}{c}-132.86 \\
(1836.17)\end{array}$ \\
\hline$\lambda_{C A, I, 0}$ & $\begin{array}{l}-1.42 \\
(0.38)\end{array}$ & $\begin{array}{l}-1.26 \\
(0.37)\end{array}$ & $\begin{array}{c}-0.95 \\
(0.21)\end{array}$ & $\begin{array}{l}-1.22 \\
(0.54)\end{array}$ & $\begin{array}{l}-1.49 \\
(0.41)\end{array}$ & $\begin{array}{l}-1.10 \\
(0.79)\end{array}$ \\
\hline $\mathcal{L R}_{I, C A}$ & $\begin{array}{c}34.23 \\
(192.75)\end{array}$ & $\begin{array}{c}1.38 \\
(1.78)\end{array}$ & $\begin{array}{c}1.78 \\
(2.30)\end{array}$ & $\begin{array}{c}3.09 \\
(3.97)\end{array}$ & $\begin{array}{l}-3.18 \\
(2.14)\end{array}$ & $\begin{array}{l}-7.48 \\
(7.08)\end{array}$ \\
\hline Wald Statistic & $\begin{array}{c}2.94 \\
{[0.71]}\end{array}$ & $\begin{array}{c}9.61 \\
{[0.09]}\end{array}$ & $\begin{array}{c}8.37 \\
{[0.09]}\end{array}$ & $\begin{array}{c}7.89 \\
{[0.16]}\end{array}$ & $\begin{array}{c}9.09 \\
{[0.10]}\end{array}$ & $\begin{array}{c}9.20 \\
{[0.10]}\end{array}$ \\
\hline
\end{tabular}

In the top and bottom panels, standard errors appear in parenthesis and the brackets contain p-values. The Wald statistic and p-values in the top (bottom) panel are based on the hypothesis $\lambda_{C A, I, j}=0, j=1, \ldots, 4(j=0, \ldots, 4)$, and four (five) degrees of freedom. 


\begin{tabular}{ccccccc} 
Table A5.1 FEVD under $R 1: \mathcal{L R}_{C A, I}=0$ \\
Investment Response to the World Shock \\
Forecast Horizon & France & Germany & Italy & Japan & U.K. & U.S. \\
\hline \multirow{2}{*}{0} & 70.96 & 88.30 & 56.76 & 93.00 & 22.62 & 65.60 \\
& $(22.19)$ & $(16.95)$ & $(19.37)$ & $(17.18)$ & $(15.92)$ & $(18.12)$ \\
2 & 70.89 & 88.06 & 56.76 & 93.00 & 17.42 & 65.40 \\
& $(22.36)$ & $(17.25)$ & $(19.37)$ & $(17.19)$ & $(15.11)$ & $(18.22)$ \\
4 & 70.89 & 88.19 & 56.76 & 93.00 & 16.73 & 65.40 \\
& $(22.34)$ & $(17.29)$ & $(19.37)$ & $(17.19)$ & $(14.43)$ & $(18.22)$ \\
12 & 71.09 & 88.33 & 56.76 & 93.00 & 16.87 & 65.31 \\
& $(22.25)$ & $(17.33)$ & $(19.37)$ & $(17.19)$ & $(13.68)$ & $(18.25)$ \\
24 & 71.15 & 88.40 & 56.76 & 93.00 & 16.93 & 65.29 \\
& $(22.16)$ & $(17.35)$ & $(19.37)$ & $(17.19)$ & $(13.59)$ & $(18.25)$ \\
& & & & & &
\end{tabular}

Current Account Response to the Country-Specific Shock

\begin{tabular}{ccccccc} 
Forecast Horizon & France & Germany & Italy & Japan & U.K. & U.S. \\
\hline \multirow{2}{*}{0} & & & & & & \\
& 97.69 & 98.43 & 95.86 & 99.88 & 73.25 & 92.75 \\
& $(11.37)$ & $(8.42)$ & $(9.16)$ & $(11.23)$ & $(15.94)$ & $(10.24)$ \\
2 & 97.88 & 98.11 & 95.86 & 99.88 & 75.30 & 93.34 \\
& $(11.27)$ & $(8.69)$ & $(9.16)$ & $(11.23)$ & $(16.32)$ & $(9.86)$ \\
4 & & & & & & \\
& 97.82 & 98.14 & 95.86 & 99.88 & 76.02 & 93.30 \\
& $(11.39)$ & $(8.68)$ & $(9.16)$ & $(11.23)$ & $(15.78)$ & $(10.03)$ \\
12 & 97.71 & 98.12 & 95.86 & 99.88 & 77.74 & 93.36 \\
& $(11.07)$ & $(8.70)$ & $(9.16)$ & $(11.23)$ & $(14.02)$ & $(10.06)$ \\
\multirow{2}{*}{24} & 97.68 & 98.13 & 95.86 & 99.88 & 78.34 & 93.37 \\
& $(10.99)$ & $(8.70)$ & $(9.16)$ & $(11.23)$ & $(13.59)$ & $(10.38)$
\end{tabular}

In the top and bottom panels, small sample empirical standard errors appear in parenthesis. We generate 1000 replications of the SVAR to compute the empirical standard errors. 


\section{Table A5.2 FEVD under $R 2: \mathcal{L R}_{I, C A}=0$}

Investment Response to the World Shock

\begin{tabular}{ccccccc} 
Forecast Horizon & France & Germany & Italy & Japan & U.K. & U.S. \\
\hline \multirow{2}{*}{0} & 97.29 & 95.43 & 99.87 & 99.86 & 99.99 & 99.30 \\
& $(6.74)$ & $(11.72)$ & $(6.19)$ & $(9.26)$ & $(3.41)$ & $(6.91)$ \\
& & & & & & \\
2 & 97.27 & 95.54 & 99.87 & 99.86 & 99.60 & 99.32 \\
& $(6.75)$ & $(11.81)$ & $(6.19)$ & $(9.26)$ & $(3.72)$ & $(6.89)$ \\
4 & 97.26 & 95.44 & 99.87 & 99.86 & 99.38 & 99.32 \\
& $(6.75)$ & $(11.89)$ & $(6.19)$ & $(9.26)$ & $(3.97)$ & $(6.90)$ \\
\multirow{2}{*}{12} & 97.30 & 95.37 & 99.87 & 99.86 & 98.15 & 99.33 \\
& $(6.69)$ & $(11.76)$ & $(6.19)$ & $(9.27)$ & $(4.20)$ & $(6.90)$ \\
\multirow{2}{*}{24} & & & & & & \\
& 97.32 & 95.33 & 99.87 & 99.86 & 99.07 & 99.33 \\
& $(6.66)$ & $(11.58)$ & $(6.19)$ & $(9.27)$ & $(4.26)$ & $(6.90)$
\end{tabular}

Current Account Response to the Country-Specific Shock Forecast Horizon France Germany Italy Japan U.K. U.S.

$\begin{array}{lllllll}0 & 93.80 & 59.47 & 78.97 & 92.84 & 73.58 & 82.01\end{array}$
$\begin{array}{llllll}(11.35) & (23.06) & (17.09) & (15.67) & (14.92) & (16.31)\end{array}$

$\begin{array}{ccccccc}2 & 93.53 & 58.20 & 78.97 & 92.84 & 69.45 & 81.69 \\ & (11.74) & (23.39) & (17.09) & (15.67) & (16.81) & (16.73)\end{array}$

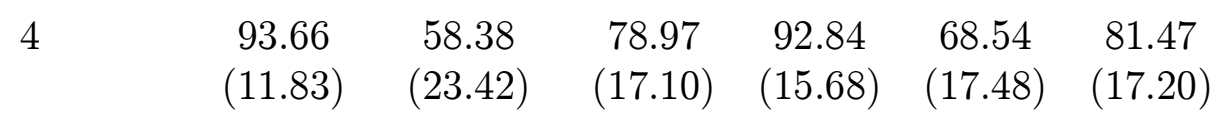

$\begin{array}{ccccccc}12 & 93.91 & 58.29 & 78.97 & 92.84 & 67.80 & 81.29 \\ & (11.90) & (23.54) & (17.10) & (15.68) & (17.90) & (17.51) \\ & & & & & & \\ 24 & 93.99 & 58.30 & 78.97 & 92.84 & 67.56 & 81.24 \\ & (11.92) & (23.50) & (17.09) & (15.69) & (18.06) & (17.62)\end{array}$

In the top and bottom panels, small sample empirical standard errors appear in parenthesis. We generate 1000 replications of the SVAR to compute the empirical standard errors. 


\section{Table A5.3 FEVD under $R 6: \mathcal{L R}_{C A, I}=-1$}

Investment Response to the World Shock

\begin{tabular}{ccccccc} 
Forecast Horizon & France & Germany & Italy & Japan & U.K. & U.S. \\
\hline \multirow{2}{*}{0} & & & & & & \\
& 34.49 & 49.92 & 75.45 & 36.28 & 47.58 & 10.78 \\
& $(17.18)$ & $(21.96)$ & $(18.83)$ & $(23.62)$ & $(20.99)$ & $(15.96)$ \\
2 & 35.59 & 49.96 & 75.45 & 36.29 & 68.06 & 63.56 \\
& $(19.09)$ & $(22.33)$ & $(18.86)$ & $(23.59)$ & $(18.46)$ & $(25.19)$ \\
4 & 37.40 & 43.37 & 75.45 & 36.28 & 86.30 & 100.00 \\
& $(22.84)$ & $(23.25)$ & $(18.50)$ & $(24.04)$ & $(16.91)$ & $(34.85)$ \\
12 & 51.52 & 49.15 & 75.45 & 36.26 & 95.96 & 100.00 \\
& $(24.42)$ & $(21.98)$ & $(17.42)$ & $(25.50)$ & $(12.67)$ & $(36.02)$ \\
& & & & & & \\
24 & 85.50 & 49.06 & 75.45 & 36.25 & 94.51 & 100.00 \\
& $(22.61)$ & $(20.70)$ & $(16.40)$ & $(25.75)$ & $(11.06)$ & $(36.62)$
\end{tabular}

Current Account Response to the Country-Specific Shock

\begin{tabular}{ccccccc} 
Forecast Horizon & France & Germany & Italy & Japan & U.K. & U.S. \\
\hline \multirow{2}{*}{0} & 4.38 & 9.30 & 26.42 & 16.09 & 31.07 & 00.04 \\
& $(9.42)$ & $(14.89)$ & $(18.35)$ & $(19.62)$ & $(12.96)$ & $(8.12)$ \\
& & & & & & \\
2 & 4.34 & 8.40 & 26.42 & 16.08 & 9.14 & 00.02 \\
& $(9.36)$ & $(14.48)$ & $(18.35)$ & $(19.75)$ & $(11.78)$ & $(16.50)$ \\
4 & & & & & & \\
& $(10.15$ & 8.57 & 26.41 & 16.06 & 6.61 & 0.00 \\
12 & & $(14.80)$ & $(18.35)$ & $(20.02)$ & $(11.99)$ & $(23.32)$ \\
& $(16.82$ & 8.54 & 26.41 & 16.05 & 5.56 & 0.00 \\
24 & & $(15.54)$ & $(18.35)$ & $(20.98)$ & $(12.42)$ & $(28.01)$ \\
& & & & & & \\
& $(15.02$ & 8.54 & 26.41 & 16.05 & 5.52 & 0.00 \\
& & $(15.63)$ & $(18.32)$ & $(21.04)$ & $(12.83)$ & $(28.51)$
\end{tabular}

In the top and bottom panels, small sample empirical standard errors appear in parenthesis. We generate 1000 replications of the SVAR to compute the empirical standard errors. 

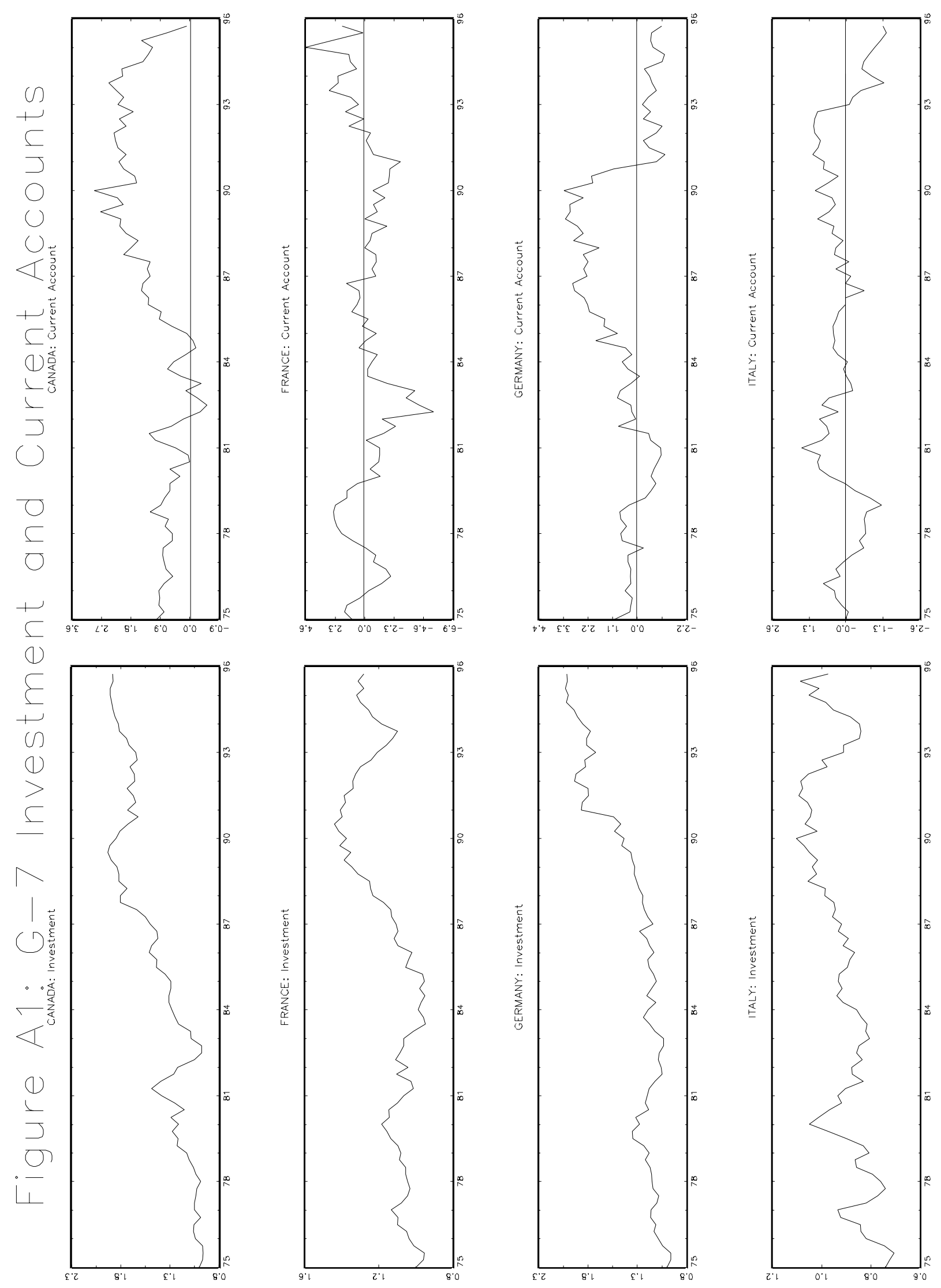

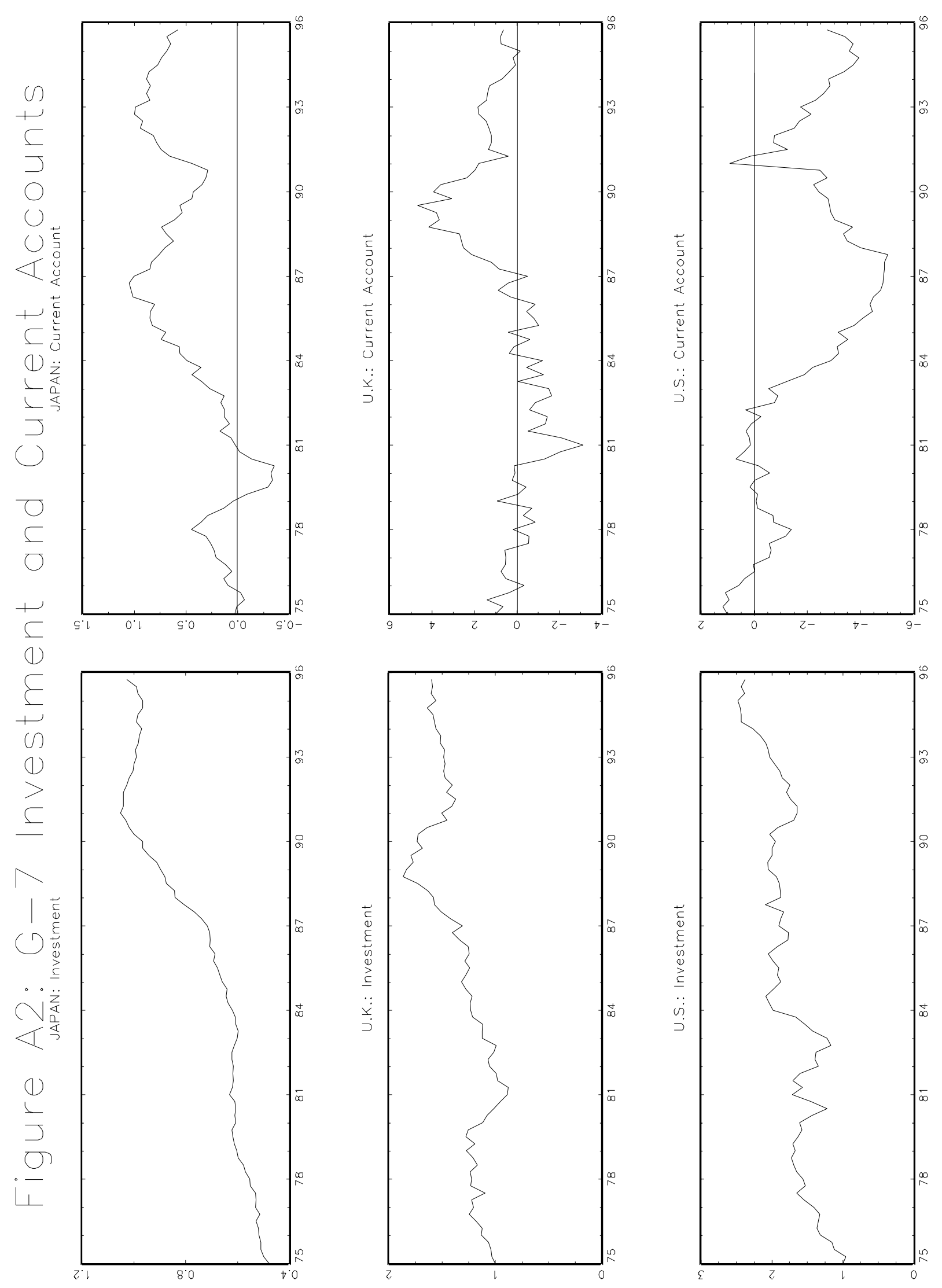

A. 21 

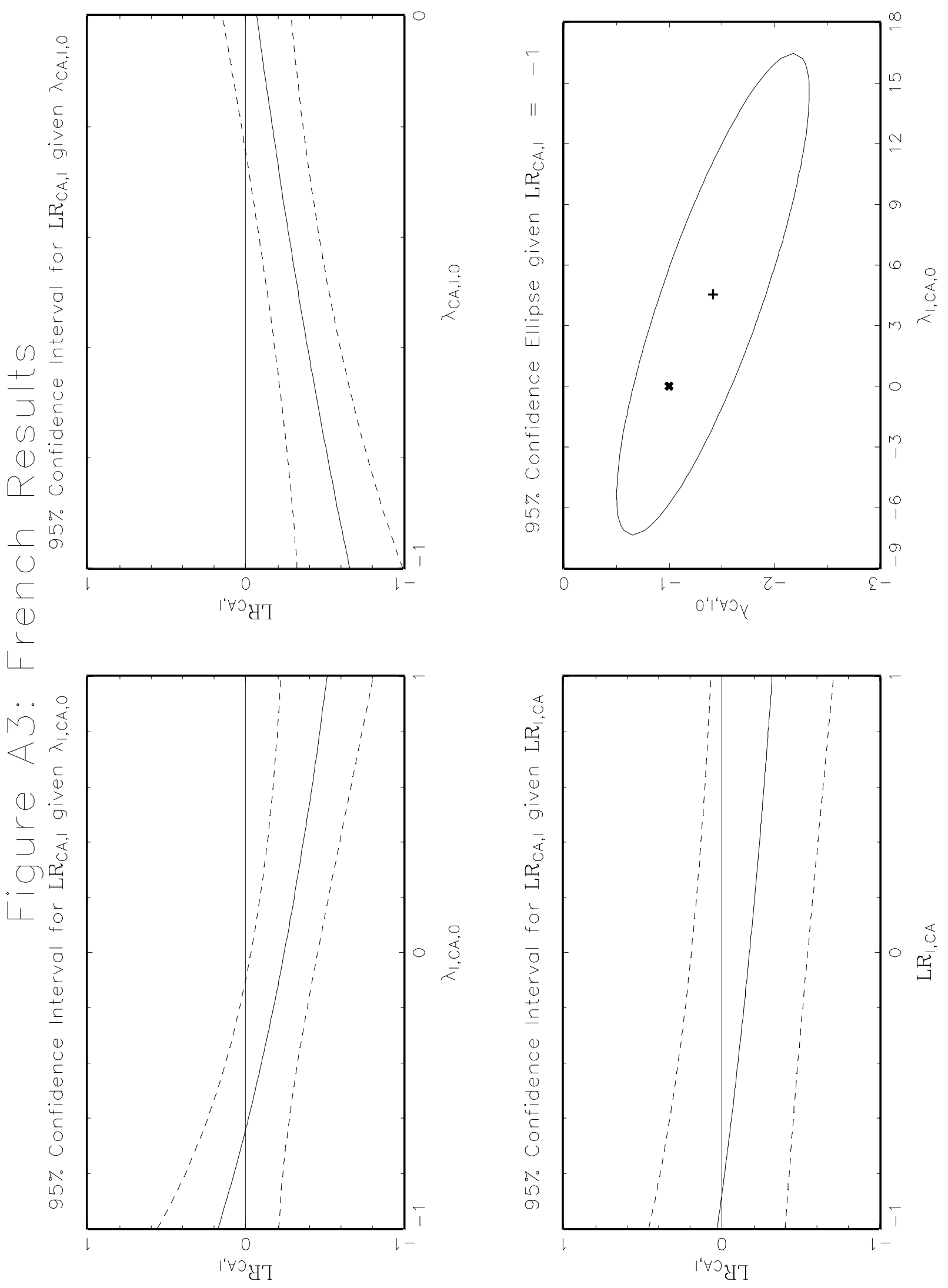

A. 22 

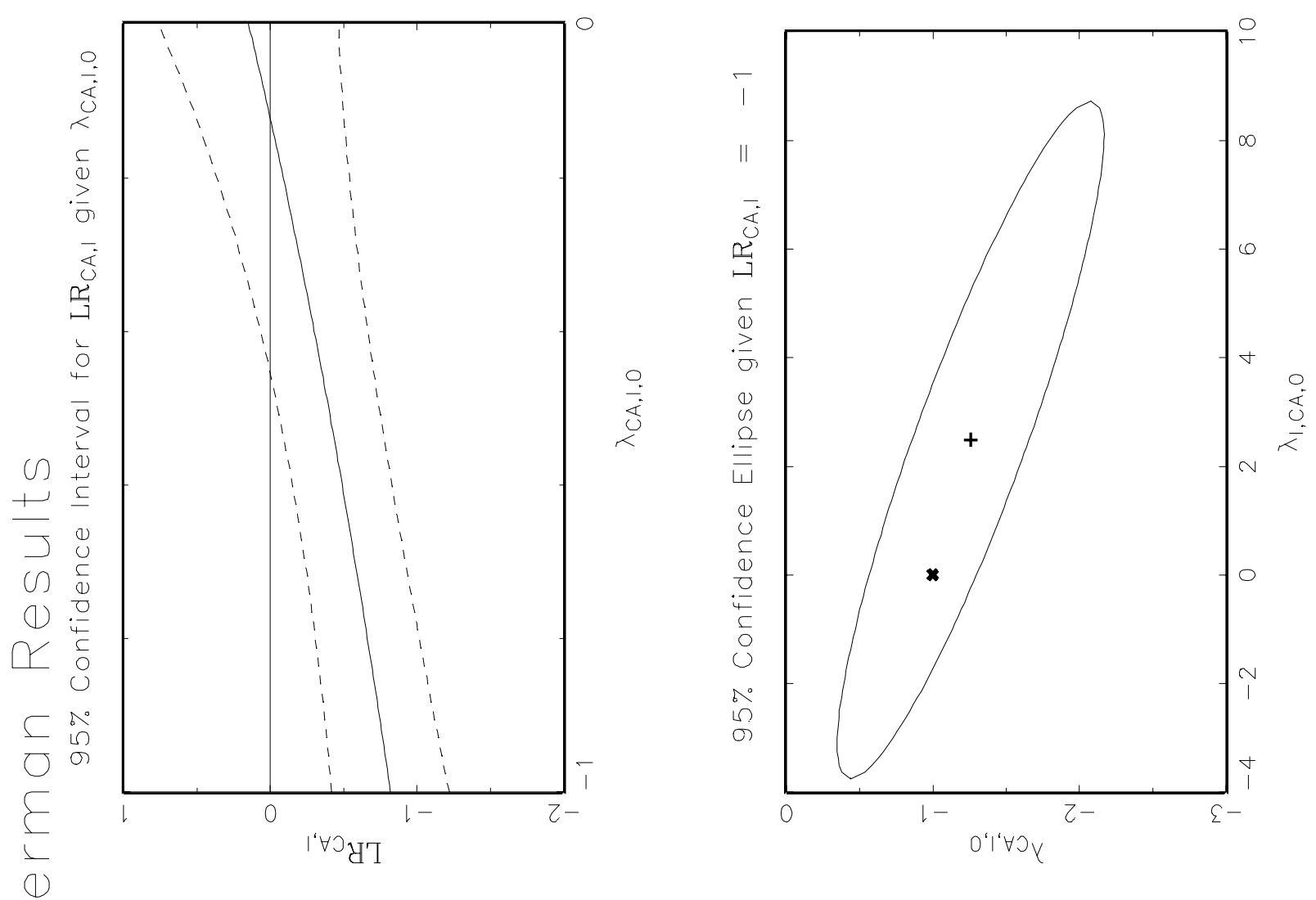

(D)
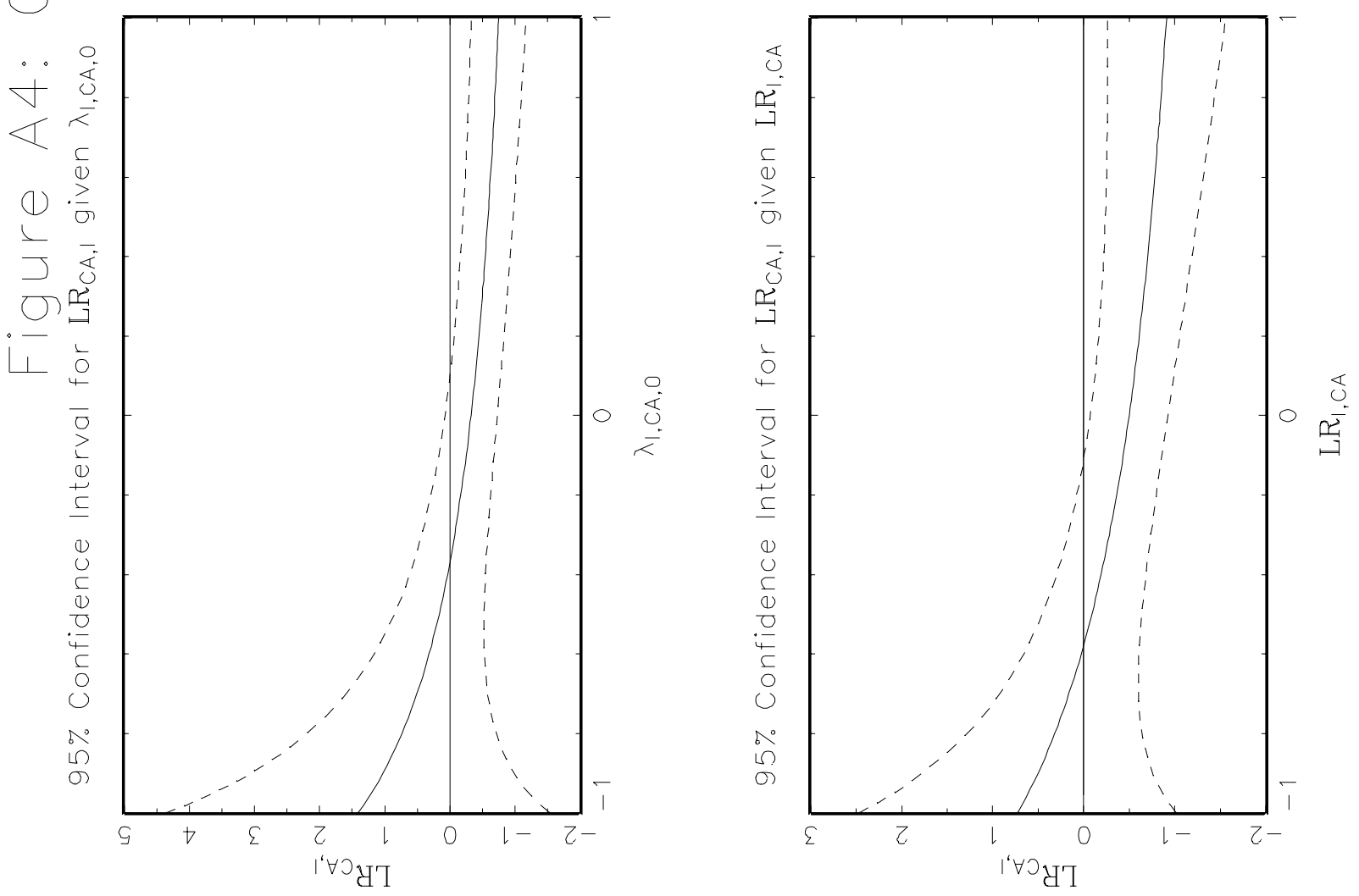

A. 23 

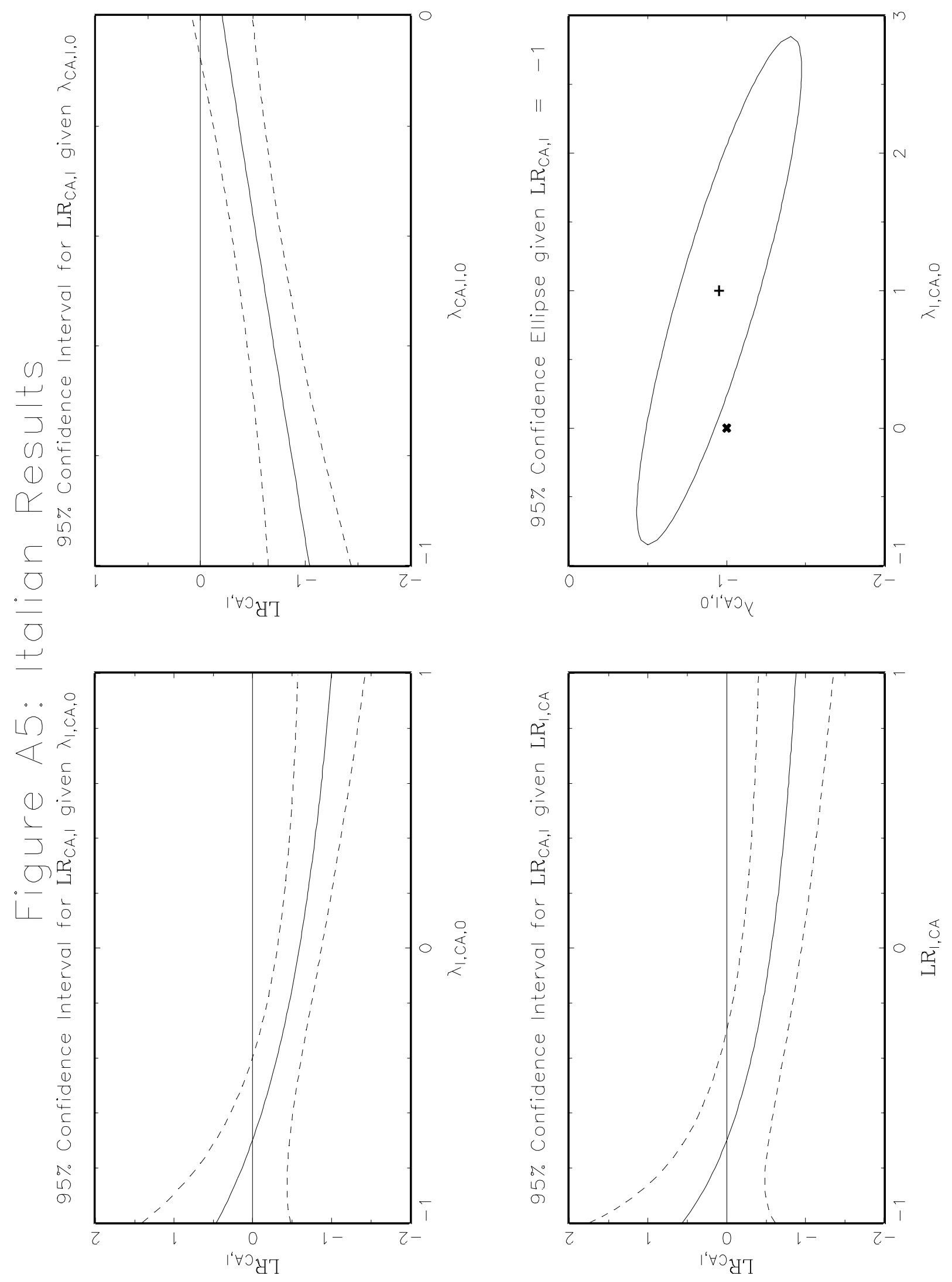

A. 24 

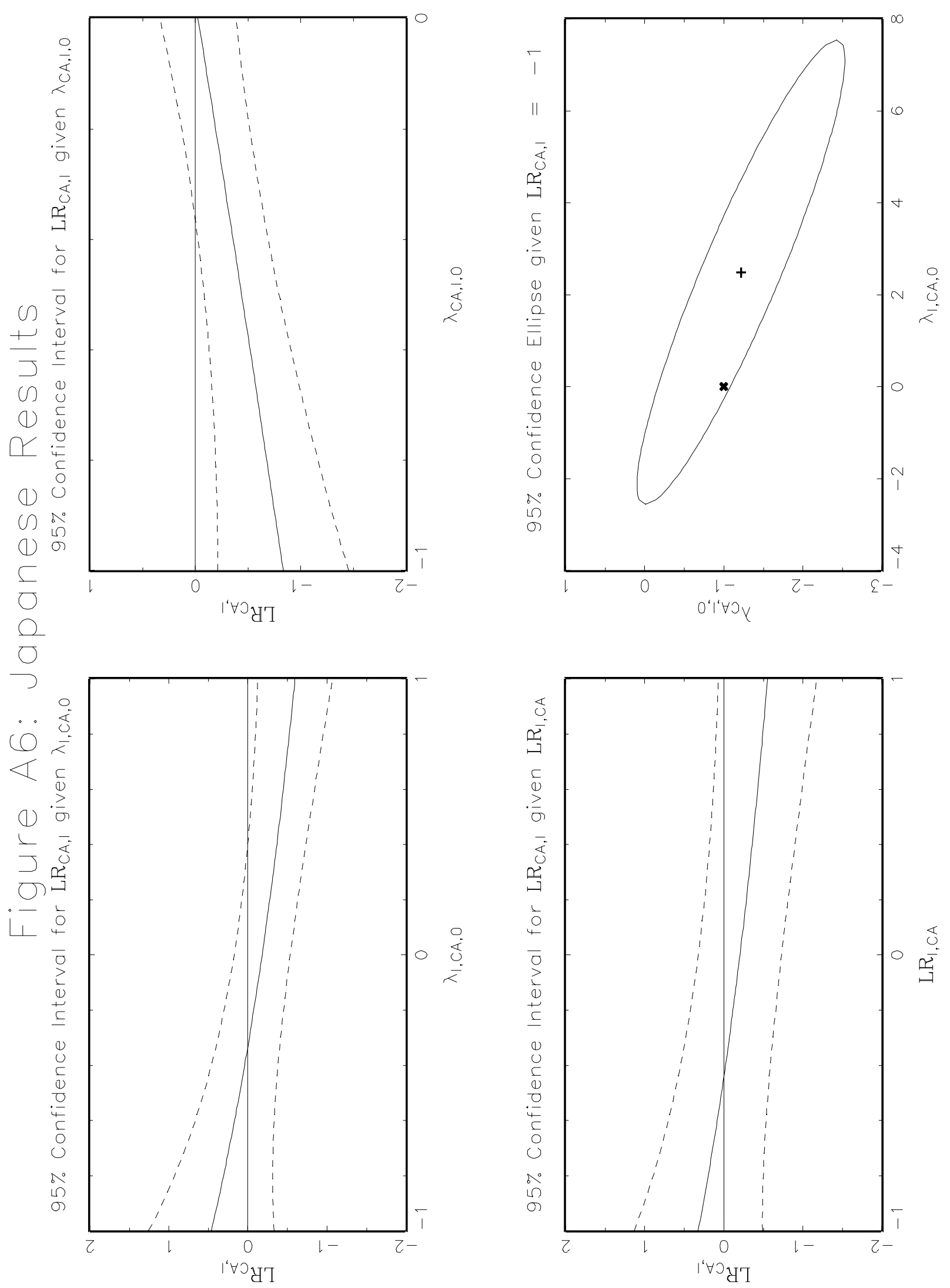

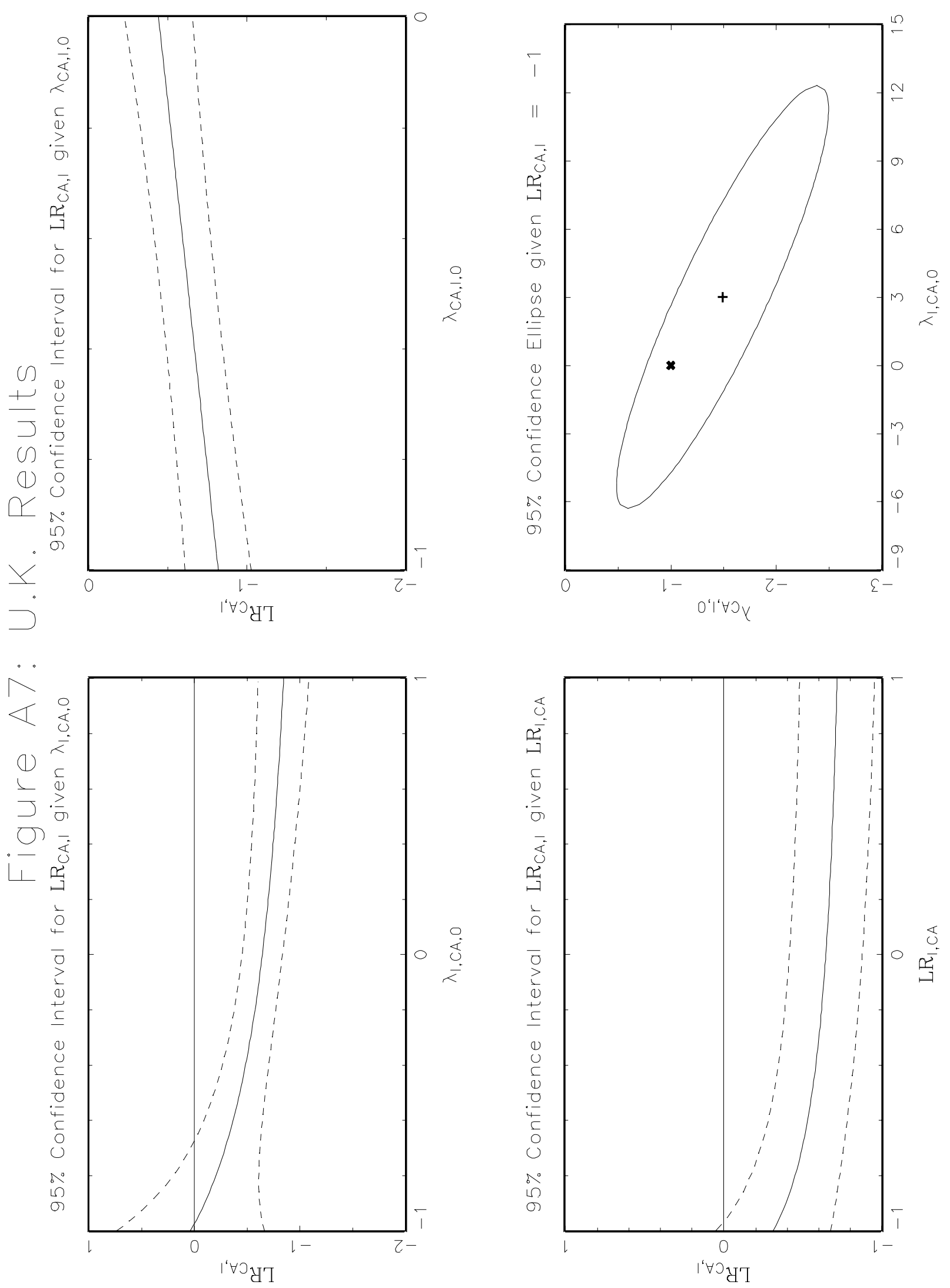

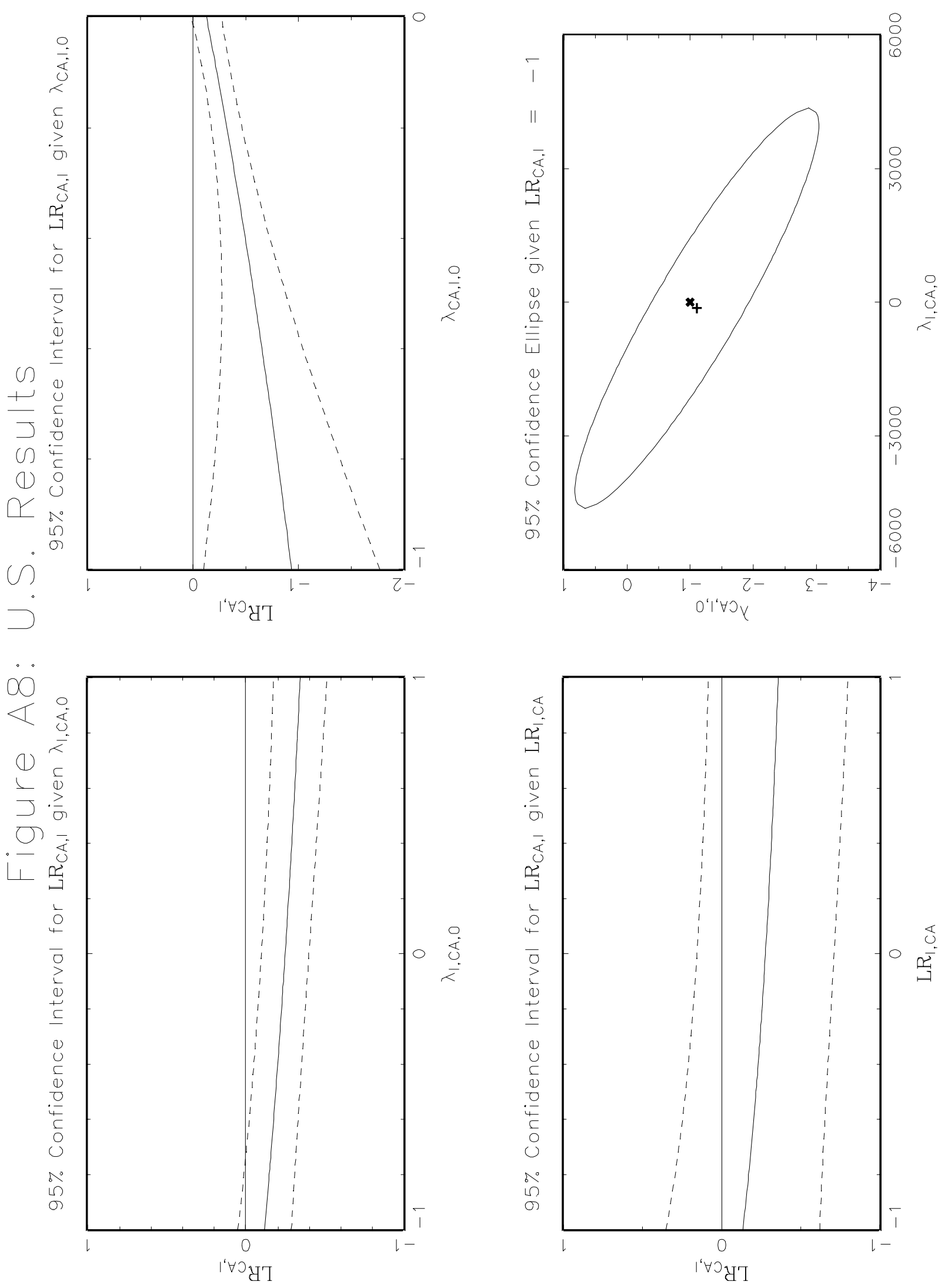

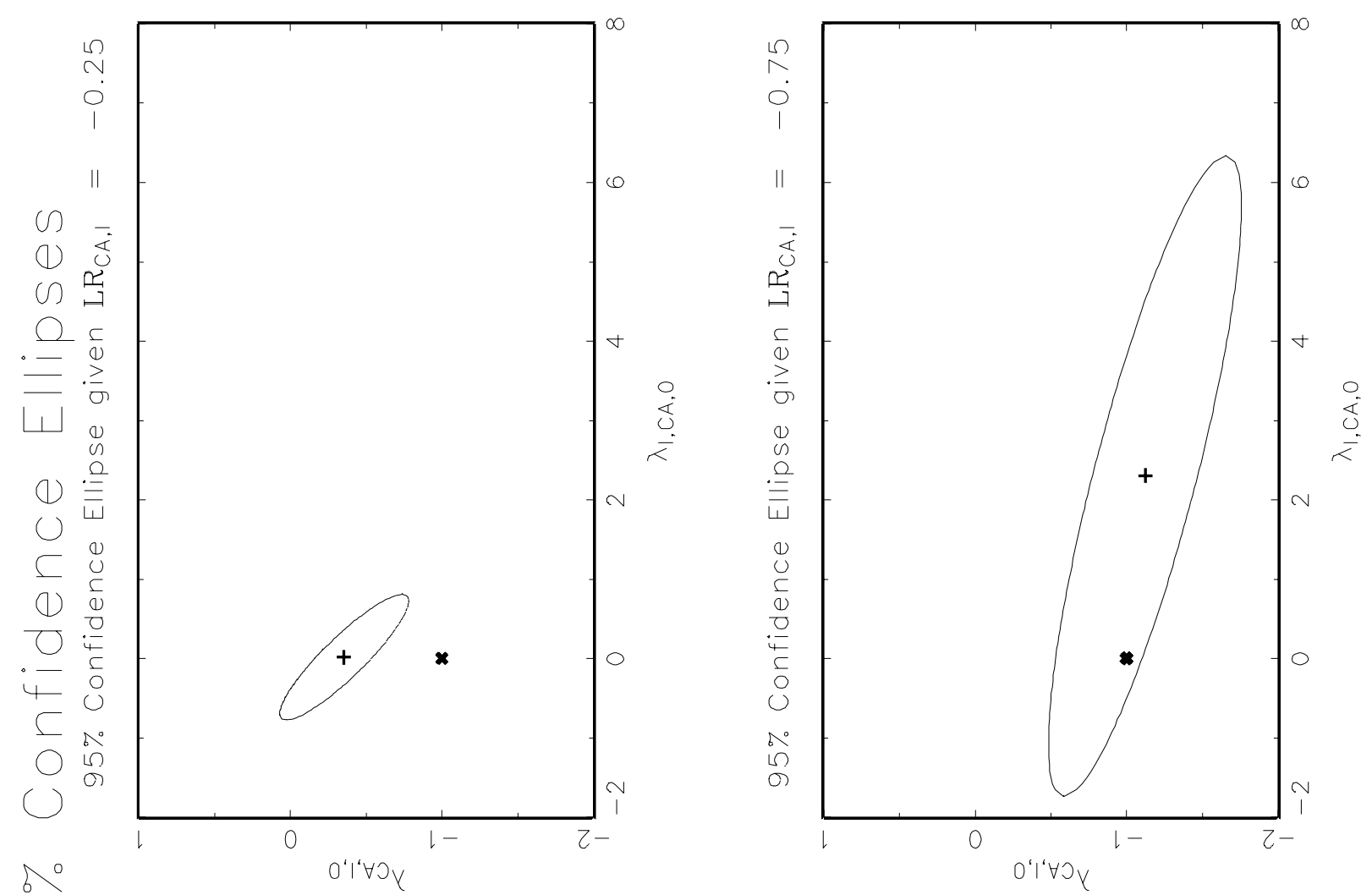

$\Omega$
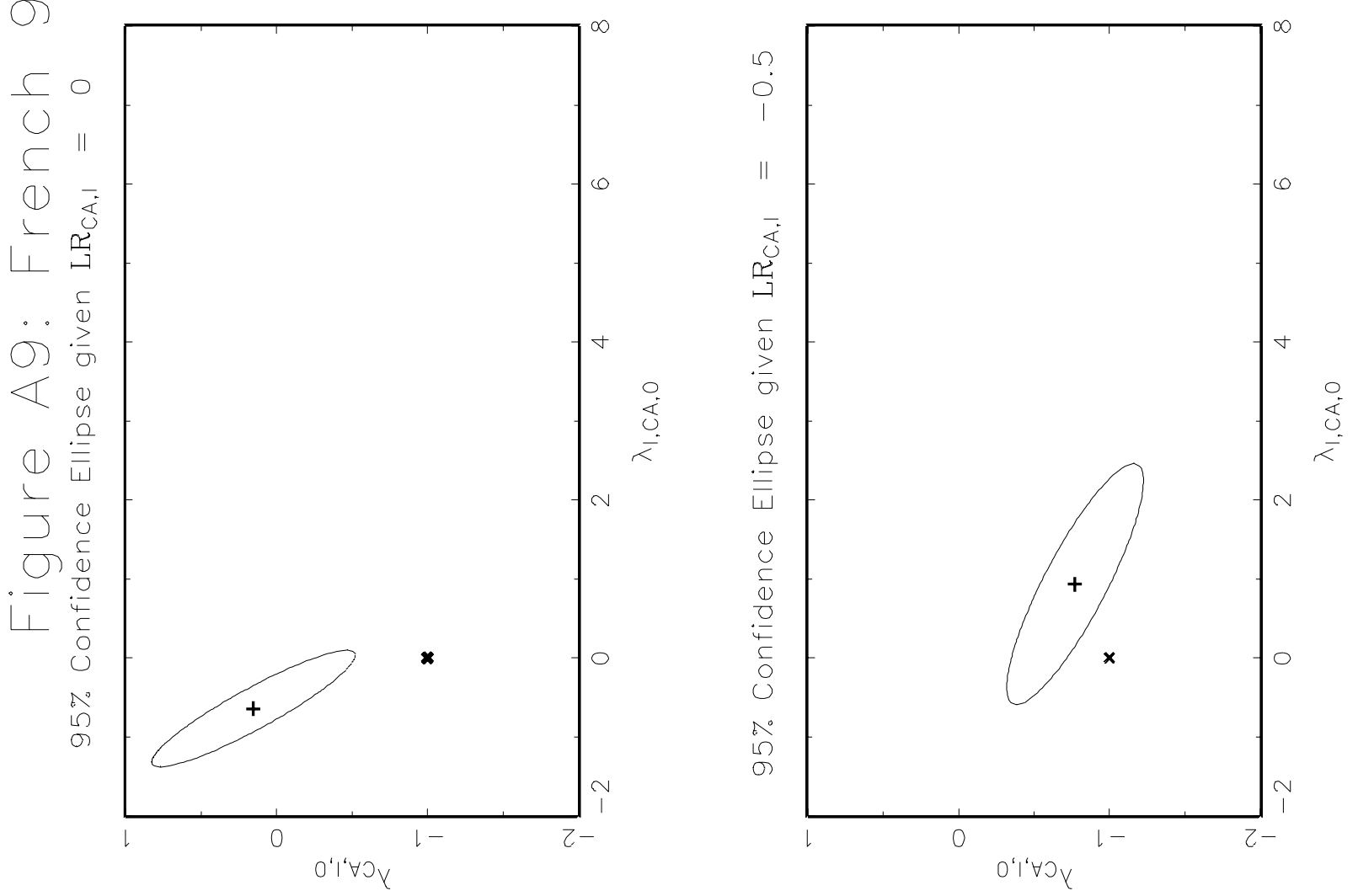

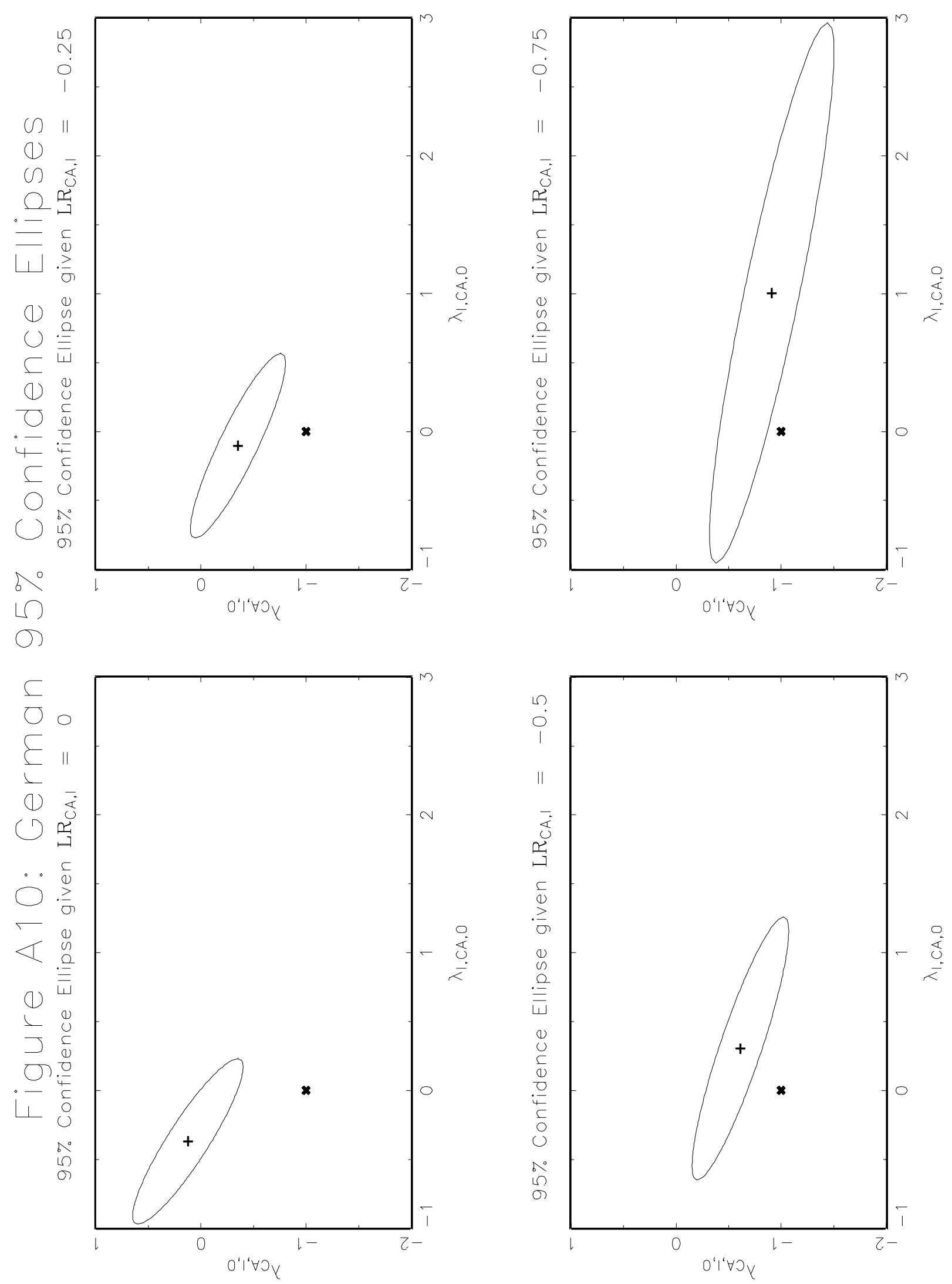

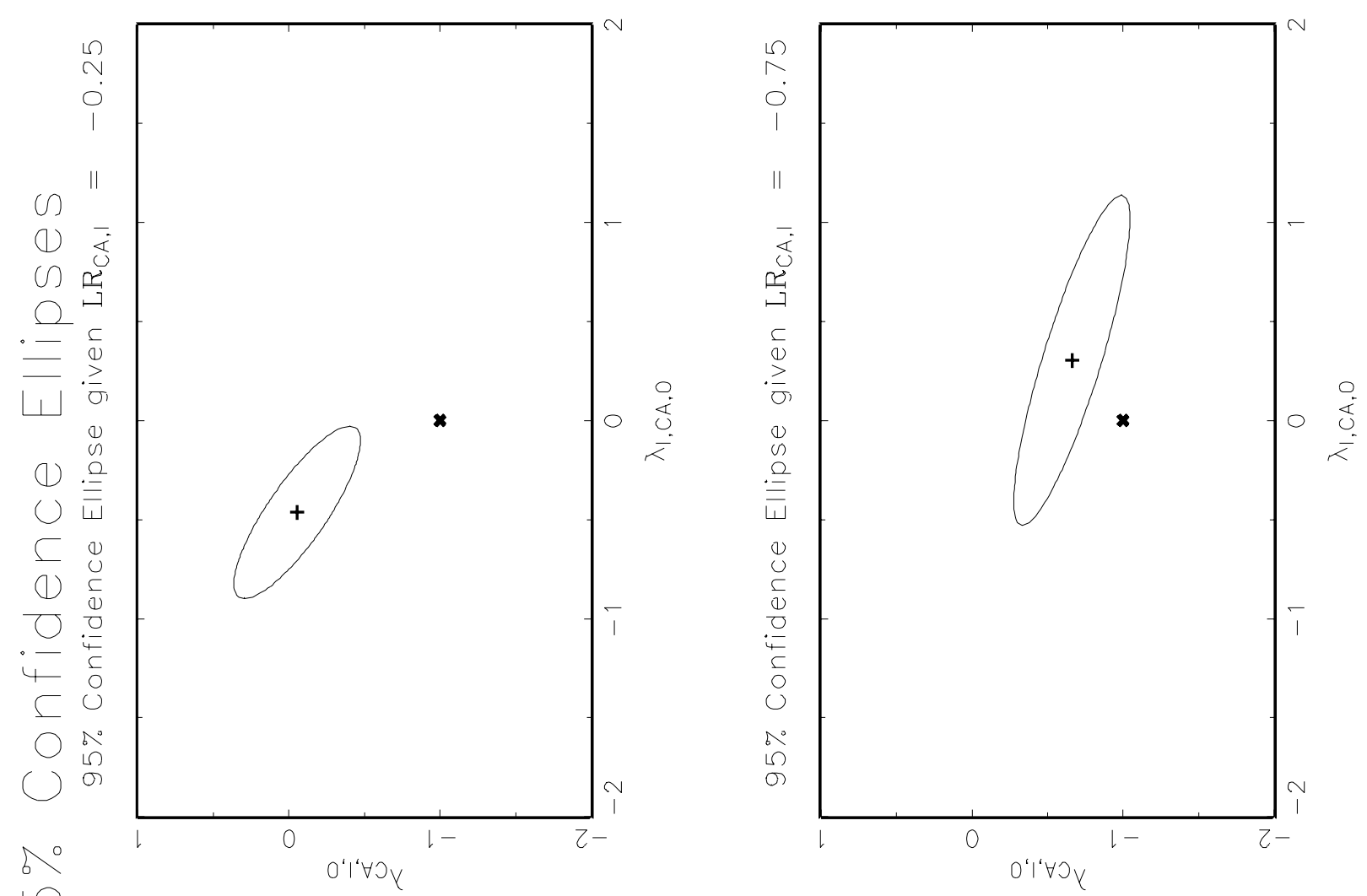

L
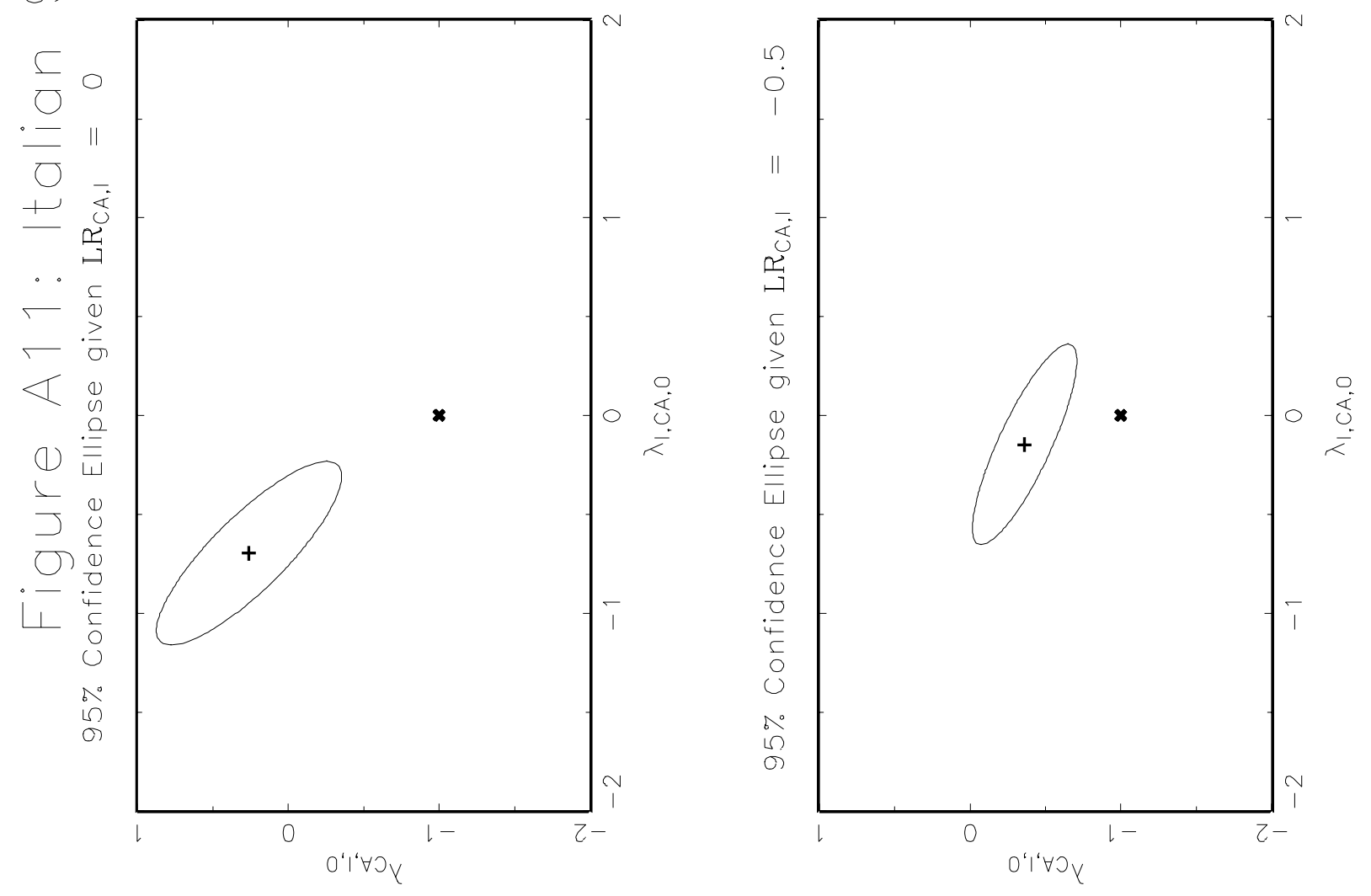

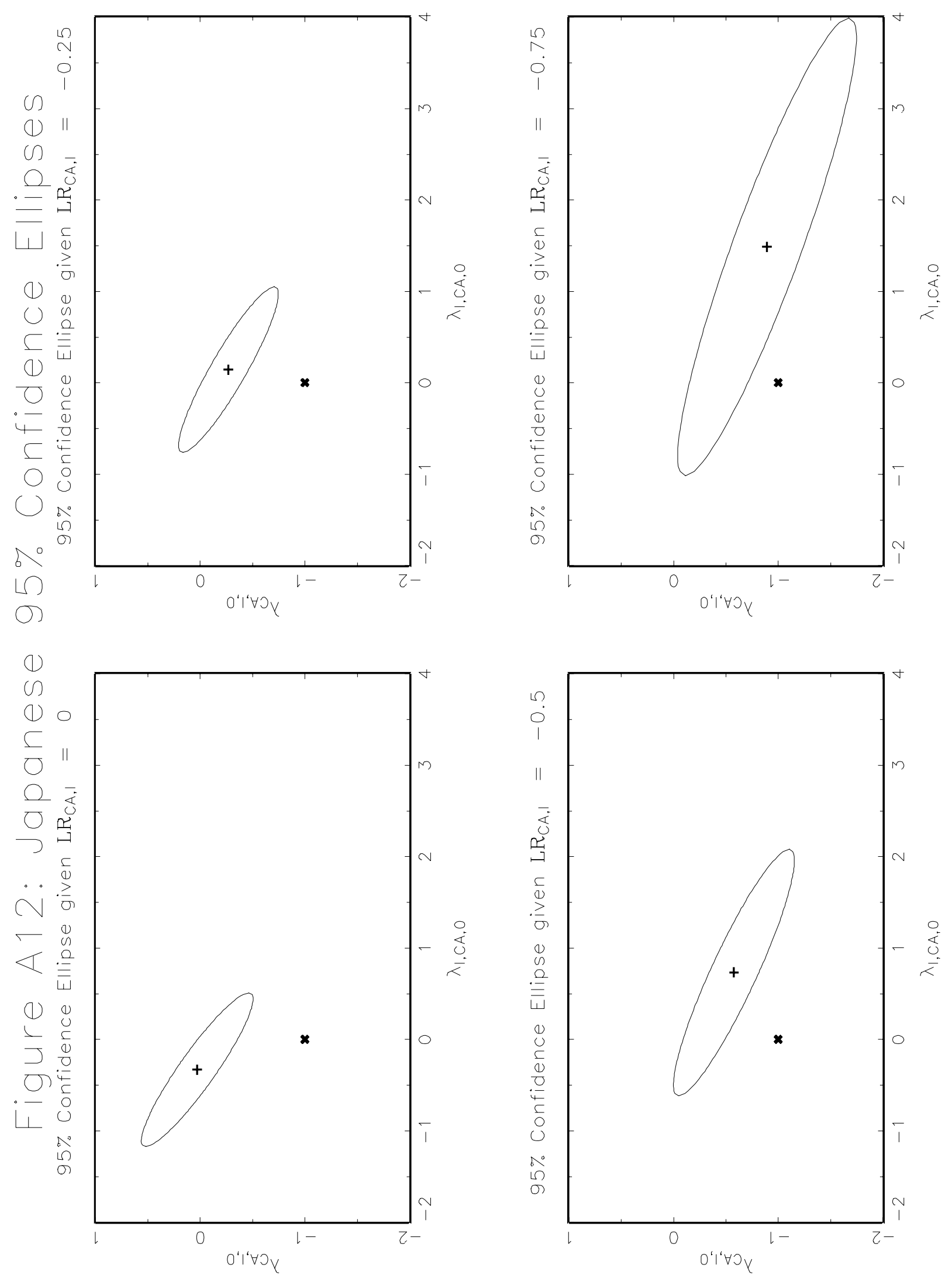

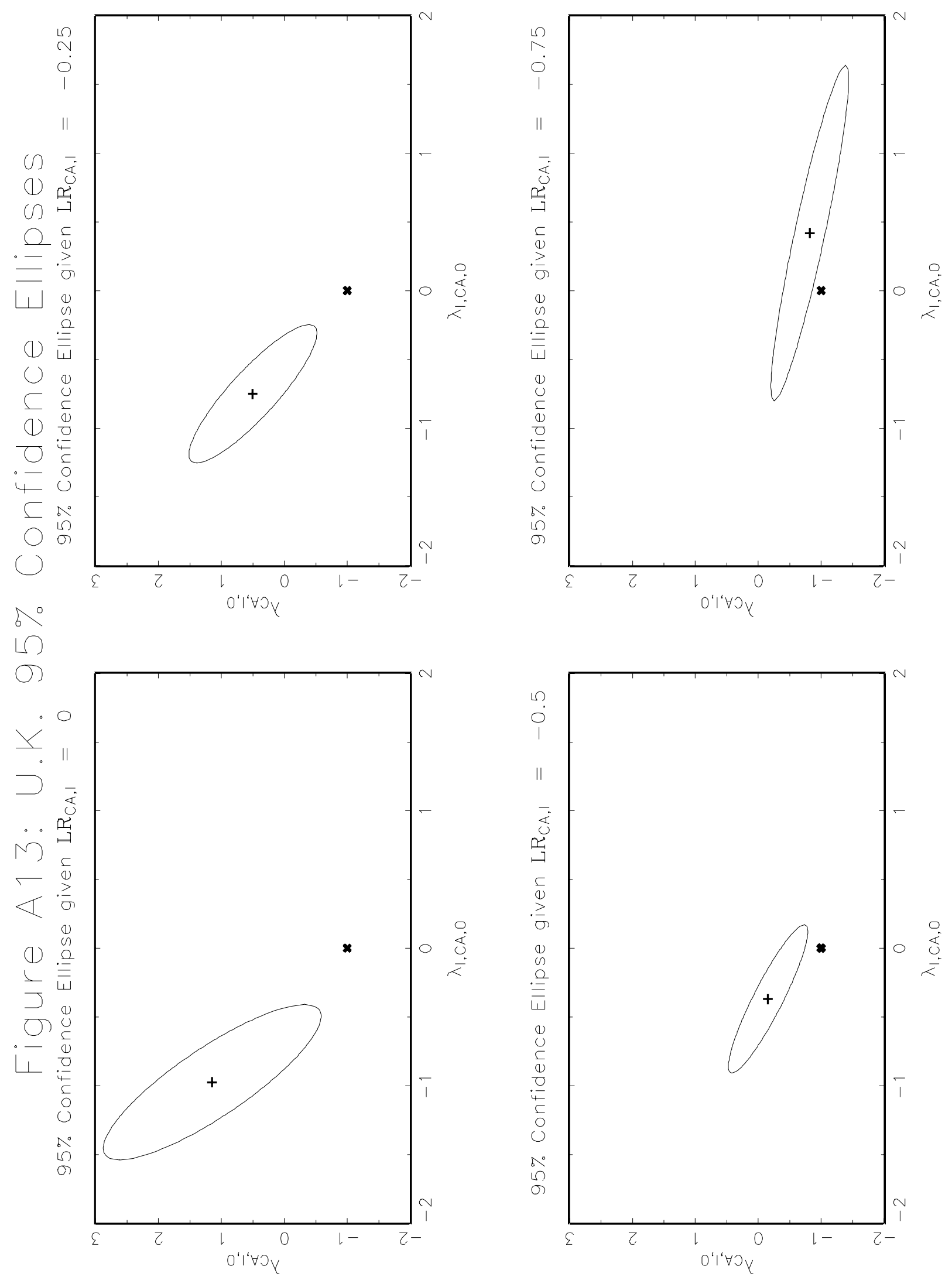

A. 32 

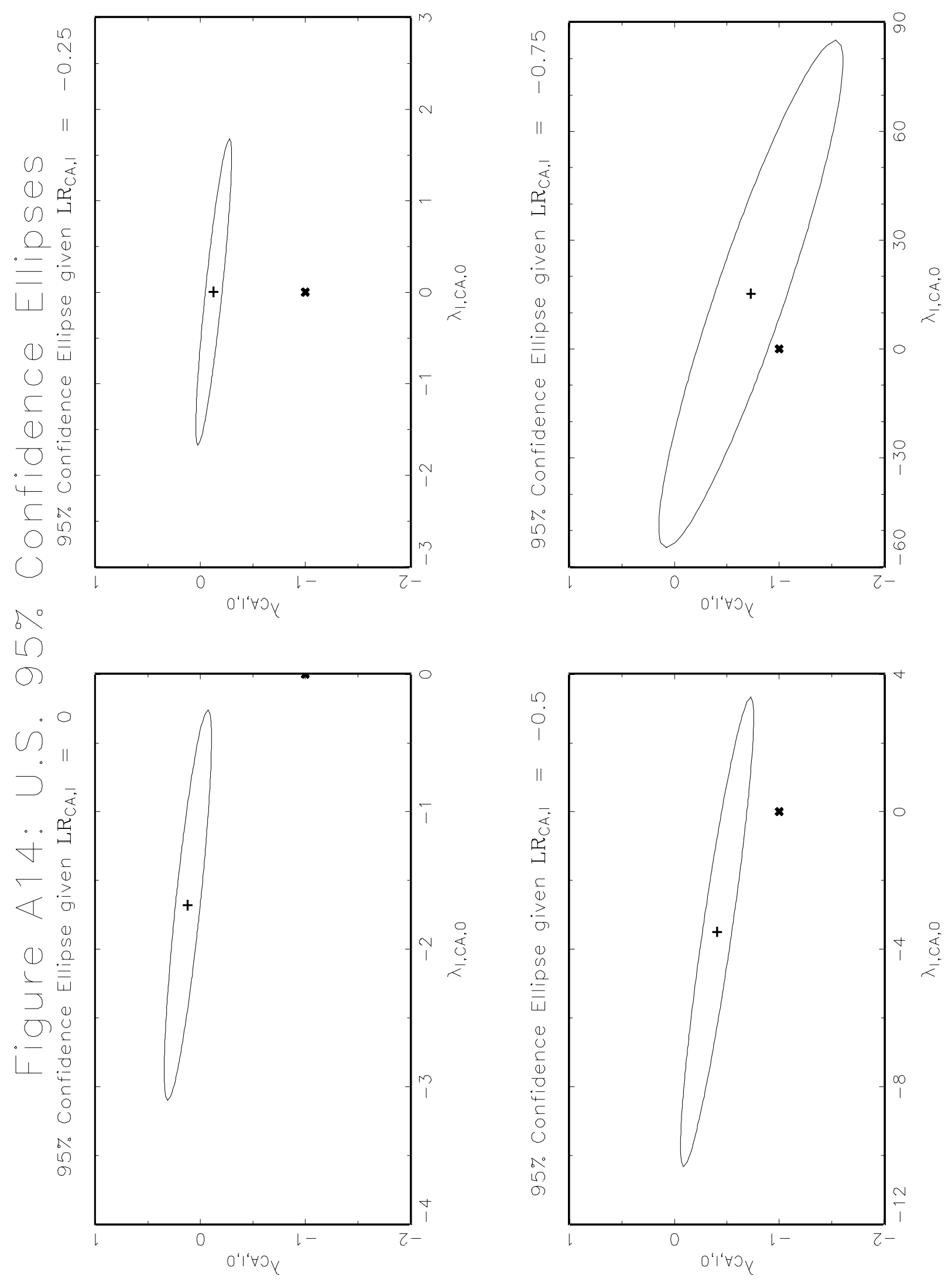

A. 33 